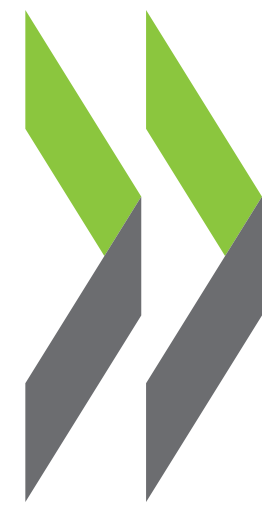

\title{
Environmentally Adjusted Multifactor Productivity
}

METHODOLOGY AND EMPIRICAL RESULTS FOR OECD AND G20 COUNTRIES 


\section{OECD GREEN GROWTH PAPERS}

The OECD Green Growth Strategy, launched in May 2011, provides concrete recommendations and measurement tools to support countries' efforts to achieve economic growth and development, while at the same time ensuring that natural assets continue to provide the ecosystem services on which our well-being relies. The strategy proposes a flexible policy framework that can be tailored to different country circumstances and stages of development.

This paper has been authorised for publication by Mr. Simon Upton, Director, Environment Directorate. OECD Green Growth Papers should not be reported as representing the official views of the OECD or of its member countries. The opinions expressed and arguments employed are those of the author(s). The statistical data for Israel are supplied by and under the responsibility of the relevant Israeli authorities. The use of such data by the OECD is without prejudice to the status of the Golan Heights, East Jerusalem and Israeli settlements in the West Bank under the terms of international law. It should be noted that Latvia was not an OECD member at the time of preparation of this publication.

Accordingly, Latvia does not appear in the list of OECD Members and is not included in the zone aggregates. This document and any map included herein are without prejudice to the status of or sovereignty over any territory, to the delimitation of international frontiers and boundaries and to the name of any territory, city or area.

OECD Green Growth Papers aim to describe preliminary results or research in progress by the author(s) and are published to stimulate discussion on specific topics and obtain feedback from interested audiences.

They complement the OECD Green Growth Studies series, which aims to provide in-depth reviews of the green growth issues faced by different sectors.

Comments on Green Growth Papers are welcomed, and may be sent to:

OECD Green Growth Unit, 2, rue André Pascal, 75775 PARIS CEDEX 16, France

or by email to greengrowth@oecd.org.

OECD Green Growth Papers are published on:

www.oecd.org/greengrowth

Please cite this paper as:

Cárdenas Rodríguez M., Haščič I. and Souchier M. (2018), "Environmentally Adjusted Multifactor Productivity: Methodology and Empirical Results for OECD and G20 Countries", OECD Green Growth Papers, No. 2018/02, OECD Publishing, Paris.

\section{(c) OECD (2018)}

You can copy, download or print OECD content for your own use, and you can include excerpts from OECD publications, databases and multimedia products in your own documents, presentations, blogs, websites and teaching materials, provided that suitable acknowledgment of OECD as source and copyright owner is given. All requests for commercial use and translation rights should be submitted to rights@oecd.org. 


\begin{abstract}
This paper further refines the OECD framework for measuring the environmentally adjusted multifactor productivity growth that seeks to incorporate environmental services in productivity analysis. Compared to standard productivity measurement, this framework allows accounting also for the use of natural capital (currently including 14 types of fossil fuels and minerals) and the emission of pollutants as negative by-products (currently including 8 types of greenhouse gases and air pollutants). An updated series of the indicator is presented, with a geographic coverage extended to all OECD and G20 countries for the 1990-2013 time period. The indicators presented here allow the sources of economic growth to be better identified, and growth prospects in the long run to be better assessed.
\end{abstract}

JEL classification: D24, O44, O47, Q3, Q52, Q53, Q56.

Keywords: productivity measurement, multifactor productivity, total factor productivity, green productivity, growth accounting, exhaustible natural capital, emission shadow prices, air pollution.

\title{
RÉSUMÉ
}

Le présent rapport affine le cadre de mesure de la croissance de la productivité multifactorielle corrigée des incidences environnementales utilisé par l'OCDE pour incorporer les services environnementaux dans l'analyse de la productivité. Comparé à la mesure classique de la productivité, ce cadre permet également de tenir compte de l'utilisation du capital naturel (actuellement 14 types de combustibles fossiles et minéraux) et des émissions de polluants en tant que sous-produits négatifs (actuellement 8 types de gaz à effet de serre et polluants atmosphériques). Une série actualisée de cet indicateur, dont la couverture géographique s'étend à tous les pays de l'OCDE et du G20, est présentée pour la période 1990-2013. Ces indicateurs permettent de mieux identifier les sources de croissance économique et de mieux évaluer les perspectives de croissance sur le long terme.

Classification JEL : D24, O44, O47, Q3, Q52, Q53, Q56.

Mots clés : mesure de la productivité, productivité multifactorielle, productivité totale des facteurs, productivité verte, comptabilité de la croissance, capital naturel non renouvelable, prix virtuel des émissions, pollution atmosphérique. 


\section{ACKNOWLEDGMENTS}

This paper was prepared by Miguel Cárdenas Rodríguez, Ivan Haščič and Martin Souchier, under the supervision of Nathalie Girouard, head of Environmental Performance and Information Division of the OECD Environment Directorate. We thank Esther Naikal and Christopher Sall (World Bank) as well as colleagues from the OECD Statistics Directorate Pierre-Alain Pionnier, Shunta Yamaguchi and Belen Zinni for kindly providing data and helpful guidance. A previous version of this paper benefited from the comments of Nicola Brandt, Brendan Gillespie, Nick Johnstone, Tomasz Koźluk, Pierre-Alain Pionnier, Mauro Pisu, Paul Schreyer and Simon Upton. Thanks also to Vera Zipperer for helpful advice and Ghania Souihi for assistance with reviewing the shadow price literature. Jennifer Humbert and Jacqueline Maher provided editorial assistance.

The paper was reviewed by the OECD Environmental Policy Committee and its Working Party on Environmental Information. It also benefited from the comments received from country Delegates to the Working Party No. 1 on Macro-Economic and Structural Policy Analysis of the Economic Policy Committee (EPC) and the Committee on Statistics and Statistical Policy (CSSP). 


\section{FOREWORD}

The OECD Working Party on Environmental Information (WPEI) requested the Secretariat, namely the Environment Directorate in co-operation with the Economics Department and the Statistics Directorate, to elaborate the OECD green growth headline indicators, proposed by the Reflection Group back in 2012. Environmentally adjusted multifactor productivity growth (EAMFP) has been proposed for inclusion in the set of headline indicators. ${ }^{1}$

\section{OECD Green Growth headline indicators}

\begin{tabular}{|c|c|}
\hline \multicolumn{2}{|c|}{ Environmental and resource productivity } \\
\hline Carbon productivity & 1. $\mathbf{C O}_{2}$ productivity \\
\hline Resource productivity & 2. Non-energy material productivity \\
\hline Multifactor productivity & 3. Multifactor productivity including environmental services \\
\hline The natural asset base \\
\hline Renewable and non-renewable stocks & 4. Natural resource index \\
\hline Biodiversity and ecosystems & 5. Changes in land use and cover \\
\hline $\begin{array}{c}\text { Environmental health and risks } \\
\text { Environmental quality of life }\end{array}$ & 6. Air pollution (population exposure to PM 2.5) \\
\hline $\begin{array}{c}\text { Technologyand innovation, environmental goods } \\
\text { and services, prices and transfers, etc. }\end{array}$ & Placeholder - no indicator specified \\
\hline
\end{tabular}

Source: OECD (2014a), Green Growth Indicators.

Multifactor productivity is - as its name suggests - a comprehensive measure of productivity where the underlying production function accounts for multiple factor inputs, traditionally labour and produced capital. ${ }^{2}$ While single-factor productivity is intuitively simple, such measure offers a biased view of the economy because it forces all variation in output growth to be explained by a single factor input (e.g. consumption of fossil fuels or material resources) while the role of other factors is ignored. Multi-factor productivity aims at addressing precisely this shortcoming, and as such is a valuable component of the OECD set of Green Growth headline indicators.

Building on the earlier work carried out by the OECD, this paper presents the results of the recent progress in elaborating the EAMFP indicator - notably, a refined methodology and results with an expanded geographical and temporal coverage, and guidance for interpretation of the indicator.

\footnotetext{
${ }^{1}$ The green growth (GG) headline indicators is a small set of indicators selected to track central elements of GG and to facilitate communication with policy makers, the media and citizens (see ENV/EPOC/WPEI(2012)2). The set has been proposed following the decisions of three OECD bodies - the Committee on Statistics and Statistical Policy (CSSP), the Working Party on Environmental Information (WPEI) of the Environmental Policy Committee (EPOC), and Working Party 1 (WP1) of the Economic Policy Committee (EPC).

${ }^{2}$ See OECD (2001) for a discussion of the advantages of multifactor compared with single-factor productivity measures. (The literature often refers to total versus partial productivity measures.)
} 
TABLE OF CONTENTS

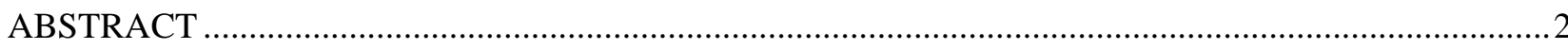

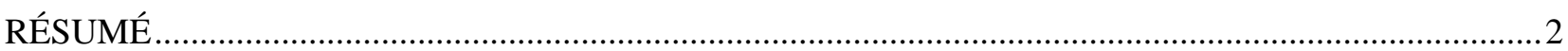

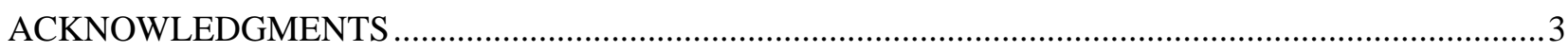

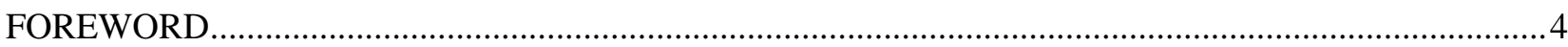

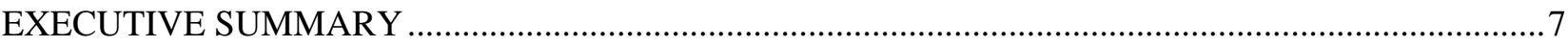

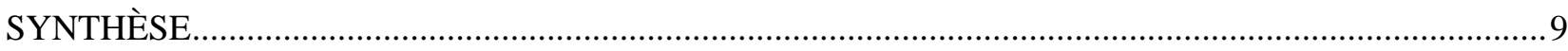

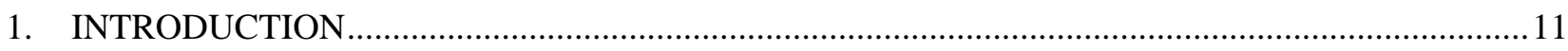

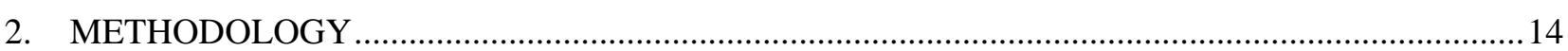

2.1. Integrating natural capital and pollution in a growth accounting framework ...............................14

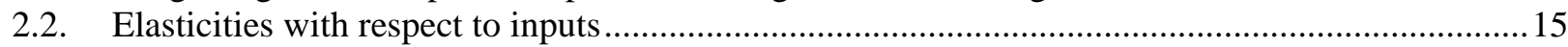

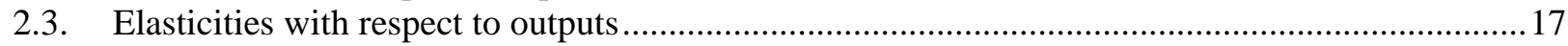

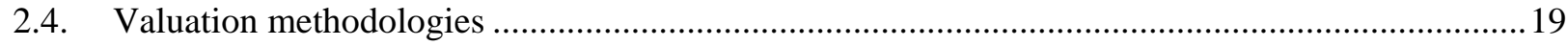

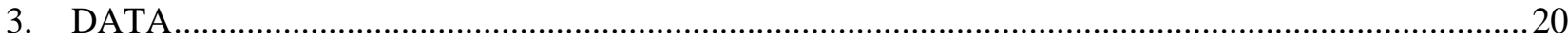

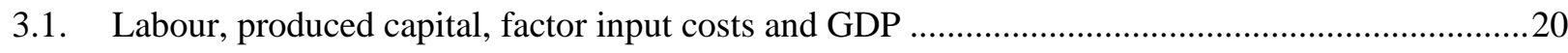

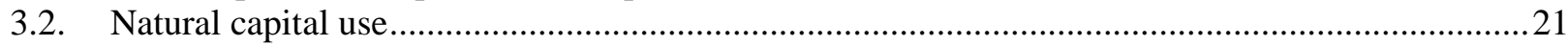

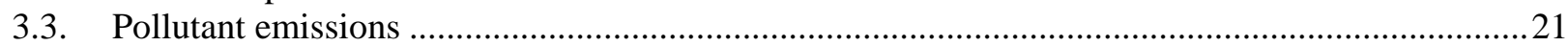

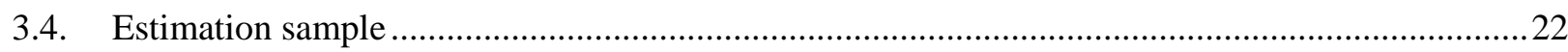

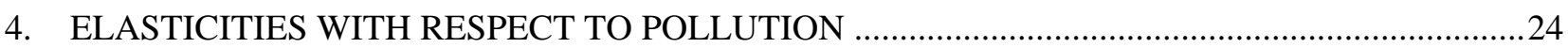

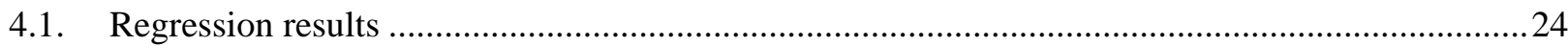

4.2. Estimated elasticities of GDP with respect to pollution..........................................................26

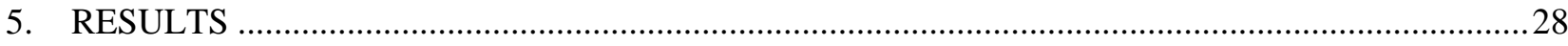

5.1. Growth accounting with air pollution and subsoil natural assets .................................................28

5.2. Environmentally adjusted multifactor productivity growth .........................................................32

5.3. Contribution of natural capital use to output growth .....................................................................3

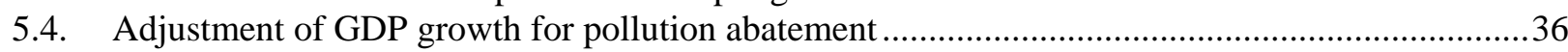

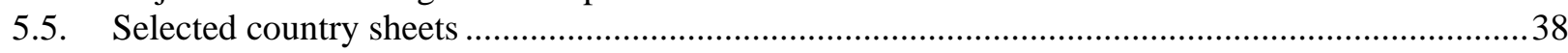

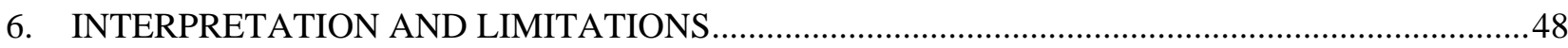

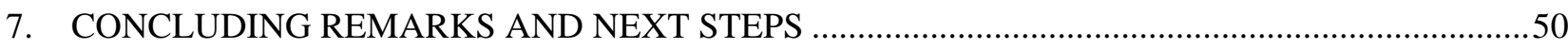

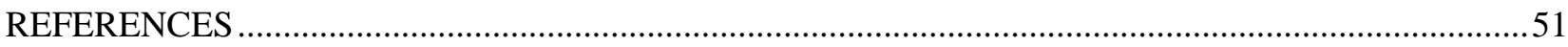

ANNEX 1. REVIEW OF METHODOLOGIES FOR PRODUCTIVITY ANALYSIS .........................55

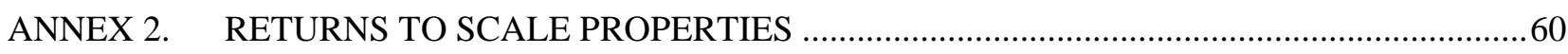

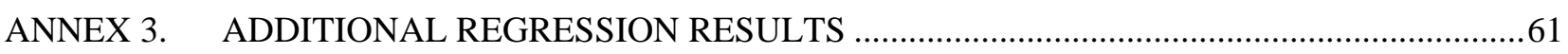

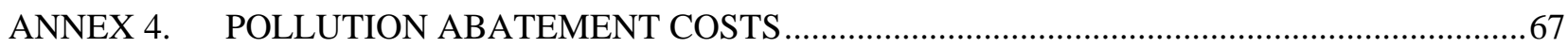

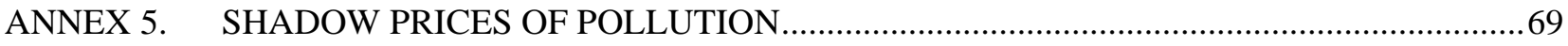

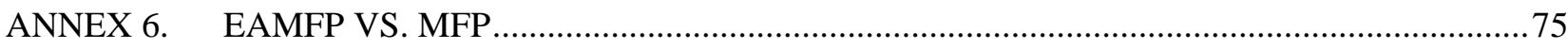




\section{Tables}

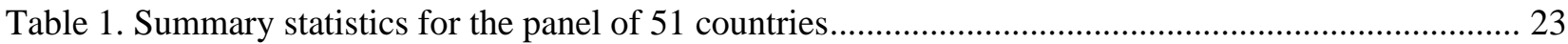

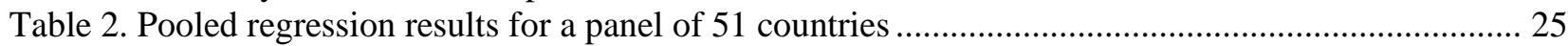

Table 3. Growth accounting, long-term annual averages ..................................................................... 28

Table A1.1. Alternative methodological approaches to MFP calculation used in OECD work .................. 58

Table A3.1. RCM regression results with pollutants included separately (full sample) ............................. 61

Table A3.2. Summary statistics for the PRODB panel (20 countries) ......................................................... 62

Table A3.3. Regression results with pollutants included separately (PRODB panel, 20 countries) ............. 64

Table A3.4. Pooled estimation results (PRODB panel, 20 countries) .......................................................... 64

Table A3.5. Summary statistics for the TED sub-sample (31 countries) ……........................................... 65

Table A3.6. Regression results with pollutants included separately (TED panel, 31 countries).................. 66

Table A3.7. Pooled estimation results (TED panel, 31 countries) ............................................................ 66

Table A4.1. Cost of abating an additional percentage of CO2 in 2012 (million USD 2005 using PPP) ..... 68

\section{Figures}

Figure 1.The pollution-adjusted GDP growth and the EAMFP (\%), OECD and BRIICS......................... 13

Figure 2. Elasticities of GDP with respect to pollution $\varepsilon$ YRi ...................................................................... 27

Figure 3. Adjustment of GDP growth for pollution abatement (circa 1991-2013 average) ......................... 31

Figure 4. Contribution of inputs to pollution-adjusted GDP growth (circa 1991-2013 average)................. 31

Figure 5. EAMFP growth (circa 1991-2013 average) .............................................................................. 32

Figure 6. The highest EAMFP relative to other sources of growth (circa 1991-2013 average)................... 33

Figure 7. Growth in contribution of natural capital (subsoil assets), circa 1991-2013 average ................... 34

Figure 8. The highest contribution of natural capital (subsoil assets) relative to other sources of growth

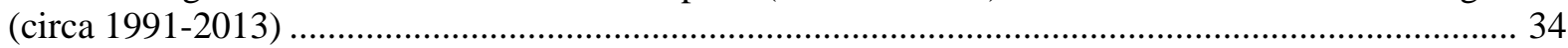

Figure 9. Growth in adjustment for pollution abatement (air emissions), circa 1991-2013 average ........... 36

Figure 10. The highest adjustment for pollution abatement, as a share of GDP growth (circa 1991-2013) 37

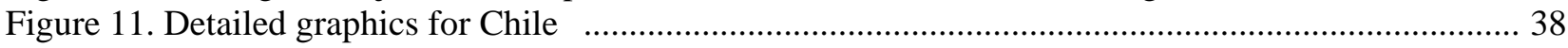

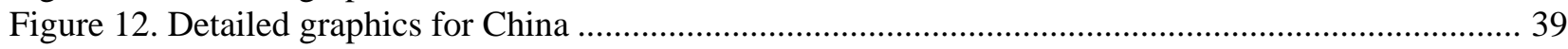

Figure 13. Detailed graphics for Germany

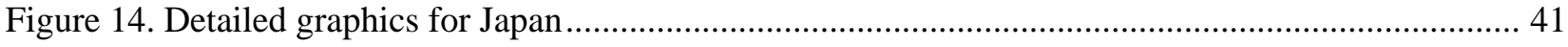

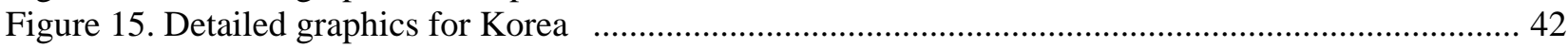

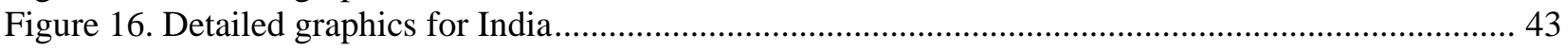

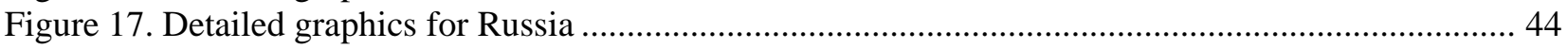

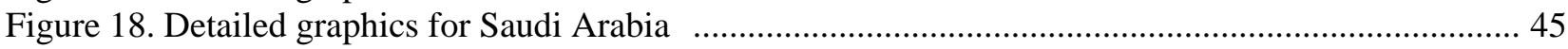

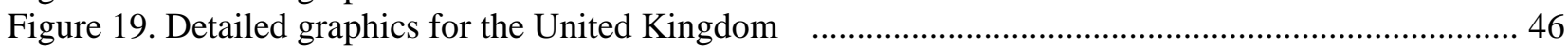

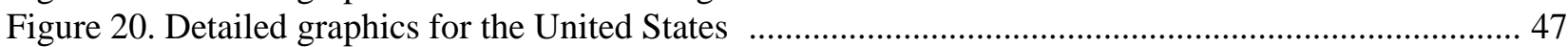

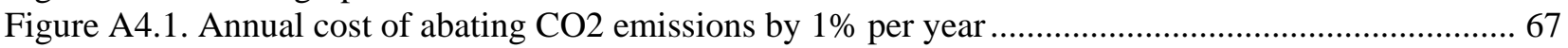

Figure A5.1. Shadow price per tonne of CO2 (USD 2005 PPP .............................................................. 71

Figure A5.2. Estimated shadow prices of pollution (USD 2005 using PPP) …......................................... 72

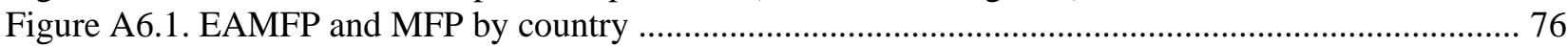




\section{EXECUTIVE SUMMARY}

Growth in environmentally adjusted multifactor productivity (EAMFP) has been identified as a green growth headline indicator. It measures a country's ability to generate income from a given set of inputs, while accounting for the consumption of natural resources and production of undesirable environmental outputs. The EAMFP has the potential to complement the traditional measure of productivity - multifactor productivity (MFP) - widely used by economic and finance policy makers, and thus foster greater consideration of environmental concerns in economic policy decisions.

The framework for measuring the EAMFP provides opportunities to develop two related indicators that could be useful for green growth analysis: the growth contribution of natural capital which measures how much current income growth depends on natural resource use; and the growth adjustment for pollution abatement which measures to what extent economic growth has been achieved at the expense of environmental quality.

The primary benefit of this environmentally adjusted productivity measurement framework is that it allows for a more accurate assessment of economic performance. By not taking account of environmental considerations, the traditional MFP indicator provides an incomplete description of the economy. This may result in a misleading understanding of growth prospects and the choice of inappropriate policy options. For example, in countries that hold production costs down by relying on heavily polluting technologies, MFP may suggest an overly optimistic assessment of economic potential.

By decomposing overall growth in GDP into the contributions of individual factor inputs - labour, produced capital and natural capital - the EAMFP measurement framework allows the sources of growth to be identified more accurately. In some countries, the contribution of natural resource extraction to economic growth is rather high and this might raise concerns over the expected future growth path of these economies. The indicator measuring the contribution of natural capital to output growth allows long-run growth prospects to be assessed when natural capital becomes scarce.

In the long run, productivity growth leads to higher per capita income and rising living standards. Understanding the role of policy and market factors, including environmental policy, for countries' long-run growth prospects is another practical application of the EAMFP measurement framework.

This paper refines the OECD productivity measurement framework and expands the measurement of the EAMFP and the related indicators to all OECD and G20 countries for the 1990-2013 period. Currently, the framework allows accounting for the extraction of 14 types of subsoil natural assets (fossil fuels and minerals) and 8 types of air emissions (greenhouse gases and air pollutants).

The main findings indicate that in some countries, such as the Russian Federation (hereafter 'Russia'), Saudi Arabia, Chile, Israel and the People's Republic of China (hereafter 'China'), reliance on the extraction of subsoil assets has contributed to a significant share of income growth, supporting concerns about their ability to sustain past growth rates in the long run. This is all the more important in countries where productivity growth has been slow or has even decreased. In other countries, including the United Kingdom, declining extraction of subsoil assets has been compensated through greater reliance on other 
inputs to maintain output growth, or through productivity improvements. In countries such as Finland, Japan or Germany the bulk of income growth has been generated essentially via productivity gains.

Interestingly, long-run EAMFP growth rates have been rather similar between the OECD and BRIICS countries. The key factor that explains their different overall growth performance is the extent to which they rely on factor inputs: BRIICS countries have drawn to a much greater extent on increased utilisation of inputs (including labour, produced capital and natural capital) to generate additional growth, while in OECD countries growth has been generated almost exclusively through productivity gains.

The results also point to a shift towards cleaner production processes in many countries. In fact, most OECD countries have decreased their emissions over the last two decades, and their GDP growth rates would need to be adjusted upwards to correctly assess their growth performance. Such adjustment sheds light on the 'green' growth performance of countries, including those where significant pollution abatement efforts might otherwise lead us to undervalue their economic growth.

The indicators presented in this paper could be integrated into future reports on Green Growth indicators. They could also be applied in country studies such as OECD Economic Surveys and OECD Environmental Performance Reviews. This would provide a basis for assessing their policy relevance. To support these efforts, further work should be carried out to address current data gaps, e.g. by drawing on work supporting the development of the SEEA. Work on EAMFP could also contribute to analytical work on productivity more broadly and to a further greening of the suite of productivity indicators within the OECD. 


\section{SYNTHÈSE}

La croissance de la productivité multifactorielle corrigée des incidences environnementales (EAMFP) fait partie des indicateurs de la croissance verte. Elle mesure la capacité d'un pays à générer des revenus à partir d'un ensemble donné d'intrants, tout en tenant compte de la consommation de ressources naturelles et de la production d'extrants environnementaux indésirables. La EAMFP peut compléter la mesure traditionnelle de la productivité - productivité multifactorielle (MFP) - couramment utilisée par les responsables des politiques économiques et financières, et permettre ainsi d'améliorer la prise en compte des considérations environnementales dans la prise de décisions économiques.

Le cadre de mesure de la EAMFP offre la possibilité de développer deux indicateurs connexes qui pourraient se révéler utiles pour l'analyse de la croissance verte : la contribution du capital naturel à la croissance qui permet de mesurer la part de la croissance des revenus qui dépend de l'utilisation de ressources naturelles; et l'ajustement de la croissance pour les réductions d'émissions polluantes qui permet de mesurer la part de la croissance économique générée au détriment de la qualité de l'environnement.

Le premier avantage de ce cadre de mesure de la productivité corrigée des incidences environnementales est qu'il permet d'évaluer avec plus de justesse la performance économique. En excluant les considérations environnementales, l'indicateur classique de la MFP donne une image incomplète de l'économie qui peut être trompeuse et nuire à la compréhension des perspectives de croissance et au choix des mesures appropriées. La MFP peut ainsi donner une image exagérément optimiste du potentiel économique des pays qui maintiennent les coûts de production à des niveaux bas en recourant à des technologies très polluantes.

En décomposant la croissance globale du PIB pour isoler la contribution des différents facteurs de production - travail, capital produit et capital naturel - le cadre de mesure de la EAMFP permet d'identifier les sources de croissance de façon plus précise. Dans certains pays, la contribution de l'extraction des ressources naturelles à la croissance économique est relativement élevée, ce qui peut soulever certaines interrogations quant à l'évolution de leur trajectoire de croissance. L'indicateur qui mesure la contribution du capital naturel à la croissance de la production permet ainsi d'évaluer les perspectives à long terme de la croissance lorsque le capital naturel s’appauvrit.

Sur le long terme, la croissance de la productivité se traduit par une augmentation du revenu par habitant et une amélioration du niveau de vie. Le cadre de mesure de la EAMFP peut être aussi utilement appliqué pour comprendre le rôle de facteurs politiques et marchands, y compris de la politique environnementale, dans les perspectives de croissance à long terme des pays.

Le présent rapport affine le cadre de mesure de la productivité de l’OCDE et applique la mesure de la EAMFP et des indicateurs connexes à tous les pays de l'OCDE et du G20 pour la période 1990-2013. Actuellement, ce cadre permet de tenir compte de l'extraction de 14 types de ressources naturelles souterraines (combustibles fossiles et minéraux) et 8 types d'émissions atmosphériques (gaz à effet de serre et polluants atmosphériques). .

Les principales conclusions du rapport révèlent que dans certains pays, comme la Fédération de Russie, l'Arabie Saoudite, le Chili, Israël ou encore la République populaire de Chine, l'extraction de d'actifs du sous-sol fortement contribué à la croissance des revenus, ce qui fait qu'on peut se demander si ces pays seront capables de maintenir à terme les taux de croissance enregistrés par le passé. Cette question est d'autant plus importante dans les pays où la croissance de la productivité est faible, voire en recul. D'autres pays, dont le Royaume-Uni, ont compensé le ralentissement de l'extraction de d'actifs du sous-sol 
en tablant davantage sur d'autres intrants pour maintenir la croissance de la production, ou en améliorant leur productivité. Dans d'autres pays comme la Finlande, le Japon ou l'Allemagne, le gros de la croissance des revenus est à mettre au compte des gains de productivité.

Fait intéressant, les taux de croissance à long terme de la EAMFP des pays de l'OCDE et des BRIICS sont assez similaires. Les différences entre leurs taux de croissance économique tiennent principalement à la contribution relative des facteurs de production : dans les BRIICS l'intensification de la croissance est principalement à mettre au compte de l'utilisation accrue d'intrants (travail, capital produit et capital naturel), tandis que dans les pays de l'OCDE, elle repose presque exclusivement sur des gains de productivité.

Les résultats indiquent par ailleurs dans beaucoup de pays, une évolution vers des procédés de production plus propres. De fait, la plupart des pays de l'OCDE ont réduit leurs émissions au cours des vingt dernières années et le taux de croissance de leur PIB devrait être ajusté à la hausse pour évaluer correctement leurs résultats en matière de croissance. Ces ajustements font ressortir les performances en matière de croissance "verte ", notamment dans les pays qui ont déployés d'importants efforts pour lutter contre la pollution et dont la croissance économique pourrait, si l'on n'en tient pas compte, se trouver sousévaluée.

Les indicateurs présentés dans ce rapport pourraient être intégrés dans les rapports à venir sur les Indicateurs de Croissance Verte. Ils pourraient également être appliqués dans les études nationales, notamment les Études Économiques et les Examens Environnementaux de l'OCDE, ce qui permettrait d'évaluer leur pertinence pour l'action. Les travaux doivent être poursuivis pour approfondir ces questions et notamment remédier aux déficits de données, en s'appuyant par exemple sur les recherches menées à l'appui du développement du Système de comptabilité économique et environnementale intégrée (SCEE). Les travaux sur la EAMFP pourraient aussi contribuer aux analyses plus générales de la productivité et à l'intégration des considérations environnementales dans les indicateurs de productivité au sein de l'OCDE. 


\section{INTRODUCTION}

Multifactor productivity (MFP) is a commonly used indicator of economic performance. It plays an important role in computing an economy's underlying productive capacity ("potential output") and it is a key variable in estimating long-term growth prospects. Objectives of productivity measurement often include tracing technical change (disembodied technological improvements) or identifying technical efficiency (elimination of technical and organisational inefficiencies in production). As such, multifactor productivity reveals how an economy functions as a whole, and that helps explain differences in standards of living, e.g. changes in income per capita in the long run. (See OECD 2001 for a thorough introduction to productivity measurement.)

Traditional measures of productivity growth fail to fully account for the role of environmental services in production. These measures are unbalanced for two reasons. First, while income generated through the use of domestic natural assets is fully reflected, no account is taken of the natural resource input (in terms of the resource rents). Increased natural resource use is therefore wrongly interpreted as a rise in productivity. Second, while the costs of investing in pollution abatement are fully captured (in terms of factor inputs including labour and produced capital), no account is taken of the benefits of such investments because pollution is not considered as an output of the production process. Increased abatement efforts therefore make productivity appear falsely low. (See Brandt et al., 2014; 2013 for an in-depth discussion.)

Correcting those omissions is important because traditional productivity measures can potentially lead to a misleading idea of growth prospects and thus the choice of inappropriate policy options. Accounting for both environment-related inputs, such as the use of natural resources, and environment-related outputs, such as air pollution, allows those omissions to be corrected and can provide a better understanding of the role of environmental services for productivity and economic growth. This adjusted measure of MFP has the potential to encourage the incorporation of environmental considerations in economic policy decisions.

Increasingly, countries have started calculating such productivity measures at the industry level, accounting for the effects of intermediate inputs such as energy and materials (e.g. Canada, USA, Mexico, Australia and the EU). ${ }^{3}$ This paper builds on such initiatives and aims at developing an indicator of environmentally adjusted multifactor productivity (EAMFP) at the country level which makes adjustments for natural capital inputs and for negative by-products of the production process (hereafter referred to as undesirable outputs). The aim is to produce the indicator annually and for a large number of countries.

EAMFP growth measures the residual growth in the joint production of both the desirable and the undesirable outputs that cannot be explained by changes in the consumption of factor inputs (including labour, produced capital and natural capital). Therefore, for a given growth of input use, EAMFP increases when GDP increases or when pollution decreases.

As part of the growth accounting framework underlying the EAMFP indicator, the growth contribution of natural capital and growth adjustment for pollution abatement indicators are derived:

- Growth contribution of natural capital - measures to what extent a country's growth in output is attributable to domestic natural resource use;

\footnotetext{
${ }^{3}$ Such industry-level productivity measures are typically referred to as KLEMS - accounting for capital (K), labour (L), energy (E), materials (M) and purchased services (S).
} 
- Growth adjustment for pollution abatement - measures to what extent a country's GDP growth should be corrected for pollution abatement efforts - adding what has been undervalued due to resources being diverted to pollution abatement, or deducing the 'excess' growth which is generated at the expense of environmental quality.

The key contributions of this paper are:

i) Further refinement of the OECD methodology for measuring EAMFP with a view to improving the ease of interpretation of the indicator which is now expressed in units of GDP growth. This allows the implications of EAMFP to be intuitively better understood (in previous work the results were expressed in units of effective output growth);

ii) The development of two related indicators: the growth contribution of natural capital and the growth adjustment for pollution abatement. These two indicators are published alongside the EAMFP to help better understand the sources of economic growth;

iii) Further refinement of the methodology for estimating the pollution elasticities with a view to obtaining elasticities that vary by country (in previous work, the same elasticity was applied across all countries). More granular country-specific estimates allow to better account for environmental services;

iv) An extended account of air emissions including greenhouse gases $\left(\mathrm{CO}_{2}, \mathrm{CH}_{4}, \mathrm{~N}_{2} \mathrm{O}\right)$ and air pollutants $\left(\mathrm{PM}_{10}, \mathrm{CO}, \mathrm{NMVOC}, \mathrm{SO}_{\mathrm{X}}, \mathrm{NO}_{\mathrm{X}}\right)$ (previous work covered only three types of air emissions);

v) Geographic coverage extended to all OECD and G20 countries (46 countries) over the 1990-2013 timeframe (previous work covered 25 countries over 1990-2008).

\section{Key findings}

The findings indicate that in some countries, including Russia, Saudi Arabia, Chile and China, reliance on the extraction of natural resources (subsoil assets) has contributed to a significant share of income growth, supporting concerns about their ability to sustain past growth rates in the long run. This is all the more important in countries where productivity growth has been slow or has even decreased. In other countries, including the UK, declining extraction of natural resources (subsoil assets) has been compensated through greater reliance on other inputs to maintain output growth, or through productivity improvements. In fact, in countries such as Finland, Japan or Germany the bulk of income growth has been generated essentially via productivity gains.

Interestingly, long-run EAMFP growth rates have been rather similar between OECD and BRIICS countries. As shown in Figure 1, the key factor that explains their different overall growth performance is the extent to which they rely on factor inputs: BRIICS countries have drawn to a much greater extent on increased utilisation of factor inputs (including labour, produced capital and natural capital) to generate additional growth, while in OECD countries growth has been generated almost exclusively through productivity gains. 
Figure 21. The pollution-adjusted GDP growth and the EAMFP (\%), OECD and BRIICS

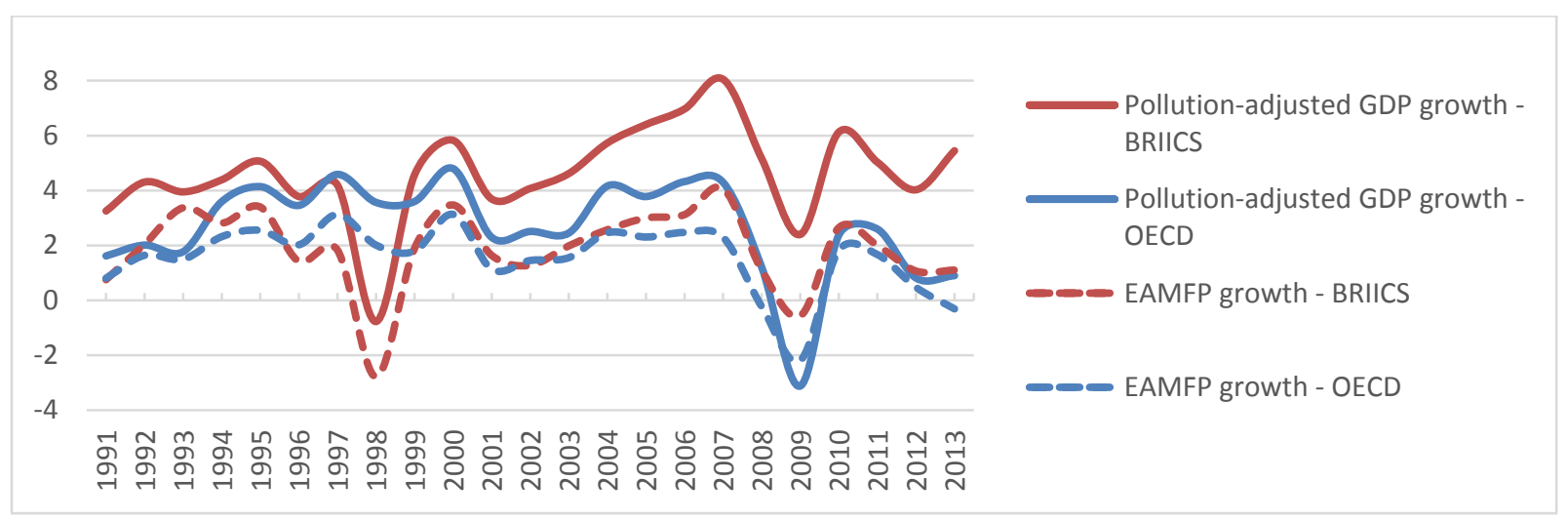

Our results also point to a shift towards more environmentally friendly production processes in many countries. In fact, most OECD countries have decreased their emissions over the last two decades, and their GDP growth rates should be adjusted upwards to correctly assess their growth performance. Such adjustment helps shed light on the 'green' growth performance of countries, including those where significant pollution abatement efforts might otherwise lead us to undervalue their economic growth.

It is important to emphasise that the coverage of environmental services in the EAMFP indicator presented here remains partial, confined to a number of air emissions, and when accounting for the use of domestic natural capital, limited to the extraction of mineral resources. Given such partial coverage, the name "environmentally adjusted MFP" is at this stage not fully accurate. Permitting better data availability, future work could improve upon the indicator presented here and expand the coverage to other, equally important, environmental pressures such as effluents to water bodies and use of natural capital such as land, soils, freshwater, native forests or wild fisheries. In the meantime, the EAMFP remains a work-inprogress that provides partial - but nonetheless important - information on the relationship between the composition of growth and its claims on environmental assets.

The remainder of this paper is organised as follows. Section 2 presents the refinements of the extended growth accounting framework and the related methodology used to evaluate the required elasticities with respect to inputs and outputs. The data used in this paper are discussed in Section 3. The empirical estimation of elasticities is presented in Section 4. The key findings are presented in Section 5 including the empirical results on the EAMFP and the related indicators. Finally, the paper concludes by outlining possible next steps that would allow further advancing the productivity measurement agenda (Section 7). The more technical discussion and results are included as Annexes at the end of the paper. For a brief non-technical overview, the reader is invited to focus on Section 5 where the key results are discussed. 


\section{METHODOLOGY}

\subsection{Integrating natural capital and pollution in a growth accounting framework}

This section develops a growth accounting framework that takes into account labour, produced capital and natural capital as inputs and air pollution as undesirable output. The approach presented here builds on the model developed by Brandt et al. (2013; 2014). ${ }^{4}$

Consider the following transformation function:

$$
H(Y, R, L, K, S, t) \geq 1
$$

where L, K and S denote labour, produced capital and natural capital, respectively; $\mathrm{Y}$ represents the desirable output of the economy (GDP) and R the undesirable output (air pollution). Note that K, S and R represent vectors of multiple types of produced capital, natural capital and pollution. $\mathrm{H}$ is increasing in inputs $\mathrm{K}, \mathrm{L}$ and $\mathrm{S}$ and undesirable output $\mathrm{R}$, and decreasing in good output $\mathrm{Y}$.

The transformation function is homogeneous of degree 1 in inputs and $\theta$ in good and undesirable outputs such that $H(\lambda . Y, \lambda . R, L, K, S, t)=\lambda^{\theta} . H(Y, R, L, K, S, t)$. No a priori assumption is made on $\theta$ and therefore on the returns to scale properties of the function. This parameter is country-specific, i.e. each country has its own returns to scale properties. An estimated value for $\theta$ is provided in Annex 2.

Change over time $t$ of the transformation function $H$ provides a measure of growth in environmentally adjusted multifactor productivity (EAMFP). ${ }^{56}$

Totally log-differentiating equation [1] with respect to time yields:

$$
\frac{d \ln H(Y, R, L, K, Z, t)}{d t}=\frac{\partial \ln H}{\partial Y} \frac{\partial Y}{\partial t}+\frac{\partial \ln H}{\partial R} \frac{\partial R}{\partial t}+\frac{\partial \ln H}{\partial L} \frac{\partial L}{\partial t}+\frac{\partial \ln H}{\partial K} \frac{\partial K}{\partial t}+\frac{\partial \ln H}{\partial S} \frac{\partial S}{\partial t}+\frac{\partial \ln H}{\partial t}=0
$$

Using the fact that $\partial \ln X=\frac{\partial X}{X}$, we rearrange equation [2]:

$$
\frac{\partial \ln H}{\partial t}=-\frac{H_{Y} Y}{H} \frac{\partial \ln Y}{\partial t}-\frac{H_{R} R}{H} \frac{\partial \ln R}{\partial t}-\frac{H_{L} L}{H} \frac{\partial \ln L}{\partial t}-\frac{H_{K} K}{H} \frac{\partial \ln K}{\partial t}-\frac{H_{S} S}{H} \frac{\partial \ln S}{\partial t}
$$

Using the definition of elasticity $\varepsilon_{\mathrm{HX}}=\frac{H_{X} X}{H}$, we get:

$$
\frac{\partial \ln H}{\partial t}=-\varepsilon_{H Y} \frac{\partial \ln Y}{\partial t}-\varepsilon_{H R} \frac{\partial \ln R}{\partial t}-\varepsilon_{H L} \frac{\partial \ln L}{\partial t}-\varepsilon_{H K} \frac{\partial \ln K}{\partial t}-\varepsilon_{H S} \frac{\partial \ln S}{\partial t}
$$

\footnotetext{
${ }^{4}$ See Annex 1 for a review of alternative methodologies for productivity analysis.

${ }^{5}$ Environmentally adjusted multifactor productivity (EAMFP) should be interpreted broadly, comprising both movements toward the production frontier (improved technical efficiency) and shifts of the production frontier (technical change). Intuitively, both types of improvements allow producing more with fewer resources.

${ }^{6}$ For a complete review of the assumptions underlying the growth accounting framework, see OECD (2001, p.18).
} 
The term $\varepsilon_{\mathrm{HY}}$ is the elasticity of the transformation function with respect to good output $\mathrm{Y}$. It is negative because $\mathrm{H}$ is decreasing in output and both $\mathrm{Y}$ and $\mathrm{H}$ are positive. By contrast, elasticities with respect to undesirable output and inputs are positive since $\mathrm{H}$ is increasing in inputs and pollution.

To obtain a measure of productivity that is directly comparable with output (GDP) growth, equation [4] is divided by the elasticity of the transformation function with respect to good output $\varepsilon_{H Y}$. Expressing the results in terms of the GDP growth is intuitively much easier to understand than when results are expressed in terms of the effective output growth. Moreover, this approach is consistent with OECD's traditional productivity measurement framework in which MFP is expressed in terms of GDP growth.

Therefore, the EAMFP growth is defined as ${ }^{7}$

$$
\frac{\partial \ln E A M F P}{\partial t} \equiv \frac{\partial \ln Y}{\partial t}-\varepsilon_{Y R} \frac{\partial \ln R}{\partial t}-\varepsilon_{Y L} \frac{\partial \ln L}{\partial t}-\varepsilon_{Y K} \frac{\partial \ln K}{\partial t}-\varepsilon_{Y S} \frac{\partial \ln S}{\partial t}
$$

Finally, the growth accounting equation decomposing the pollution-adjusted GDP growth into factor inputs growth and EAMFP growth can be written as:

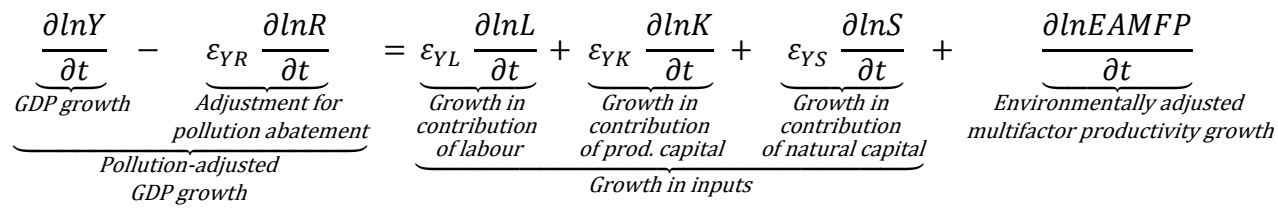

Equation [6] describes how inputs are used in the economy to produce outputs. EAMFP growth is the residual, i.e. the share of pollution-adjusted GDP growth that cannot be explained by growth in the use of factor inputs. It acknowledges changes in the production of both the desirable and the undesirable outputs. That is, for a given growth of input use, multifactor productivity increases when GDP increases or when pollution decreases. The pollution abatement term measures variations in emissions, expressed in equivalent GDP growth. It is positive when pollution decreases and negative when pollution increases in a given year. The pollution-adjusted GDP growth should therefore be understood as an indicator of how GDP is changing both in terms of quantity and in terms of pollution intensity.

In this framework elasticities play a key role as they allow converting or "pricing” pollution and inputs variations in terms of output variation. For example, the larger the elasticity of output with respect to pollution $\varepsilon_{Y R}$, the more is output growth dependent on pollution emissions and the higher the cost of pollution abatements in terms of foregone output growth. As such, $\varepsilon_{Y R}$ measures the trade-off between producing more and polluting less. The methodology to obtain these elasticities is described next.

\subsection{Elasticities with respect to inputs}

As suggested by equation [5], computing the EAMFP growth requires some knowledge of the elasticities of the transformation function with respect to inputs and outputs. Information on the elasticities, (that is, on the technological properties of firms) can be inferred from the behaviour of firms in the market

\footnotetext{
${ }^{7}$ Note that the elasticities of output with respect to pollution and inputs can be deducted from the elasticities of the transformation function. For example, the elasticity of output with respect to pollution is equal to $\varepsilon_{\mathrm{YR}}=$ $\left(-\varepsilon_{\mathrm{HR}} / \varepsilon_{\mathrm{HY}}\right)$. It measures the percentage change in output associated with a marginal increase in pollution. This can be seen from log-differentiating equation [1] with respect to pollution and keeping inputs and productivity constant which yields $\frac{\partial Y}{\partial R}=-\frac{H_{R}}{H_{Y}}$. It follows that $\varepsilon_{\mathrm{YR}}=\frac{\partial Y}{\partial R} \frac{R}{Y}==-\frac{H_{R}}{H_{Y}} \frac{R}{Y} \frac{H}{H}=-\frac{\varepsilon_{H R}}{\varepsilon_{\mathrm{HY}}}$. Elasticities of output with respect to inputs are obtained in a similar manner.
} 
- that is, from observations of the consumption of inputs and the production of outputs, and the prices that firms face in the markets. Such elasticities can be either computed using a profit-maximisation approach or estimated econometrically.

The profit maximisation method, which is usually used in traditional multifactor productivity analyses, offers several advantages. First, it involves no econometric estimation and is therefore immune to sample size issues or estimation instability. Second, values of elasticities do not vary when the sample changes, making the growth accounting results consistent over time when recalculations of the growth accounting framework are conducted. Third, elasticities can change both over time and between countries whereas they can only vary between countries with the econometric approach.

The advantages of the econometric approach are that it doesn't require any assumption of profit-maximising behaviour of firms and doesn't require price data of any kind.

In this paper, the two approaches are combined: For labour, produced capital and natural capital, which are all traded in the markets, and therefore have explicit prices, their elasticities will be calculated from their cost shares in the economy. For the elasticities with respect to outputs, they will be estimated econometrically because pollution does not have an explicit price ${ }^{8}$.

Solving a profit maximisation problem provides a measure of the elasticity of the transformation function with respect to labour, produced capital and natural capital. Formally, the profit maximisation problem of the producer can be written as:

$$
\operatorname{Max} P_{Y} \cdot Y+P_{R} \cdot R-w \cdot L-u_{K} \cdot K-u_{S} \cdot S \quad \text { such that } \quad H(Y, R, L, K, S, t) \geq k
$$

where $k$ is the efficiency level; it is superior or equal to 1 and is exogenously given for each country. It should be understood as the efficiency level of firms each year. Introducing this parameter allows us to relax the assumption that production is fully efficient since $\mathrm{k}$ is superior or equal to 1 . As we assumed that the efficiency level was constant over time, $k$ should be constant as well ${ }^{9}$.

$P_{Y}, w, u_{K}$ and $u_{S}$ denote the price of good output $Y$, the unit cost of labour (wage), the user cost of produced capital and the user cost of natural capital. The user cost of natural capital may be explicit, such as license fees for exploiting a mine or using a stream to run a hydropower station, or implicit if the producer is an owner-user of the natural capital stock (Brandt et al., 2013). In that case, $u_{S}$ would be the private shadow price of using the natural capital in production, or the reduction in the value of the natural capital stock that results from extracting one (further) unit of the resource. As such, the user cost of natural capital is not observed, but under some conditions, it is equal to the market price of extracted natural capital minus the extraction costs (i.e. the unit rent) ${ }^{10}$. This is the approach used to calculate the user cost of natural capital that underlies the analysis in this paper.

8 Pollution is typically not traded in the markets and although in some cases such markets have been "constructed" by governments (e.g. emissions trading schemes for selected sectors), in most cases, the "private cost” for producers implied by environmental regulations is not directly observable.

9 If the residual in [6] were to be interpreted as a change in both productivity and efficiency, $k$ would vary as well.

10 This rule is deduced from the optimal extraction path of a non-renewable capital stock. The static efficiency condition of a Hamiltonian-based maximisation problem requires the user cost of capital, defined as the change in the net present value of the resource rent, to be equal to the market price minus the extraction cost. Key assumptions relate to the cost of extracting natural resources which should follow a normal distribution and should not depend on the remaining stock of natural resources. This is the method followed by the World Bank in its WAVES database. A mathematical proof of this rule can be found in Brandt et al. (2013). 
$P_{R}$ denotes the implied private cost of undesirable output i.e. the marginal cost for producers of complying with environmental regulations. It is expressed in terms of foregone goods and services that could have been produced otherwise (Brandt et al., 2014). Those implied private costs are also called pollutant shadow prices in the literature. For the purpose of calculating the EAMFP, only the pollution elasticities are required; the implicit private cost of pollution, which is derived using the estimated elasticity, is only a 'by-product' of our empirical methodology (see Annex 5).

Solving the Lagrangian for the first-order conditions with respect to inputs yields:

$$
w=\lambda . H_{L} ; u_{K}=\lambda \cdot H_{K} ; u_{S}=\lambda \cdot H_{S} ; \lambda \cdot(H(Y, R, L, K, S, t)-k)=0 \text { and } \lambda \geq 0
$$

Using the total value of inputs $\gamma$ and applying the Euler theorem gives:

$$
\gamma \equiv w \cdot L+u_{K} \cdot K+u_{S} \cdot S=\lambda \cdot\left(H_{L} \cdot L+H_{K} \cdot K+H_{S} \cdot S\right)=\lambda \cdot H
$$

As a result, the elasticities of the transformation function with respect to $\mathrm{L}, \mathrm{K}$ and $\mathrm{S}$ are:

$$
\begin{gathered}
\varepsilon_{H L} \equiv \frac{H_{L} L}{H}=\frac{w L}{\lambda \cdot H}=\frac{w L}{\gamma} \\
\varepsilon_{H K} \equiv \frac{H_{K} K}{H}=\frac{u_{K} K}{\lambda \cdot H}=\frac{u_{K} K}{\gamma} \\
\varepsilon_{H S} \equiv \frac{H_{S} S}{H}=\frac{u_{S} S}{\lambda \cdot H}=\frac{u_{S} S}{\gamma}
\end{gathered}
$$

Therefore, as suggested in Brandt et al. (2013), under profit maximisation the elasticities are equal to the shares of labour, produced capital and natural capital in the input mix. Note that $\varepsilon_{H L}, \varepsilon_{H K}$ and $\varepsilon_{H S}$ are expected to be positive because input costs $\left(w, u_{K}, u_{S}\right)$ and quantities $(L, K, S)$ are positive.

The calculation of the input cost shares requires data on prices for all three inputs. Data on wages are available for all countries included in our sample. The user cost of natural capital can be approximated, as mentioned above, using the unit rent (i.e. market price minus extraction costs) which is available for most countries. Data on the user cost of produced capital is not available for a subset of countries. For these countries, the cost share of capital is derived endogenously as the difference between nominal GDP and labour cost. This calculation requires the assumption of constant returns to scale and perfect competition, implying zero profits. As explained in Brandt et al. (2013), assigning all non-labour income to produced capital does not allow for unmeasured inputs and, when they are present, their income would be included in the estimate of the cost (or income) of produced capital. Hence, when including natural capital, the cost shares of labour and produced capital need to be adjusted downwards. The shares of labour, produced capital and natural capital are calculated for consecutive time periods as Törnqvist indexes; in our case, we use two-period averages.

\subsection{Elasticities with respect to outputs}

While the elasticities with respect to inputs can be derived from market outcomes, pollution is not traded in the economy. Therefore, the elasticities with respect to good output $\mathrm{Y}$ and pollutants $\mathrm{R}$ have to be 
estimated econometrically. Since the elasticities with respect to inputs are available (see above), we aggregate all inputs into one variable: ${ }^{11}$

$$
\frac{\partial \ln X}{\partial t} \equiv \varepsilon_{H L} \frac{\partial \ln L}{\partial t}+\varepsilon_{H K} \frac{\partial \ln K}{\partial t}+\varepsilon_{H S} \frac{\partial \ln S}{\partial t}
$$

where $\frac{\partial \ln X}{\partial t}$ is an elasticity-weighted growth rate of inputs.

Using this expression and rearranging equation [5] yields:

$$
\frac{\partial \ln Y}{\partial t}=\frac{\partial \ln E A M F P}{\partial t}-\frac{1}{\varepsilon_{H Y}} \frac{\partial \ln X}{\partial t}-\frac{1}{\varepsilon_{H Y}} \sum \varepsilon_{H R j} \frac{\partial \ln R_{j}}{\partial t}
$$

For the purposes of econometric estimation, equation [12] is specified as follows:

$$
\dot{Y}_{i t}=\alpha_{i}+\delta_{t}+\gamma_{i} \dot{X}_{i t}+\sum \beta_{j i} \dot{R}_{j i t}+u_{i t} \forall j \in[1 ; 8]
$$

where $\dot{Y}_{i t}$ is the growth rate of output (GDP), $\dot{X}_{i t}$ is the elasticity-weighted growth rate of inputs and $\dot{R}_{j i t}$ is the growth rate of each undesirable output $\left(\mathrm{CO}_{2}, \mathrm{NO}_{\mathrm{X}}, \mathrm{SO}_{\mathrm{X}}, \mathrm{PM}_{10}, \mathrm{CH}_{4}, \mathrm{CO}, \mathrm{NMVOC}, \mathrm{N}_{2} \mathrm{O}\right)^{12}$. The intercept $\alpha_{i}$ captures the productivity growth. Time dummies $\delta_{t}$ are included in the estimation to allow the intercept to vary over time $t$ and across countries $i$. Finally, $u_{i t}$ is an error term that is assumed to be distributed normally with variance $\sigma_{\varepsilon}$ and mean 0 .

The elasticities of the transformation function with respect to desirable and undesirable outputs can then be calculated using the estimated coefficients as follows:

$$
\varepsilon_{H Y i}=-\frac{1}{\gamma_{i}} \text { and } \varepsilon_{H R j i}=\frac{\beta_{j i}}{\gamma_{i}} \forall j \in[1 ; 8]
$$

Several econometric methods can be used to estimate equation [13]. They differ in the way how heterogeneity across countries and over time is captured. The simplest option is to forbid heterogeneity in the intercept and in the coefficients using a pooled OLS estimation; this would imply that all countries have the same elasticity of pollution and the same productivity growth.

An alternative approach allows for heterogeneity in the intercept but not in the coefficients, and can be implemented using a fixed effects or random effects regression. Consequently, this approach introduces heterogeneity in productivity growth but implies common elasticities of pollution across countries (this is the approach adopted in Brandt et al. 2014).

The proposed approach allows heterogeneity in both the intercept and the slope coefficients by estimating a random coefficients model (RCM). The RCM yields country-specific elasticities reflecting

\footnotetext{
${ }^{11}$ Pooling inputs in one variable also offers several advantages in the estimation: it increases the number of degrees of freedom and reduces the multicollinearity likely to appear between input variables.

12 Note that one could also consider pollutants as endogenous and output as exogenous. However, as we want all pollutants to be estimated simultaneously, we have to choose equation [13]. Moreover, getting inputs and outputs on the same side of the equation would generate a multicollinearity problem (between inputs and the desirable output).
} 
heterogeneity in the relation between GDP and pollution, and allows the EAMFP to be calculated more accurately ${ }^{13}$.

\subsection{Valuation methodologies}

Growth accounting methods require data on input and output prices to compute the EAMFP. The productivity measurement framework discussed in this paper values environmental inputs and outputs from the producer's perspective: On the one hand, the user cost of natural capital inputs reflects the private user cost of firms that extract natural capital or use it in other ways to generate income (approximated by unit rent which is the market price net of extraction costs). Natural resources are thus treated in the same way as labour and produced capital. This makes sense because the underlying question is the efficiency with which producers use labour, produced and natural capital to generate income, given the prices which they face. However, it has implications for the interpretation of the results: Observed prices do not necessarily reflect the social cost of using natural capital, which may be much larger in some cases. For example, given the important biodiversity and life-support functions of many aquatic and wetland ecosystems, and often inadequate government policy to internalise these functions, the social cost of water abstraction is likely to be much larger than the market price of irrigation water. For example, the option values and nonuse values (altruism, bequest and existence values) of associated biodiversity losses will be excluded (see e.g. Pearce et al., 2006). The environmental damage that results from uses of water for agricultural and residential purposes is thus not fully captured by the productivity framework presented here.

Similarly, undesirable outputs (pollution) are valued by their "price” from the producer perspective: a shadow price of pollution is estimated as the producer's marginal cost of abating one unit of undesirable output - that is, how much output would need to be foregone if the firm's emissions were reduced by one unit. ${ }^{14}$ However, the marginal cost of pollution is a function of the regulatory environment which may or may not take into account the total value of environmental damages (see e.g. Pearce et al., 2006). If environmental policy fails to fully internalise the negative environmental externality (e.g. emission tax does not equal the marginal environmental damages), the shadow prices estimated as cost of pollution from the producer perspective may be very different from social cost of pollution. For example, given the important negative effects of air pollution on human and ecosystem health, the overall cost of emissions to society is likely to be much larger than the production gains due to higher labour productivity. Again, this approach can be justified for productivity measurement because the underlying question is that of the efficiency of producers in transforming inputs into outputs given the prices and regulations that they face. The EAMFP measurement framework thus not only allows the efficiency of generating private income to be assessed, but at the same time also attempts to assess the efficiency of generating social welfare although only to a limited extent.

\footnotetext{
${ }^{13}$ The estimated elasticities with respect to pollution and output vary across countries but not over time. It is impossible to estimate coefficients that vary across both dimensions, the problem would become deterministic. On the other hand, elasticities with respect to individual inputs are based on their cost shares (from the profit maximisation approach), hence varying both across countries and over time.

${ }^{14}$ Some authors have used 'assumed' prices based on e.g. market prices from emission trading systems (for $\mathrm{CO}_{2}$, $\mathrm{SO}_{2}$ ). However, such observed prices do not necessarily reflect the 'opportunity costs' of emissions abatement due to the presence of other market regulations such as subsidies for investment in development and deployment of energy efficient technologies.
} 


\subsection{Labour, produced capital, factor input costs and GDP}

The OECD Productivity Database (OECD 2015a) is the main source of data on labour, produced capital and the corresponding factor input costs (unit labour cost and user cost of capital). The database currently covers 20 OECD countries ${ }^{15}$ for 1990-2013. The Total Economy Database (TED) of the Conference Board (2014) is used to extend the geographical coverage to all 35 OECD member countries, 3 candidate accession countries and all remaining G20 economies. ${ }^{16,}{ }^{17}, 18$

Similarly to the OECD Productivity Database, the TED uses a growth accounting framework to compute the contribution of inputs to aggregate GDP growth. While TED's primary data sources are the OECD and Eurostat ${ }^{19}$, other data sources include the UN Economic Commission for Europe, the UN Economic Survey of Europe, the Asian Development Bank, the Asian Productivity Organization, and the GGDC 10-Sector Database for Latin American countries.

There are two key methodological differences when comparing the OECD and the TED databases. First, concerning the calculation of the user cost of capital: In the OECD Productivity database the user cost of capital is derived exogenously from the long-run rate of return, the depreciation rate, and the price of investment and investment goods (Brandt et al., 2013; OECD, 2009); On the other hand, the TED database does not provide the exogenous estimates of user cost of capital, only the share of labour in total cost is available. Therefore for the purpose of this paper, and following Brandt et al. (2013; 2014), the cost share of produced capital is calculated endogenously as the difference between nominal GDP and labour $\operatorname{cost}^{20}$. As such, for countries where the user cost of produced capital is calculated endogenously, the EAMFP measurement relies on the assumptions of constant returns to scale and perfect competition, implying zero profits (see Brandt et al., 2013).

The second methodological difference concerns the calculation of the contribution of labour to GDP growth. In the TED database the labour variable is adjusted by an index reflecting the composition of

15 The 20 countries include: Australia, Austria, Belgium, Canada, Denmark, Finland, France, Germany, Ireland, Italy, Japan, Korea, Netherlands, New Zealand, Portugal, Spain, Sweden, Switzerland, the UK and the US.

${ }^{16}$ Fifty-one countries in total, including all OECD member countries, accession candidates, and remaining G20 economies including all EU28 member states (as per the membership of the European Union in the G20).

${ }^{17}$ The statistical data for Israel are supplied by and under the responsibility of the relevant Israeli authorities. The use of such data by the OECD is without prejudice to the status of the Golan Heights, East Jerusalem and Israeli settlements in the West Bank under the terms of international law.

${ }^{18}$ Note by Turkey: The information in this document with reference to "Cyprus" relates to the southern part of the Island. There is no single authority representing both Turkish and Greek Cypriot people on the Island. Turkey recognises the Turkish Republic of Northern Cyprus (TRNC). Until a lasting and equitable solution is found within the context of the United Nations, Turkey shall preserve its position concerning the “Cyprus issue”.

Note by all the European Union Member States of the OECD and the European Union: The Republic of Cyprus is recognised by all members of the United Nations with the exception of Turkey. The information in this document relates to the area under the effective control of the Government of the Republic of Cyprus.

${ }^{19}$ Data for the 20 countries included in both the OECD's and the TED's databases present only minor differences due to the methodological differences discussed below.

${ }^{20}$ Moreover, under the TED methodology, labour is distinguished into labour quantity and labour composition, and produced capital into Information and Communication Technology (ICT) capital and non-ICT capital. Aggregating these pairs of subcategories is fully consistent with the OECD Productivity framework. For more information on the TED’s methodology see Conference Board (2014). 
labour, constructed on the basis of weighted measures of different skill-level groupings in the labour force. However, for the purpose of this paper, such adjustment of the labour variable is not conducted in order to improve the comparability of the variables drawing on the two databases. Thus, for all countries in our sample the labour variable reflects only the changes in "labour quantity" (hours worked) ${ }^{21}$.

Finally, data on GDP, GDP deflators and PPP rates for the 20 countries covered by the OECD Productivity database are retrieved from the OECD National Accounts Statistics database (OECD, 2015b and OECD 2015c). Data for the remaining countries are taken from World Development Indicators database (World Bank, 2015).

\subsection{Natural capital use}

Data on natural capital currently include 14 types of subsoil assets, including fossil fuels (hard coal, soft coal, gas, oil) and minerals (bauxite, copper, gold, iron ore, lead, nickel, phosphate, silver, tin and zinc). Production data are taken from the Natural Resource Accounts (OECD 2015d), complemented with information from the Wealth Accounting and the Valuation of Ecosystem Services (WAVES) database (World Bank 2014). This is done by individual resource type; for example, data on oil and natural gas extraction in the Netherlands are obtained from the accounts, while data on the remaining natural resources are taken from the WAVES. ${ }^{22}$

Natural capital unit rent data are obtained from the WAVES database. According to World Bank's methodology, unit rent is calculated as the difference of market prices and extraction costs. Extraction costs for different countries and regions were originally estimated from case studies. These cost estimates are then applied to subsequent years adjusting for inflation using the Manufactures Unit Value Index (MUV) from the World Bank's Commodity Price Data (a.k.a. Pink Sheet) ${ }^{23}$. In order to smooth the extrapolation of extraction costs and commodity price fluctuations, we apply a five-year moving average to unit rents. Multiplying production volumes by unit rents yields production values (in monetary units) by resource type, country and year.

The natural capital variable does not include timber as a distinct natural resource type. This is because timber, alongside with other "cultivated biological resources" are already included as fixed assets in the capital account ${ }^{24}$ and the available timber data do not distinguish between timber from cultivated versus timber from natural forests.

\subsection{Pollutant emissions}

Data on pollutant emissions currently cover 8 types of air emissions, including three greenhouse gases - carbon dioxide $\left(\mathrm{CO}_{2}\right)$, methane $\left(\mathrm{CH}_{4}\right)$, nitrous oxide $\left(\mathrm{N}_{2} \mathrm{O}\right)$ - and five air pollutants - sulphur oxides $\left(\mathrm{SO}_{\mathrm{X}}\right)$, nitrogen oxides $\left(\mathrm{NO}_{\mathrm{X}}\right)$, particulate matter smaller than 10 microns $\left(\mathrm{PM}_{10}\right)$, carbon monoxide $(\mathrm{CO})$

${ }^{21}$ This adjustment aims at capturing the effect of labour quality. In the absence of such adjustment to the Labour variable, the MFP measure would include this effect. Moreover, under the TED methodology, produced capital is accounted separately as Information and Communication Technology (ICT) capital and non-ICT capital. Aggregating these subcategories into produced capital is fully consistent with the OECD Productivity framework. For more information on the TED’s methodology see Conference Board (2014).

${ }^{22}$ Data from the accounts are converted to the units used in WAVES. In the case of natural gas, the conversion is done from cubic meters to units of energy by applying an implicit gross calorific value of natural gas calculated using the IEA's Natural Gas Information dataset.

${ }^{23}$ By extrapolating production costs using the MUV, there might be cases in which estimated costs are higher than prices. For these years, the rental rate is assumed to be zero, resulting in zero rents.

${ }^{24}$ System of National Accounts 2008, http://unstats.un.org/unsd/nationalaccount/docs/SNA2008.pdf 
and non-methane volatile organic compounds (NMVOC) ${ }^{25}$. The data refer to total national emissions of pollutants, and are obtained from the Air Emission Accounts (OECD 2015e) ${ }^{26}$, complemented with information from the Emission of Air Pollutants and Greenhouse Gas Emissions by Source dataset (OECD $2015 \mathrm{f}$ and OECD 2015g). Both datasets are part of the OECD Environment Statistics database.

To help interpolate missing values and to extend the geographical coverage beyond OECD countries, additional data is extracted from the Emissions Database for Global Atmospheric Research (EDGAR) developed by the European Commission's Joint Research Centre and the Netherlands Environmental Assessment Agency (EC-JRC/PBL, 2015). ${ }^{27}$ In particular, series for $\mathrm{CO}_{2}, \mathrm{NO}_{\mathrm{X}}, \mathrm{CH}_{4}, \mathrm{SO}_{\mathrm{X}}, \mathrm{N}_{2} \mathrm{O}$ are interpolated using growth rates from EDGAR for countries with data gaps and replaced entirely when a time series for a country is missing for more than half of the years covered in the analysis. Series for CO, NMVOCs and $\mathrm{PM}_{10}$ are not interpolated; they are replaced entirely for a country only if time series are missing for more than half the years. ${ }^{28}$ In addition, before the imputation, EDGAR data series are smoothed using a 3-year moving average due to high yearly fluctuations (relative to OECD data). EDGAR data are available for 1970-2012 for $\mathrm{CO}_{2}, \mathrm{CH}_{4}$ and $\mathrm{N}_{2} \mathrm{O}$, and 1970-2008 for the remaining pollutants. Finally, to prevent the influence of potential outliers, the $1^{\text {st }}$ and $99^{\text {th }}$ percentiles of the distribution for $\mathrm{SO}_{\mathrm{x}}$, $\mathrm{CO}$ and NMVOC are excluded from the estimation sample.

Finally, note that while the Air Emission Accounts developed under the SEEA framework follow the resident principle, emissions data from the remaining sources rather follow the territorial principle ${ }^{29}$. The two approaches likely lead to some differences in total emissions. However, it is important to recall that the EAMFP framework is based on calculation of growth rates, therefore, if the differences in the amount of emissions from both approaches are fairly constant over time, one can correctly infer the adjustment for pollution abatement from inventories of air emissions.

\subsection{Estimation sample}

Our estimation sample includes 51 countries (OECD and G20) and spans over 24 years (1990-2013). The panel is unbalanced as some countries lack data at the tails of the time period. Table 1 provides summary statistics for the estimation sample corresponding to our preferred model (discussed below).

${ }^{25}$ Non-methane volatile organic compounds (NMVOCs) are a diverse group of chemical compounds, emitted primarily from solvent and product use (paint application, dry-cleaning), road transport, and energy production and use across all sectors of the economy (including combustion and non-combustionemissions - from venting and fugitive emissions). Emissions of NMVOC have been regulated by the Gothenburg Protocol, not least because some of them are precursors to the formation of ground-level ozone while others are directly hazardous to human health (e.g. benzene).

${ }^{26}$ These accounts have been compiled from national sources, according to the guidelines set out in the System of Environmental-Economic Accounting, Central Framework (SEEA-CF).

${ }^{27}$ In version 4.2, EDGAR emissions data are modelled by individual countries using country-specific information (e.g. technology mix, emission factors and annual data by sector and fuel type). EDGAR data for GHGs are converted from kilo-ton to tonnes of $\mathrm{CO}_{2}$ equivalent using the Global Warming Potential conversion factors applied by the UNFCCC (http://unfccc.int/ghg_data/items/3825.php), assuming a 100-year time horizon. Moreover, EDGAR data cover only $\mathrm{SO}_{2}$ emissions - and this information is taken as a proxy for $\mathrm{SO}_{\mathrm{X}}$. In practice $\mathrm{SO}_{\mathrm{X}}$ includes many types of compounds containing sulphur and oxygen.

${ }^{28}$ This distinction across pollutants was done due to the rather low correlation $(<40 \%)$ between EDGAR data and OECD data for the latter pollutants.

${ }^{29}$ Nearly all data used in the EAMFP framework are collected based on the resident principle (e.g. for the calculation of GDP tourism is considered as exports, or as foreign imports). On the natural capital side, this principle is respected for data on natural capital extraction and rents from both the OECD Natural Resources Accounts and the World Bank WAVES database. 
Table 3. Summary statistics for the panel of 51 countries

\begin{tabular}{|c|c|c|c|c|c|c|c|}
\hline \multirow{2}{*}{$\frac{\text { Variable }}{\text { GDP growth }}$} & \multirow{4}{*}{$\begin{array}{l}\text { overall } \\
\text { between } \\
\text { within }\end{array}$} & \multirow{4}{*}{$\frac{\text { Mean }}{3.11}$} & \multirow{2}{*}{$\begin{array}{r}\text { Std. Dev. } \\
3.87\end{array}$} & \multirow{2}{*}{$\frac{\text { Min }}{-14.81}$} & \multirow{2}{*}{$\frac{\operatorname{Max}}{21.83}$} & \multicolumn{2}{|c|}{ Observations } \\
\hline & & & & & & $N=$ & 787 \\
\hline & & & 1.82 & 0.16 & 10.48 & $n=$ & 51 \\
\hline & & & 3.41 & -16.40 & 19.57 & $\mathrm{~T}=$ & 15 \\
\hline \multirow{3}{*}{$\begin{array}{l}\text { Total factor inputs } \\
\text { growth }\end{array}$} & overall & 2.23 & 2.51 & -11.50 & 11.60 & $N=$ & 787 \\
\hline & between & & 1.48 & -1.07 & 5.79 & $n=$ & 51 \\
\hline & within & & 2.02 & -11.06 & 11.15 & $\mathrm{~T}=$ & 15 \\
\hline \multirow[t]{3}{*}{$\mathrm{CO}_{2}$ growth } & overall & 0.99 & 4.89 & -19.54 & 20.18 & $N=$ & 787 \\
\hline & between & & 2.32 & -3.60 & 6.54 & $\mathrm{n}=$ & 51 \\
\hline & within & & 4.32 & -17.64 & 21.44 & $\mathrm{~T}=$ & 15 \\
\hline \multirow[t]{3}{*}{$\mathrm{CH}_{4}$ growth } & overall & -0.15 & 2.65 & -10.04 & 14.66 & $N=$ & 787 \\
\hline & between & & 1.61 & -3.65 & 3.52 & $n=$ & 51 \\
\hline & within & & 2.07 & -9.08 & 14.52 & $\mathrm{~T}=$ & 15 \\
\hline \multirow[t]{3}{*}{$\mathrm{N}_{2} \mathrm{O}$ growth } & overall & -0.62 & 4.94 & -39.76 & 19.82 & $N=$ & 787 \\
\hline & between & & 1.70 & -4.92 & 2.63 & $n=$ & 51 \\
\hline & within & & 4.65 & -39.49 & 21.60 & $\mathrm{~T}=$ & 15 \\
\hline \multirow[t]{3}{*}{ NOx growth } & overall & -0.55 & 5.13 & -25.26 & 20.20 & $N=$ & 787 \\
\hline & between & & 2.54 & -4.95 & 4.65 & $\mathrm{n}=$ & 51 \\
\hline & within & & 4.50 & -23.94 & 18.57 & $T=$ & 15 \\
\hline \multirow[t]{3}{*}{ SOx growth } & overall & -3.07 & 8.82 & -36.68 & 27.04 & $N=$ & 787 \\
\hline & between & & 4.55 & -13.01 & 4.40 & $n=$ & 51 \\
\hline & within & & 7.66 & -32.10 & 28.53 & $\mathrm{~T}=$ & 15 \\
\hline \multirow[t]{3}{*}{ CO growth } & overall & -2.57 & 6.39 & -33.79 & 24.63 & $N=$ & 787 \\
\hline & between & & 2.63 & -9.50 & 4.63 & $n=$ & 51 \\
\hline & within & & 5.82 & -27.65 & 25.03 & $\mathrm{~T}=$ & 15 \\
\hline \multirow[t]{3}{*}{ NMVOC growth } & overall & -1.43 & 4.62 & -18.81 & 17.45 & $N=$ & 787 \\
\hline & between & & 2.34 & -7.98 & 2.73 & $\mathrm{n}=$ & 51 \\
\hline & within & & 4.02 & -18.44 & 15.38 & $\mathrm{~T}=$ & 15 \\
\hline \multirow[t]{3}{*}{$\mathrm{PM}_{10}$ growth } & overall & -1.21 & 10.91 & -69.25 & 108.95 & $N=$ & 787 \\
\hline & between & & 2.85 & -11.06 & 7.16 & $n=$ & 51 \\
\hline & within & & 10.54 & -68.82 & 107.72 & $T=$ & 15 \\
\hline
\end{tabular}

Overall, GDP, total factor inputs and $\mathrm{CO}_{2}$ emissions have increased on average. By contrast, all other pollutant emissions have decreased. Comparison of the standard deviations shows that there is much less heterogeneity in the panel for greenhouse gases than for local air pollutants. Moreover, for all variables there is a larger variation over time (within) than across countries (between).

Growth accounting approaches usually calculate growth rates as logarithmic changes; this is due to the underlying neoclassical growth model developed in continuous time. This choice could however affect the computation of the residual (EAMFP). In this paper, growth rates are calculated as discrete changes because they are better adapted to the scale of variation in natural resource use and pollution, which can show dramatic changes year-on-year. ${ }^{30}$

\footnotetext{
${ }^{30}$ For small changes in the underlying variable, the difference between discrete-time and the logarithmic (continuous) growth rates is rather low. For positive changes of GDP and inputs, MFP figures will be higher when growth rates are calculated in discrete time compared to continuous time. For negative changes in inputs or outputs, the differences will be even greater due to the concavity of the logarithmic growth approximation, leading the calculated MFP to be significantly more negative when logarithmic growth rates are used
} 


\section{ELASTICITIES WITH RESPECT TO POLLUTION}

\subsection{Regression results}

In this paper, the empirical methodology for estimating the pollution elasticities is refined with a view to obtaining more granular country-specific estimates of the elasticities. Equation [13] is estimated as a random coefficients model (RCM) using the maximum likelihood method. A pooled regression approach is followed to correct for possible multicollinearity. ${ }^{31}$ While there is no strong indication of multicollinearity, the partial correlation among some pollutants, especially $\mathrm{CO}_{2}, \mathrm{SO}_{\mathrm{X}}$ and $\mathrm{NO}_{\mathrm{X}}$, could pose problems for a selected group of countries. ${ }^{32}$

The pooled approach consists of estimating the elasticities of all pollutants in a single (pooled) equation. This approach allows dealing with the omitted variable bias and single-out the effect of each pollutant. ${ }^{33}$ Overall, multicollinearity statistics show weak evidence of inflated variance of the estimator, suggesting that this approach should be the preferred one. Moreover, it allows estimating a single elasticity with respect to output to be used for EAMFP calculation $\left(\varepsilon_{\mathrm{HY}} \text { in equation [4] }\right)^{34}$. The mean coefficients for the two RCM specifications are displayed in Table 2. For comparison, results of ordinary least squares (OLS), fixed effects (FE), and random effects (RE) regressions are also presented. Statistical tests are performed to compare the alternative estimation methods and determine the degree of heterogeneity in our sample (see Annex 3).

compared with the discrete-time alternative. These considerations might be of limited importance for traditional MFP calculations because GDP, labour and produced capital change relatively little over time.

However, natural resource use and pollution can show dramatic changes year-on-year, with potentially important effects on EAMFP calculation. Indeed, for substantial decreases, the logarithmic growth rates can result in changes even smaller than $-100 \%$ which is of course conceptually implausible (the threshold occurs at discrete-time changes lower than $(1 / e-1) \approx-63 \%$ which correspond to a logarithmic change lower than $-100 \%)$. Thus, given that for the countries in our sample almost all pollutant emissions have decreased on average, and these negative changes are often important (see Table 1 with descriptive statistics), a choice is made to calculate the growth rates in discrete time.

${ }^{31}$ An alternative approach was adopted by Brandt et al. (2014) who estimated the elasticity of each pollutant in separate regressions. In this case, the issue of potential multicollinearity is avoided because the coefficients for each pollutant are estimated without the other (correlated) pollutants in the regression. However, the estimated coefficients could be biased because it is likely that one pollutant would capture also the effects of other pollutants on output (i.e. omitted variable bias). For comparison, estimation results using this approach are shown in Annex 3.

32 The covariance among the random effects of each coefficient is assumed to be zero; this assumption ensures convergence in the presence of the relatively large number of coefficients that need to be estimated.

${ }^{33}$ In practice there is obviously a trade-off between the omitted variable bias (estimations done separately) and the multicollinearity concerns (pooled estimation).

${ }^{34}$ Note that the estimation of equation [4] also provides a predicted country-specific value for the intercept. This intercept can in fact be an approximation of EAMFP since it captures the difference between the dependent variable, pollution and total factor inputs growth. Results show small differences between the EAMFP from the intercept and the one obtained by growth accounting (after the estimation of elasticities). We expect to see such difference since EAMFP estimated as the intercept would share a common trend among all countries. 
Table 4. Pooled regression results for a panel of 51 countries

\begin{tabular}{|c|c|c|c|c|c|}
\hline Dependent variable: & (1) & (2) & (3) & (4) & (5) \\
\hline GDP growth & OLS & FE & $\mathrm{RE}$ & $\mathrm{RCM}$ & $\mathrm{RCM}$ \\
\hline Total factor inputs growth & $0.70^{\star \star \star}$ & $0.70^{\star \star \star}$ & $0.70 * \star \star$ & $0.67^{\star \star \star}$ & $0.69 * \star *$ \\
\hline CO2 growth & $0.17^{\star \star \star}$ & $0.17^{\star \star \star}$ & $0.17^{\star \star \star}$ & $0.10^{\star \star}$ & $0.11 * \star \star$ \\
\hline $\mathrm{CH} 4$ growth & $0.10^{*}$ & $0.14^{*}$ & $0.12^{\star \star \star}$ & $0.10^{\star *}$ & $0.10^{\star *}$ \\
\hline $\mathrm{N} 2 \mathrm{O}$ growth & 0.04 & 0.03 & $0.04^{\star *}$ & 0.01 & \\
\hline NOX growth & -0.05 & -0.05 & $-0.05^{\star}$ & 0.03 & \\
\hline SOX growth & -0.02 & -0.02 & -0.02 & $-1.20 \mathrm{E}-02$ & \\
\hline CO growth & -0.01 & -0.01 & -0.01 & -0.01 & \\
\hline NMVOC growth & $0.08^{\star *}$ & 0.05 & $0.06^{\star *}$ & $0.04^{*}$ & $0.07^{\star \star}$ \\
\hline PM10 growth & 8.30E-04 & $-8.80 \mathrm{E}-05$ & 3.30E-04 & $3.00 \mathrm{E}-03$ & \\
\hline $\mathrm{BIC}$ & 3881.87 & 3728.06 & 3858.28 & 3758 & 4285.17 \\
\hline $\mathrm{N}$ & 787 & 787 & 787 & 787 & 893 \\
\hline Year dummies & Yes & Yes & Yes & Yes & Yes \\
\hline
\end{tabular}

In models (4) and (5) the variables with statistically significant coefficients include total factor inputs, $\mathrm{CO}_{2}, \mathrm{CH}_{4}$ and NMVOC. While inputs, $\mathrm{CO}_{2}$ and $\mathrm{CH}_{4}$ are significantly heterogeneous across countries, NMVOC is not ${ }^{35}$. Therefore, we will use predicted country-specific coefficients based on our preferred RCM estimation (model 4) to obtain the elasticities of the transformation function with respect to output, $\mathrm{CO}_{2}$ and $\mathrm{CH}_{4}$, and use the mean coefficient to compute the elasticity with respect to NMVOC. The elasticities are discussed next. The pollution abatement costs are explored in Annex 4 and the implied shadow prices of pollution are discussed in Annex 5.

The remaining pollutants $\left(\mathrm{SO}_{\mathrm{X}}, \mathrm{NO}_{\mathrm{X}}, \mathrm{N}_{2} \mathrm{O}, \mathrm{CO}, \mathrm{PM}_{10}\right)$ are not statistically significant, and hence we do not compute their respective elasticities. The lack of significance of these pollutants may come from the fact that the variation in GDP growth is captured only by a subset of pollutants which represent the overall effect of all pollutants on GDP growth. The calculation of EAMFP is not biased by the omission of the remaining pollutants $\left(\mathrm{SO}_{\mathrm{X}}, \mathrm{NO}_{\mathrm{X}}, \mathrm{N}_{2} \mathrm{O}, \mathrm{CO}, \mathrm{PM}_{10}\right)$ if their coefficients are insignificant because such pollutants have no effect on output growth. However, if the lack of significance is due to the limitations of the available empirical dataset (i.e. data which do not allow the coefficients to be estimated) then the resulting EAMFP will be incomplete.

Note that the relationship between GDP and pollution might go in both directions: higher GDP growth can be associated with an increase in emissions, and lower abatement efforts might enable firms to produce more (i.e. reverse-causality). One way to deal with this concern would be to rely on an instrumental variable approach. We tested numerous candidates for instrumental variables but no suitable instrument has been found. ${ }^{36}$ Given this potential issue, the elasticities obtained with the current estimations should therefore be seen as upper bounds of the true elasticities.

\footnotetext{
${ }^{35}$ The deviation across countries from the mean slope (heterogeneity of coefficients) is not different from zero at 0.05 significance level; results not reported here.

${ }^{36}$ Since data on pollution emissions are estimated using a proxy of economic activity and emission factors - pollution emission per unit of production, a good candidate to instrument pollution emissions could be those emission factors, unfortunately emissions factors data are not available to us at the time of estimation. Similarly, once available, we are considering using meteorological data, but the relevance to explain pollution emissions remains to be tested. Other instruments we have tested include: gasoline and diesel consumption from transport, total primary energy supply from coal and fossil fuels more generally, vehicle fleet, passenger cars, motorway length, road density, etc.
} 


\subsection{Estimated elasticities of GDP with respect to pollution}

Using the above regression results and equation [14] we calculate the country-specific elasticities of the transformation function with respect to $\mathrm{Y}$ and $\mathrm{R}$ which are then used for computation of the EAMFP (see Section 5). While useful, these elasticities are not easily interpretable. Therefore, we focus on the ratio of the two elasticities which yields the elasticity of GDP with respect to pollution:

$$
\varepsilon_{Y R i j}=\frac{\varepsilon_{H Y i}}{\varepsilon_{H R j i}} \quad \forall j \in[1 ; 8]
$$

These elasticities are defined as the change in output associated with a marginal increase of pollution when input use remains constant (Figure 2). They describe macro-level relationships between output and pollution emissions, and reflect the ability of a country to adjust production in order to control emissions. Elasticities presented here are constant over time, and are analogous to the marginal abatement cost (MAC) curve. The key determinants of the elasticity (and the MAC) include: (i) innovation - availability and adoption of cleaner technologies plays a key role in explaining differences in elasticities across countries. Countries where technology allows reducing production emissions at a lower cost should exhibit lower elasticities. (ii) the structure of the economy - which has a clear impact on elasticities as different sectors emit different quantities of pollutants (e.g., manufacturing and intensive agriculture will tend to increase the elasticity contrary to the service sector which is less pollution-intensive; the more prominent are polluting industries in a country's economy, the higher the elasticity is likely to be). ${ }^{37}$

While the availability of cleaner technology and the structure of the economy determine the country's ability to reduce emissions (and hence the slope of the MAC curve), the actual level of emissions and their implicit price (where countries lie on the curve) are also a function of environmental regulation (its level of ambition and its enforcement). In the short run, more stringent environmental regulation places a higher cost on polluting activities because the set of available technologies and the economic structure are fixed. However, in the long run stringent regulation will induce innovation and trigger structural changes in the economy, thus changing the country's ability (and hence the marginal cost) to abate pollution. The elasticities presented here (and the implicit prices derived in Annex 5) should therefore be understood in light of such a dynamic equilibrium.

Elasticities with respect to $\mathrm{CO}_{2}$ and $\mathrm{CH}_{4}$ differ across countries while those for NMVOC do not. This is because the estimated NMVOC coefficient is not significantly heterogeneous across countries. The heterogeneity of elasticities in $\mathrm{CO}_{2}$ and $\mathrm{CH}_{4}$ means that pollution is not related to output in a similar way across countries with a different economic structure and available technologies. Russia has the highest elasticity for both $\mathrm{CO}_{2}$ and $\mathrm{CH}_{4}$, about 0.26 and 0.4 respectively. By contrast, western European countries, Canada and the USA exhibit on average lower than average elasticities for $\mathrm{CO}_{2}$ and $\mathrm{CH}_{4}$. Still, it is difficult to obtain a clear correspondence between the geographic characteristics of countries and their ranking based on elasticities.

The elasticity of output with respect to pollution is expected to be positive or zero because pollution abatement is costly and hence does not typically come with a rise of GDP. As shown in Figure 2, for most countries the elasticities for $\mathrm{CO}_{2}, \mathrm{CH}_{4}$ and NMVOC are indeed positive. However, in some cases the elasticity of GDP with respect to pollution is actually negative (e.g. New Zealand for $\mathrm{CO}_{2}$, China for $\mathrm{CH}_{4}$ ). This rather unexpected result could arise for example if methane-intensive industries become more prominent in the economy over time while the country is experiencing a slowdown of economic growth (e.g. cattle farming, rice paddy fields, landfilling, petroleum extraction and refining, biogas production).

\footnotetext{
${ }^{37}$ This heterogeneity across industries highlights the need for measures at a more disaggregated level.
} 
Figure 22. Elasticities of GDP with respect to pollution $\left(\varepsilon_{Y R i}\right)$

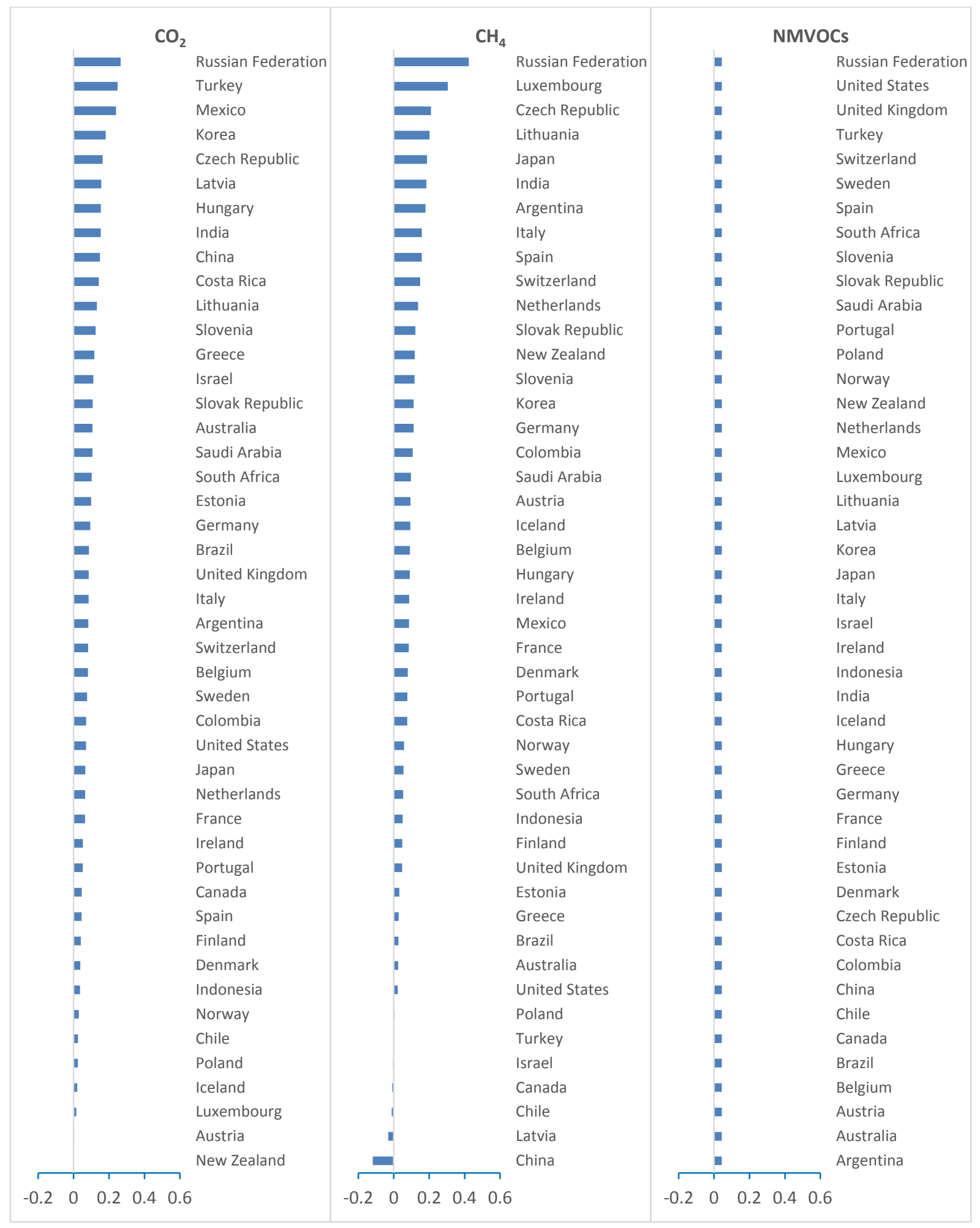




\section{RESULTS}

\subsection{Growth accounting with air pollution and subsoil natural assets}

Using equation [6] the growth of the joint outputs - GDP and pollution abatement - is decomposed into the contributions of individual inputs. The elasticities of the transformation function with respect to inputs are evaluated using each input's respective cost shares following the methodology described in Section 2.2 and equation [10]. The elasticities of the transformation function with respect to output and pollution are evaluated following the methodology outlines in Section 2.3 and the estimation results presented in Section 4. The results of the decomposition are presented in Table 3.

The first column gives the GDP growth adjusted for pollution abatement efforts. Column 2 gives the average growth in GDP during the corresponding time period. Column 3 gives the average growth in emissions reduction efforts expressed in terms of GDP growth: a positive number indicates that pollution abatement has increased on average over the period (e.g. pollution has decreased due to investment in cleaner technologies), while a negative figure means that pollution abatement has decreased on average (e.g. pollution has increased because less effort has been devoted to emission reduction). Columns 4 to 6 give the contributions of inputs to the pollution-adjusted GDP growth. Column 7 shows the residual growth of pollution-adjusted GDP that cannot be explained by growth in the use of inputs, i.e. the environmentally adjusted multifactor productivity growth.

Table 5. Growth accounting, long-term annual averages

\begin{tabular}{|c|c|c|c|c|c|c|c|c|}
\hline \multirow[b]{2}{*}{ OECD } & \multirow[b]{2}{*}{$\begin{array}{l}\text { Pollution- } \\
\text { adjusted GDP } \\
\text { growth }\end{array}$} & \multicolumn{2}{|c|}{ Growth in outputs } & \multicolumn{3}{|c|}{ Growth in inputs } & \multirow{2}{*}{$\begin{array}{c}\text { Residual growth } \\
\text { Growth of } \\
\text { environmentally } \\
\text { adjusted multifactor } \\
\text { productivity }\end{array}$} & \multirow[b]{2}{*}{ Period } \\
\hline & & $\begin{array}{l}\text { GDP } \\
\text { growth }\end{array}$ & $\begin{array}{c}\text { Adjustment } \\
\text { for pollution } \\
\text { abatement }\end{array}$ & $\begin{array}{l}\text { Growth in } \\
\text { contribution } \\
\text { of labour }\end{array}$ & $\begin{array}{c}\text { Growth in } \\
\text { contribution of } \\
\text { produced capital }\end{array}$ & $\begin{array}{l}\text { Growth in } \\
\text { contribution of } \\
\text { natural capital }\end{array}$ & & \\
\hline Australia & 3.14 & 3.29 & -0.14 & 0.57 & 0.62 & 0.15 & 1.81 & 1991-2012 \\
\hline Austria & 2.20 & 1.90 & 0.30 & 0.21 & 0.50 & 0.00 & 1.49 & $1996-2013$ \\
\hline Belgium & 2.07 & 1.80 & 0.27 & 0.24 & 0.57 & 0.00 & 1.26 & $1991-2013$ \\
\hline Canada & 2.38 & 2.36 & 0.03 & 0.50 & 0.52 & 0.01 & 1.35 & 1991-2013 \\
\hline Chile* & 5.03 & 5.20 & -0.17 & 0.64 & 2.50 & 0.35 & 1.54 & 1991-2012 \\
\hline Czech Republic* & 3.24 & 2.55 & 0.69 & -0.10 & 1.66 & 0.00 & 1.68 & $1994-2013$ \\
\hline Denmark & 1.62 & 1.48 & 0.14 & 0.07 & 0.48 & -0.01 & 1.08 & 1991-2013 \\
\hline Estonia* & 4.59 & 4.51 & 0.09 & -0.43 & 1.78 & 0.02 & 3.23 & $1996-2013$ \\
\hline Finland & 2.00 & 1.77 & 0.24 & -0.15 & 0.43 & 0.01 & 1.71 & $1991-2013$ \\
\hline France & 1.88 & 1.57 & 0.31 & 0.05 & 0.44 & 0.00 & 1.39 & 1991-2013 \\
\hline Germany & 2.13 & 1.44 & 0.69 & -0.07 & 0.42 & 0.00 & 1.78 & 1991-2013 \\
\hline Greece* & 1.09 & 1.01 & 0.08 & -0.06 & 0.81 & 0.00 & 0.33 & 1991-2013 \\
\hline Hungary* & 2.26 & 1.76 & 0.50 & -0.39 & 1.14 & -0.02 & 1.52 & $1992-2013$ \\
\hline Iceland* & 2.71 & 2.68 & 0.03 & 0.14 & 0.06 & 0.00 & 2.51 & $1991-2013$ \\
\hline Ireland & 4.66 & 4.62 & 0.04 & 0.77 & 0.80 & -0.01 & 3.09 & $1991-2013$ \\
\hline |srael* & 4.89 & 5.16 & -0.26 & 1.39 & 1.50 & 0.30 & 1.70 & 1991-2013 \\
\hline Italy & 1.03 & 0.73 & 0.30 & 0.01 & 0.33 & 0.00 & 0.69 & $1991-2013$ \\
\hline Japan & 1.34 & 0.93 & 0.42 & -0.32 & 0.53 & 0.00 & 1.13 & $1991-2012$ \\
\hline Korea & 4.39 & 5.28 & -0.89 & 0.20 & 1.32 & 0.00 & 2.87 & $1991-2013$ \\
\hline Latvia* & 4.82 & 4.59 & 0.23 & -0.53 & 3.39 & 0.00 & 1.96 & $1997-2013$ \\
\hline Luxembourg* & 3.97 & 3.68 & 0.29 & 0.94 & 1.55 & 0.00 & 1.47 & $1991-2013$ \\
\hline Mexico* & 2.13 & 2.78 & -0.65 & 0.25 & 0.89 & 0.01 & 0.98 & $1991-2013$ \\
\hline
\end{tabular}




\begin{tabular}{|c|c|c|c|c|c|c|c|c|}
\hline Netherlands & 2.39 & 1.99 & 0.40 & 0.46 & 0.57 & 0.01 & 1.35 & $1991-2013$ \\
\hline New Zealand & 2.54 & 2.63 & -0.09 & 0.82 & 0.70 & 0.02 & 0.99 & $1991-2013$ \\
\hline Norway* & 2.67 & 2.48 & 0.19 & 0.23 & 0.88 & 0.03 & 1.54 & $1991-2013$ \\
\hline Poland* & 3.76 & 3.69 & 0.06 & -0.25 & 1.40 & 0.00 & 2.61 & $1991-2013$ \\
\hline Portugal & 1.61 & 1.53 & 0.07 & 0.13 & 0.60 & 0.00 & 0.88 & 1996-2011 \\
\hline Slovak Republic* & 4.39 & 4.15 & 0.24 & -0.02 & 2.04 & 0.00 & 2.36 & $1993-2013$ \\
\hline Slovenia* & 2.67 & 2.53 & 0.14 & -0.39 & 1.09 & 0.00 & 1.97 & $1996-2013$ \\
\hline Spain & 1.96 & 2.04 & -0.08 & 0.42 & 0.54 & 0.00 & 0.99 & $1991-2013$ \\
\hline Sweden & 2.32 & 2.04 & 0.28 & 0.11 & 0.79 & 0.01 & 1.41 & $1991-2013$ \\
\hline Switzerland & 1.78 & 1.55 & 0.23 & 0.28 & 0.58 & 0.00 & 0.93 & $1991-2013$ \\
\hline Turkey* & 2.90 & 4.01 & -1.11 & 0.31 & 2.14 & 0.05 & 0.40 & 1991-2012 \\
\hline United Kingdom & 2.42 & 2.08 & 0.33 & 0.15 & 0.50 & -0.04 & 1.80 & $1991-2013$ \\
\hline United States & 2.56 & 2.48 & 0.08 & 0.32 & 0.50 & 0.02 & 1.72 & $1991-2013$ \\
\hline $\begin{array}{l}\text { Accession to } \\
\text { OECD }\end{array}$ & $\begin{array}{c}\text { Pollution- } \\
\text { adjusted GDP } \\
\text { growth }\end{array}$ & $\begin{array}{l}\text { GDP } \\
\text { growth }\end{array}$ & $\begin{array}{c}\text { Adjustment } \\
\text { for pollution } \\
\text { abatement } \\
\end{array}$ & $\begin{array}{l}\text { Growth in } \\
\text { contribution } \\
\text { of labour }\end{array}$ & $\begin{array}{c}\text { Growth in } \\
\text { contribution of } \\
\text { produced capital }\end{array}$ & $\begin{array}{c}\text { Growth in } \\
\text { contribution of } \\
\text { natural capital }\end{array}$ & $\begin{array}{l}\text { Growth of } \\
\text { EAMFP }\end{array}$ & Period \\
\hline Colombia* & 3.28 & 3.57 & -0.29 & 0.60 & 1.17 & 0.15 & 1.36 & 1991-2012 \\
\hline Costa Rica* & 4.33 & 4.83 & -0.50 & 0.92 & 1.87 & 0.00 & 1.54 & 1991-2012 \\
\hline Lithuania* & 4.81 & 4.58 & 0.23 & -0.26 & 2.06 & 0.00 & 3.01 & $1997-2013$ \\
\hline Other G20 & $\begin{array}{c}\text { Pollution- } \\
\text { adjusted GDP } \\
\text { growth }\end{array}$ & $\begin{array}{l}\text { GDP } \\
\text { growth }\end{array}$ & $\begin{array}{c}\text { Adjustment } \\
\text { for pollution } \\
\text { abatement } \\
\end{array}$ & $\begin{array}{c}\text { Growth in } \\
\text { contribution } \\
\text { of labour }\end{array}$ & $\begin{array}{c}\text { Growth in } \\
\text { contribution of } \\
\text { produced capital }\end{array}$ & $\begin{array}{c}\text { Growth in } \\
\text { contribution of } \\
\text { natural capital }\end{array}$ & $\begin{array}{l}\text { Growth of } \\
\text { EAMFP }\end{array}$ & Period \\
\hline Argentina* & 4.31 & 4.40 & -0.09 & 1.33 & 1.20 & 0.02 & 1.75 & 1991-2012 \\
\hline Brazil* & 2.73 & 3.11 & -0.38 & 0.44 & 0.88 & 0.09 & 1.32 & $1991-2013$ \\
\hline $\begin{array}{c}\text { China (People's } \\
\text { Republic of)* }\end{array}$ & 9.46 & 10.21 & -0.74 & 0.44 & 6.25 & 0.27 & 2.50 & $1991-2013$ \\
\hline India* & 5.55 & 6.52 & -0.97 & 0.89 & 2.48 & 0.08 & 2.10 & $1991-2013$ \\
\hline Indonesia* & 4.69 & 4.95 & -0.25 & 0.47 & 1.91 & 0.09 & 2.22 & 1991-2012 \\
\hline Russia* & 2.80 & 2.59 & 0.21 & 0.17 & -0.08 & 0.63 & 2.08 & 1994-2012 \\
\hline Saudi Arabia* & 3.43 & 4.29 & -0.86 & 0.43 & 0.62 & 0.55 & 1.83 & 1991-2012 \\
\hline South Africa* & 2.50 & 2.66 & -0.17 & 0.37 & 0.98 & 0.01 & 1.14 & 1991-2012 \\
\hline
\end{tabular}

Note: * indicates TED panel. The columns correspond to the terms in equation [6].

Note that the numbers displayed above refer to long-term annual averages over the last two decades, and as such they could hide important year-to-year variations. Note also that the growth accounting indicators refer to changes over time ("growth") while there might be important differences in the levels (the sizes of the economies compared). These indicators should not be confused with the contribution to the level of GDP: for example, a zero contribution of natural capital does not mean that a country did not extract any domestic resources in a given year; rather, it means that its economy has continued to rely on this input in the same way as the previous year. Similarly, a zero adjustment for pollution abatement means that the country produced the same quantity of emissions as the previous year; in such cases the pollutionadjusted economic growth would be equal to GDP growth.

Figure 3 takes a closer look at the output side by comparing the pollution-adjusted GDP growth with the un-adjusted counterpart. As mentioned before, while the cost of emission reduction is borne by producers, the benefits of such pollution abatement are not reflected in the national accounts. Therefore, a measure of GDP growth will not fully reflect the efforts made by producers to reduce such externalities. In order to produce a measure that takes these efforts into account, a pollution-adjusted GDP growth is computed, which adjusts GDP growth with the pollution abated valued from the producer's perspective. This indicator provides valuable information because it accounts for both the economic and environmental aspects of growth, and allows countries' performance to be better compared. For example, countries where 
emissions went down (e.g. Germany or Japan) need to have their income growth adjusted upwards to reflect their efforts to improve environmental quality. In contrast, countries where emissions increased (e.g. Mexico, Turkey or China) need to have their GDP growth adjusted downward. The decomposition of the pollution-adjusted GDP growth is displayed in Figure 4, providing a complete overview of the sources of growth. 
Figure 23. Adjustment of GDP growth for pollution abatement (circa 1991-2013 average)

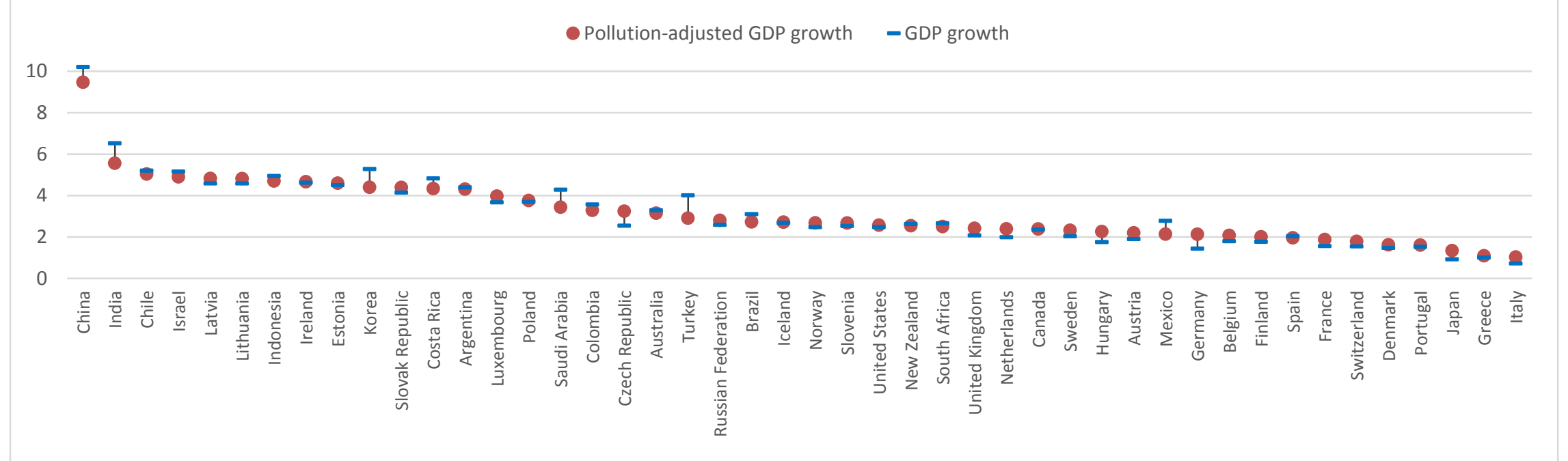

Figure 24. Contribution of inputs to pollution-adjusted GDP growth (circa 1991-2013 average)

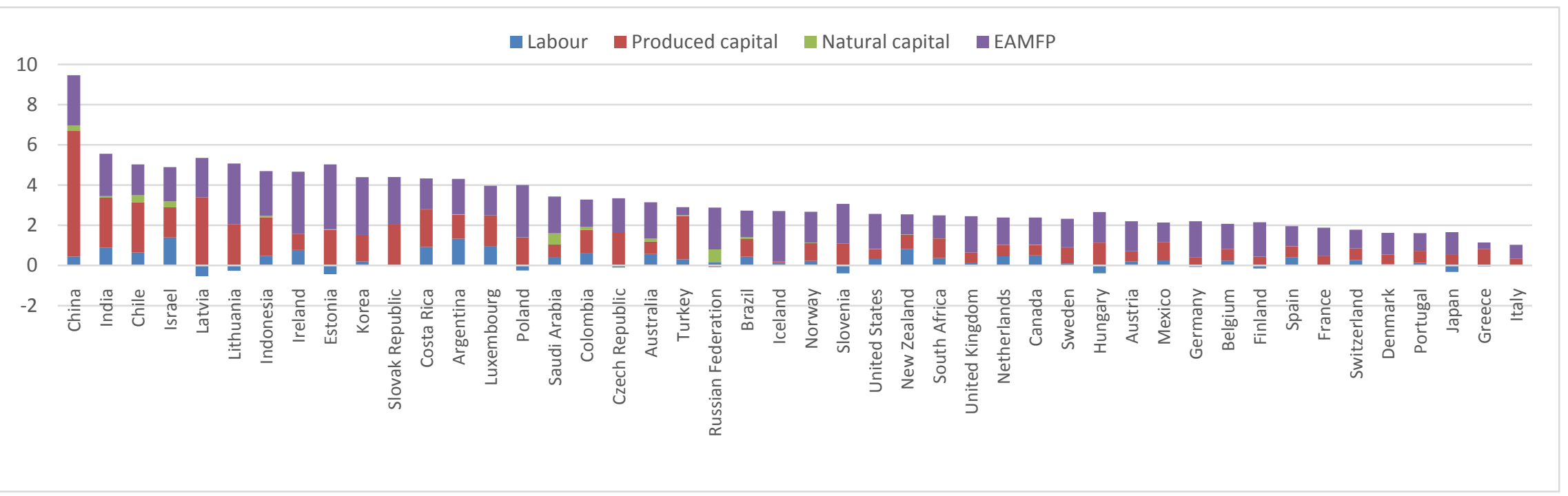




\subsection{Environmentally adjusted multifactor productivity growth}

Figure 25. EAMFP growth (circa 1991-2013 average)

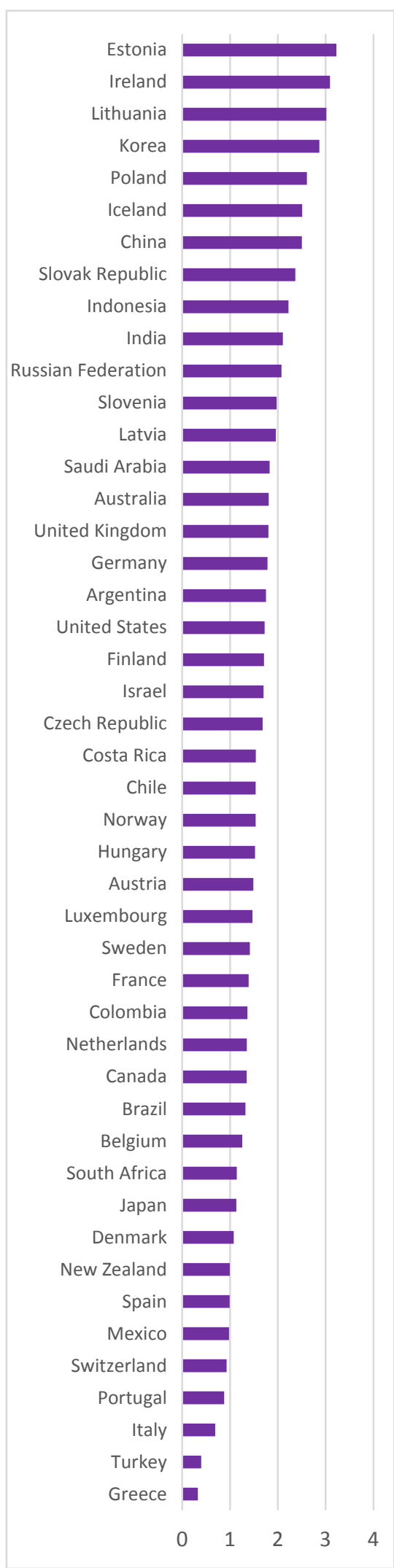

The EAMFP measures a country' ability to produce more income than it did in the past from a given set of inputs (including domestic natural resources) while accounting for the undesirable by-products (pollution). The EAMFP thus explicitly links "green" and "growth" to produce a measure of economic and environmental performance.

Countries owe their EAMFP growth to different factors: technological improvements (technical change) oriented at the production of good outputs and abatement of undesirable outputs (e.g. cleaner technologies) or at more efficient use of inputs (e.g. better skills, higher quality of fixed capital), more efficient institutions and organisations, scale economies and improved allocative efficiency (i.e. composition of input mix). Productivity changes over time and differences across countries can be complex to explain because a wide range of policy and market factors might be at play.

All OECD and G20 economies have achieved a positive productivity (EAMFP) growth over the last two decades, on average. Some of the top-ranking countries have increasingly relied on productivity (EAMFP) improvements to generate income growth while decreasing the use of factor inputs (e.g. Ireland). Some others have undergone substantial economic restructuring, often accompanied by a wide adoption of cleaner technologies (e.g. Estonia, Lithuania, Korea). On the other hand, some countries at the bottom of the chart with a low EAMFP growth generated much of their income growth from increased reliance on labour force and capital investment, and much less on technical change (e.g. Turkey and Mexico) and, if continued, this trend could compromise their long-run growth prospects. In the case of Greece, Italy and Portugal, the shrinking productivity growth along with the decreasing contribution of factor inputs is a reflection of the recent economic difficulties.

Depending on the contribution of natural capital and the adjustment for emissions reduction, the "traditional" measure of productivity (MFP) could be overvalued or undervalued with respect to the EAMFP. For example, productivity growth would be overvalued in Korea and China where output growth would be wrongly explained by an increase of productivity, whereas it has actually been fuelled by increased emissions or natural resource extraction. In contrast, productivity growth would be undervalued in Sweden because it would not acknowledge the efforts related to pollution abatement. Note that the EAMFP can be compared to the traditional MFP indicator (see Annex 6). 
Figure 26. The highest EAMFP relative to other sources of growth (circa 1991-2013 average)

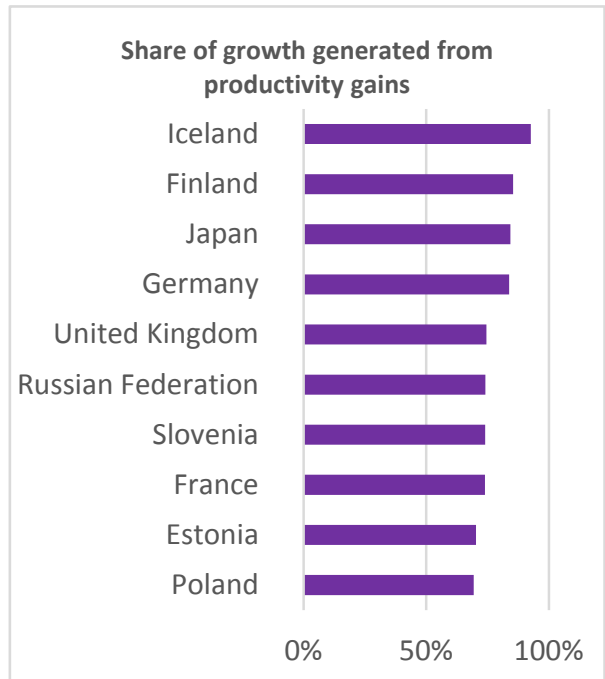

The evolution of this indicator over time is, to some extent, determined by the business cycle fluctuations that can be accounted for through supply and demand shocks. When production is constrained by an exogenous shock (e.g. contraction of a large economy), output growth will be low and, as a result, productivity growth will mechanically decrease. In such cases, to filter out the influence of economic cycles, it is helpful to express the contribution of inputs and the EAMFP in relative terms (as percent of pollution-adjusted GDP growth). Such relative contribution is presented in Figure 6 for countries with the highest contribution of productivity growth to output growth.

Analysing the EAMFP relative to other sources of growth facilitates the comparison across economies with different economic cycles. In some cases, economic restructuring brought opportunities for the adoption of cleaner and more efficient production processes. For example, Slovenia's productivity growth has more than compensated the declining contribution of labour, suggesting that key improvements in environmental and economic performance have occurred. Other countries with favourable green growth prospects include Finland, Japan and Germany, all of whom have been leaders in innovation in cleaner technologies. 


\subsection{Contribution of natural capital use to output growth}

Figure 27. Growth in contribution of natural capital (subsoil assets), circa 1991-2013 average

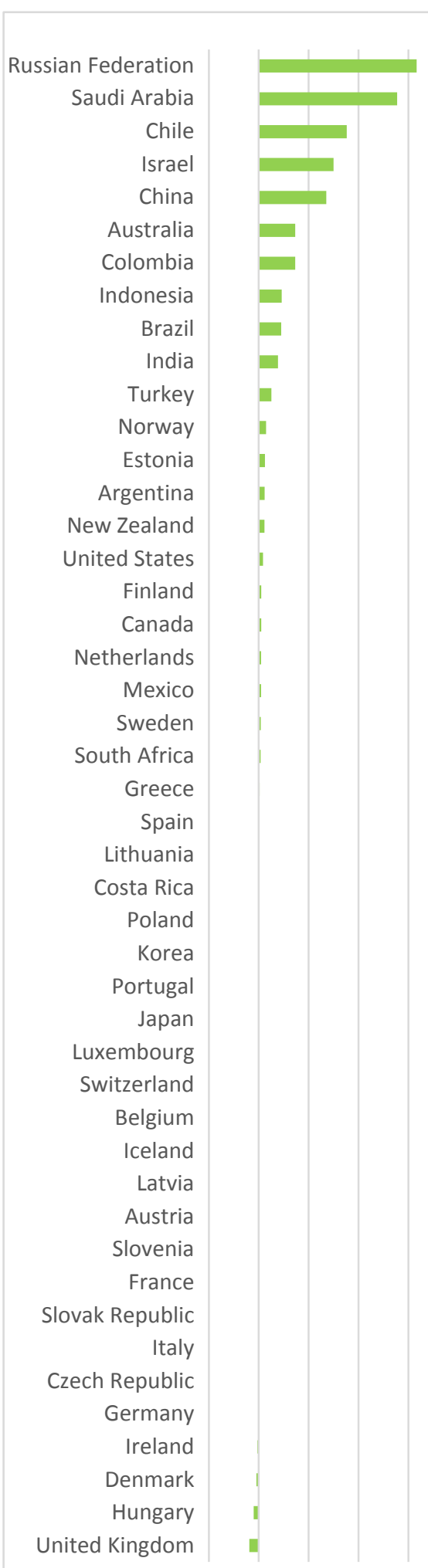

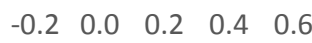

The contribution of natural capital to pollution-adjusted GDP growth indicates the extent to which countries rely on the extraction of domestic natural resources (subsoil assets) to generate economic growth. Countries with a positive contribution of natural capital have increased their use of natural resources while countries with a negative contribution have decreased it. Note that many countries have a contribution of natural capital that is close to zero because they do not rely on natural resources to generate output growth.

The contribution of natural capital is a function of the share of natural capital rents in total input costs, and the change in the use of the resources. Thus, contributions of natural capital are strongly influenced by global commodities markets since the price of commodities has an impact on the cost share and the use of resources. For example, a supply shock (e.g. discovery of large mineral reserves) or demand shock (e.g. contraction of a large economy) can drive international prices down, making resourcepoor countries increase their imports and extract less at home, causing a drop of the natural capital contribution.

Increased extraction of oil reserves explains the large positive contributions in Saudi Arabia and Russia. For example, in Saudi Arabia extraction of both oil and gas has grown by more than $3 \%$ on average for the last 20 years. The positive contribution of subsoil assets in Chile is mainly due to copper, whose extraction has grown by more than $5 \%$ on average since 1990 . By contrast, some countries have negative contributions of natural capital and therefore needed to turn to other factors to fuel their economic growth. For example, the United Kingdom has been relying less on its subsoil assets to generate growth (primarily due to a decrease in oil extraction; the contribution of gas extraction has actually increased somewhat). The United States has not relied on subsoil resources' extraction (overall) to generate growth; however, a closer inspection suggests that the contribution of oil has been increasing sharply since 2006.

Natural resources fuel a significant share of pollution-adjusted GDP growth in some countries (Figure 8). For example, more than a fifth of Russia's growth can be directly attributed to natural capital extraction, while in Saudi Arabia this represents 15\%. Interestingly, in Saudi Arabia, increased use of natural capital and increased pollution emissions explain together more than a third of its GDP growth over the last two decades.

Figure 28. The highest contribution of natural capital (subsoil assets) relative to other sources of growth (circa 1991-2013) 


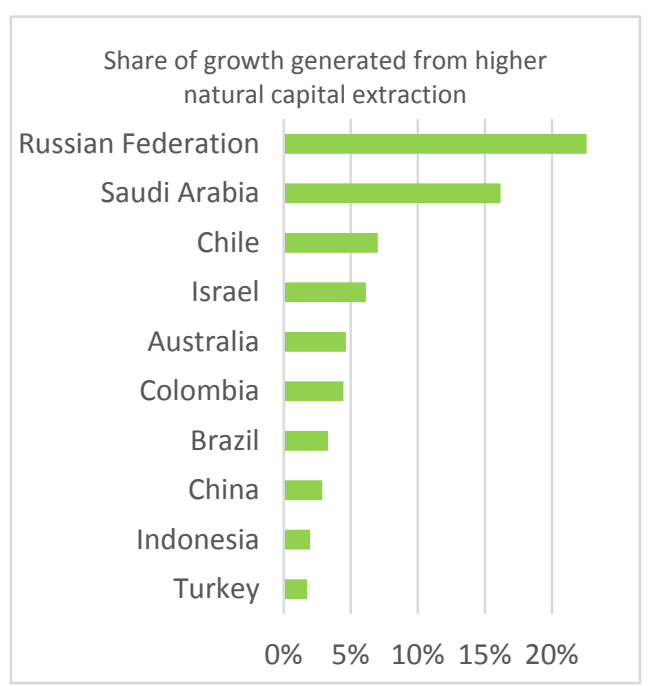

Countries such as Chile, Israel and Colombia have also relied to a non-negligible extent on subsoil assets, with resource extraction contributing about $5 \%$ to their income growth. This is, however, only the direct contribution (from an accounting perspective) and the indirect contribution of resource extraction might be much higher (e.g. through investments in produced capital and labour that such extraction requires).

The figures shown here help identify countries that rely to an important extent on resource extraction to generate income. In the face of declining stocks or negative demand shocks, these countries would need to search for alternative sources of growth in order to sustain their standards of living. 


\subsection{Adjustment of GDP growth for pollution abatement}

Figure 29. Growth in adjustment for pollution abatement (air emissions), circa 1991-2013 average

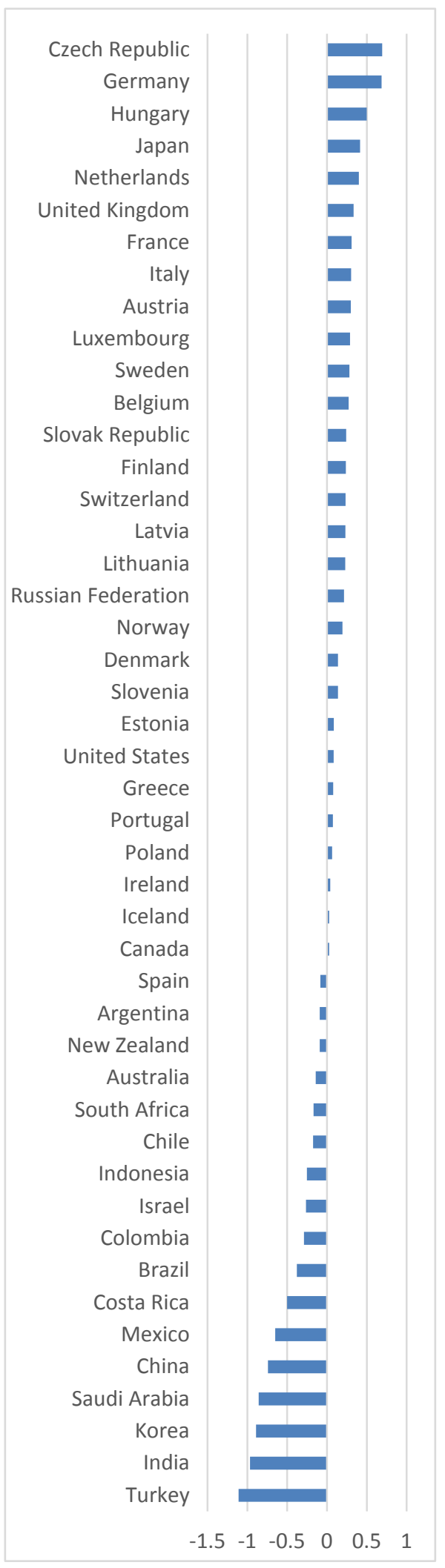

The adjustment of GDP growth for pollution abatement measures how much a country's economic growth is influenced by its emission reduction efforts. For example, in countries that have increased emissions over time (i.e. the adjustment is negative), this indicator provides insights on the extent to which national income is generated at the expense of environmental quality. On the other hand, in countries that have reduced emissions (i.e. the adjustment is positive), this indicator provides an indication of the foregone GDP growth due to pollution abatement efforts.

The adjustment for pollution abatement is composed of the elasticity of output with respect to pollution (i.e. the change of output when pollution is reduced) and the change in the level of pollution. These adjustments are strongly influenced by technological capabilities (e.g. innovative ways to abate pollution) and changes in economic structure (e.g. less emission-intensive industries). These factors can, in turn, be influenced by environmental regulations (e.g. setting a cap on emissions) and the business cycle (e.g. output contractions or expansions).

For instance, the Czech Republic suffered a significant contraction of the economy due to industrial re-structuring in the 1990s, accompanied by a drop in pollution emissions. As GDP growth rates recovered, a shift to cleaner production processes allowed a reduction in the pollution intensity of output. A shift of this sort is captured by the indicator presented in Figure 9 . Similarly, the economic downturn following the 2008 global economic crisis generated a drop in emissions in most countries. For example, air emissions from the industrial sector in Sweden dropped by $25 \%$ between 2000 and 2012 mainly due to the decline in iron, steel, pulp, paper and chemicals production after 2007 (OECD 2014c, p. 107).

In sum, cyclical factors, structural changes in the economy, adoption of cleaner technologies, input substitution (e.g. lowsulphur coal instead of high-sulphur coal) or changes in households' consumption patterns (e.g. a modal shift in transportation) can all lead to lower emissions over time (see e.g. OECD 2011, 2014d). Several of these factors can explain the high ranking of countries such as Germany, Belgium and Japan. On the other hand, countries that have relied on emission-intensive industries to generate growth (e.g. Turkey, India, Korea, Saudi Arabia, China and Mexico) tend to rank at the bottom of the chart. 
Figure 30. The highest adjustment for pollution abatement, as a share of GDP growth (circa 1991-2013)

Adjustment for pollution abatement as a share of pollution-adjusted GDP growth

Germany

Japan

Italy

Hungary

Czech Republic

Netherlands

France

United Kingdom

Austria

Belgium

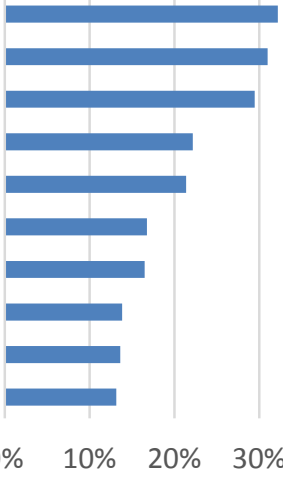

Figure 10 shows the countries where pollution abatement efforts represent the highest share of output growth. For instance, the growth of Germany, Japan and Italy should be adjusted upwards by about $30 \%$ to reflect their pollution abatement efforts. The countries that rank high have either experienced relatively low rates of economic growth (and abatement thus represents a large share of such low economic growth) or they have undertaken truly important abatement efforts, or both. In any case, the adjustment shown here helps shed new light on their growth performance. 


\section{5. $\quad$ Selected country sheets}

To allow a more in-depth examination, the indicators are now presented over time for selected countries. For guidance on interpretation of the graphics included below see the detailed discussion in Sections 5.1-5.4.

\subsubsection{Chile}

While Chile's EAMFP growth has slightly declined from the growth rates observed in the 1990s, it remains an important source of Chile's growth. Over time, the sources of growth have not changed substantially in relative terms: investments in produced capital are one of the main drivers of growth accounting, on average, for $50 \%$ of Chile's growth. Chile has one of the highest contributions of natural capital to GDP growth, following Russia and Saudi Arabia. In 1996, extraction of subsoil assets accounted for more than 1 point of its economic growth. Chile owes the important natural capital contribution to copper extraction being one of the leading exporters. After the global crisis of 2008, Chile has seen a decreasing importance of copper for its economic growth, turning to other subsoil assets such as black coal. Chile's pollution abatement efforts have fallen short compared to most OECD countries. Over the last 20 years, Chile has continued to increase its $\mathrm{CO}_{2}$ emissions.

Figure 31. Detailed graphics for Chile

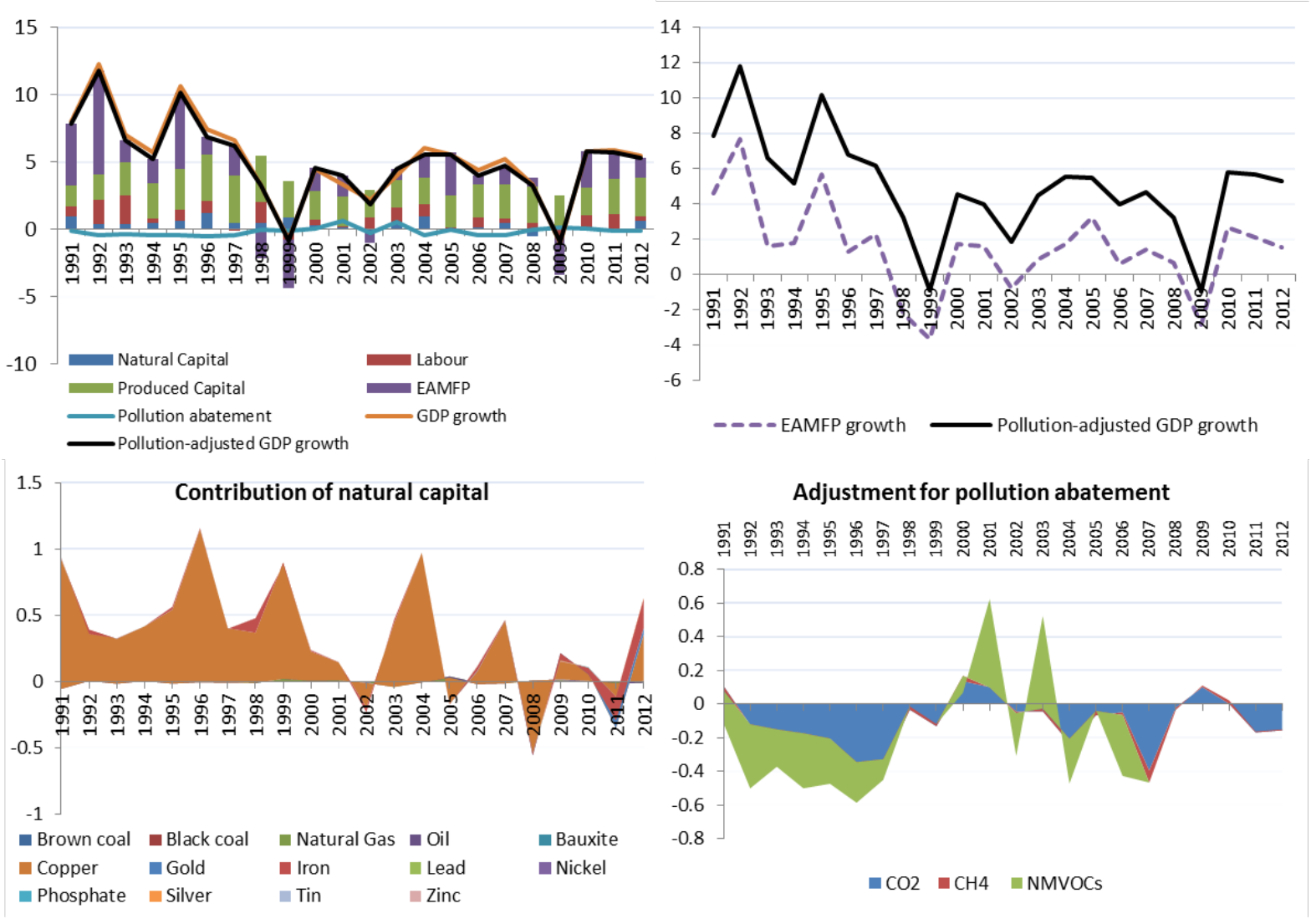




\subsubsection{China}

Productivity (EAMFP) growth in China has been decreasing at a significant rate and this might pose problems for the sustainability of Chinese economic growth in the long run. In fact, rather than productivity improvements, it is the extraction of China's natural resources that is fuelling an increasingly higher share of its growth. In comparison with other countries in this study, China extracts the most domestic subsoil assets (in value), and China ranks the fifth highest in terms of the contribution of natural resources to output growth. Since 2003, China has been increasingly relying on black coal, iron and oil to fuel its growth. In addition, China's pollution abatement has lagged behind all countries in the sample. China is currently the biggest emitter of $\mathrm{CO}_{2}$ and has the most $\mathrm{CO}_{2}$-intensive production among the OECD and G20 countries. Interestingly, China has also substantially increased its methane emissions (methane is typically associated with cattle and rice farming, landfilling, petroleum extraction and refining, or biogas production). More recently, China has continued to generate economic growth at the expense of higher pollution, albeit at a somewhat slower rate.

\section{Figure 32. Detailed graphics for China}

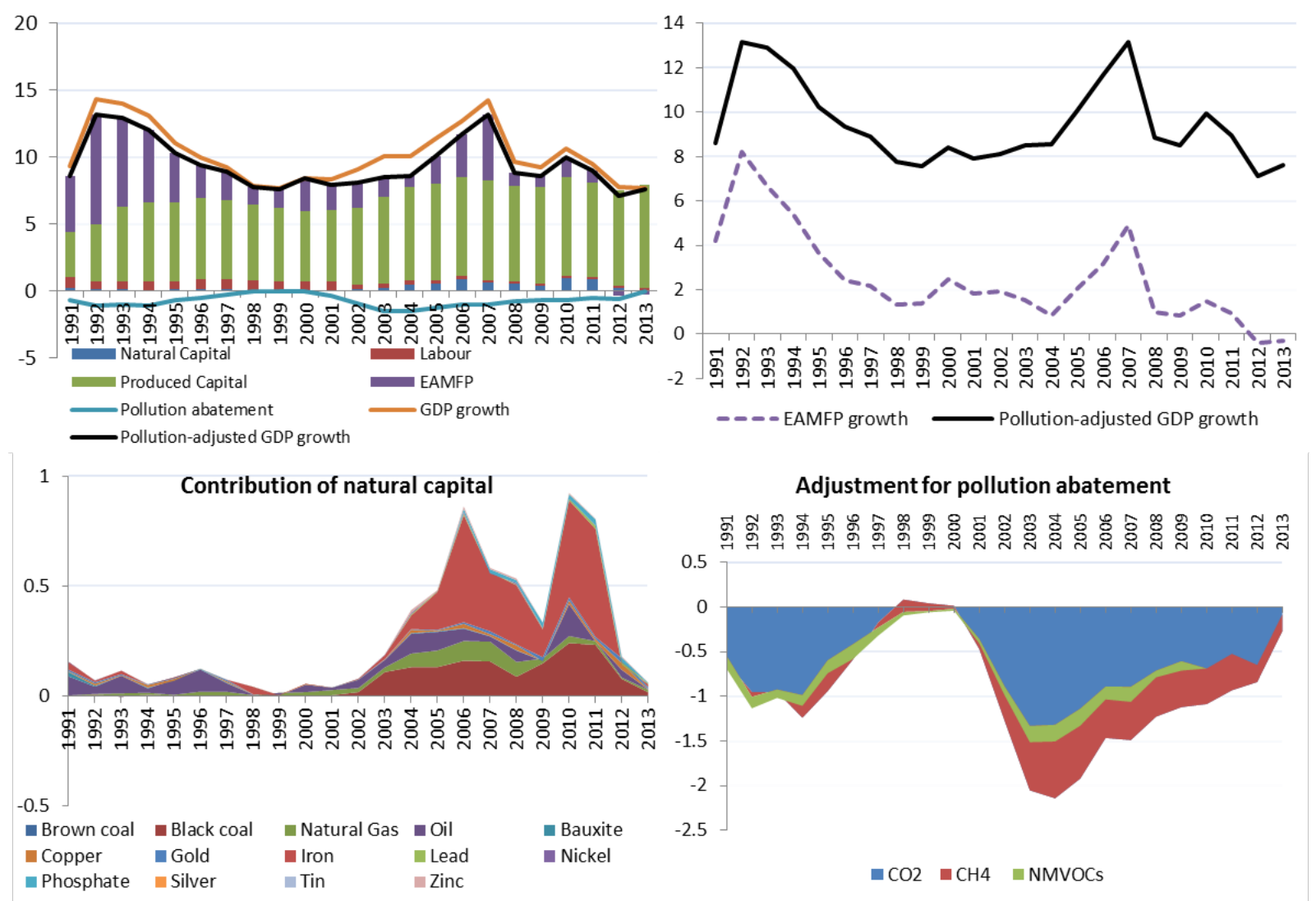




\subsubsection{Germany}

Germany ranks high among those countries that have relied almost exclusively on productivity (EAMFP) improvements to fuel output growth (note that there is a very narrow gap between output and EAMFP growth in Figure 13, upper-right panel). Germany has relied only very marginally on the extraction of its natural resources (subsoil assets) to generate growth. The extraction has remained fairly constant until the year 2007 when there have been reductions in the extraction of natural gas, iron and oil; however, this was negligible compared to its GDP growth. On the other hand, Germany's pollution abatement has been very important, essentially in $\mathrm{CO}_{2}$ and $\mathrm{CH}_{4}$.

\section{Figure 33. Detailed graphics for Germany}

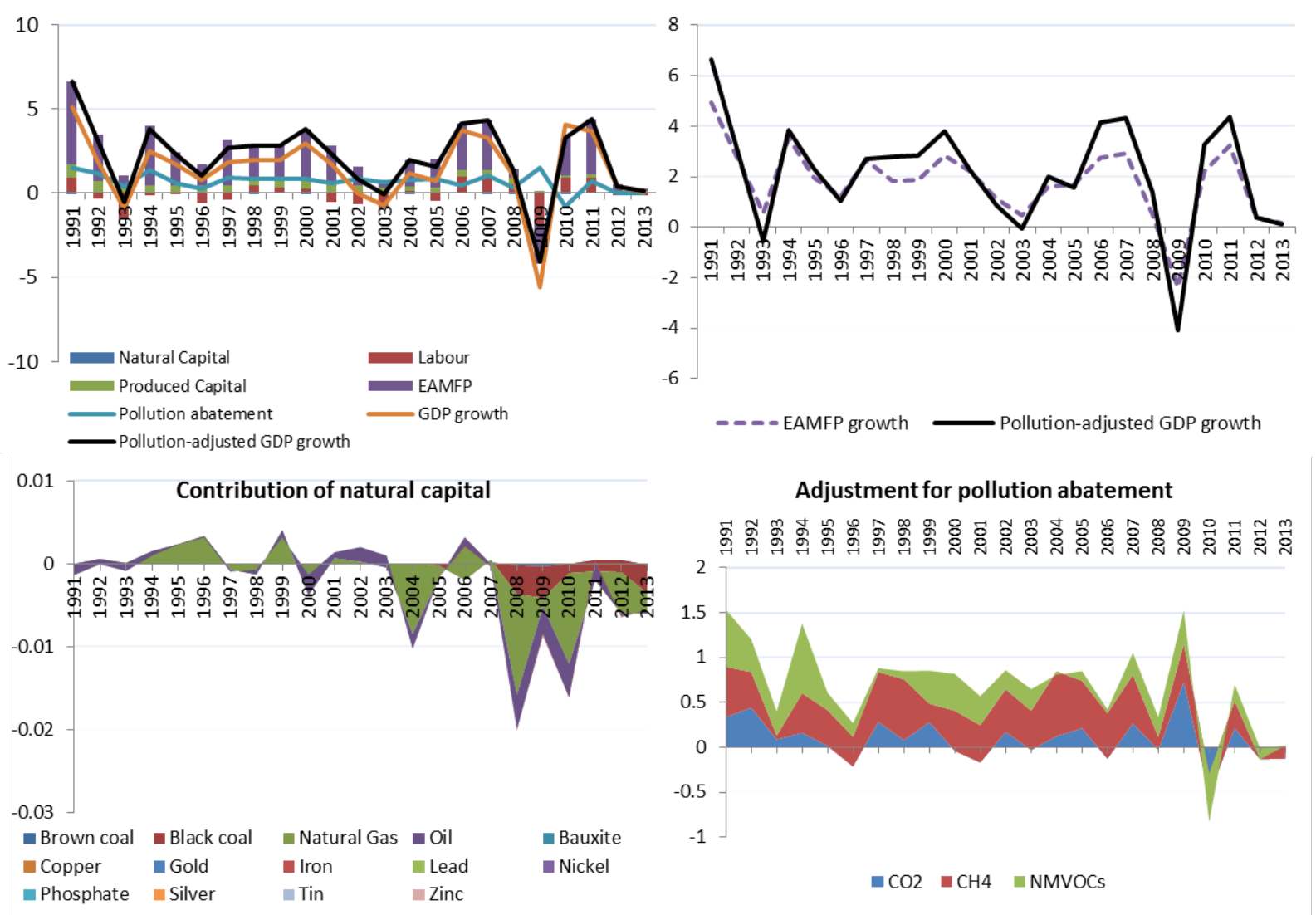




\subsubsection{Japan}

The key driver of Japan's economic growth has been growth in EAMFP. The contribution of domestic natural capital (subsoil assets) has been negligible (composed mainly of oil and natural gas extraction). In terms of pollution emissions, while Japan is the fifth largest emitter in absolute terms, it ranks second lowest in $\mathrm{CO}_{2}$-intensity per capita (in 2012). Japan has made important pollution abatement efforts in the 1990-2010 period, however the trend of reduction of emissions has slowed down more recently.

Figure 34. Detailed graphics for Japan

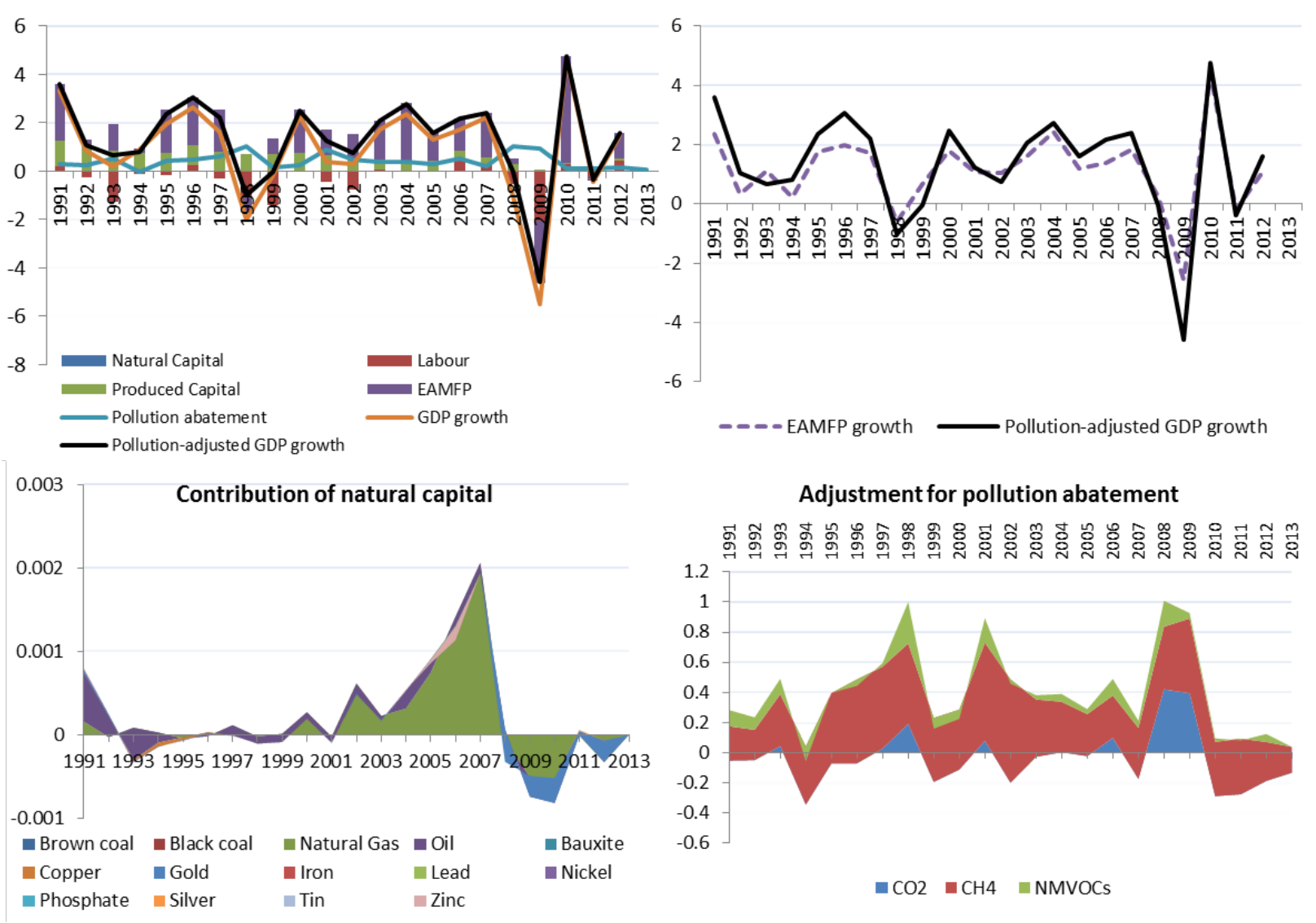




\subsection{5. $\quad$ Korea}

Korea's growth has increasingly been drawing on productivity (EAMFP) improvements, mirroring the pattern in other advanced economies. Reliance on the extraction of domestic natural resources (subsoil assets) in Korea has been one of the lowest in the OECD and G20 countries. However, Korea's emissions have increased, as shown by the negative adjustment for pollution abatement, except for the economic slowdown in 1998. In fact, Korea (together with Turkey and Mexico) has been one of the OECD countries that have relied most on pollution-intensive activities to generate output growth.

\section{Figure 35. Detailed graphics for Korea}
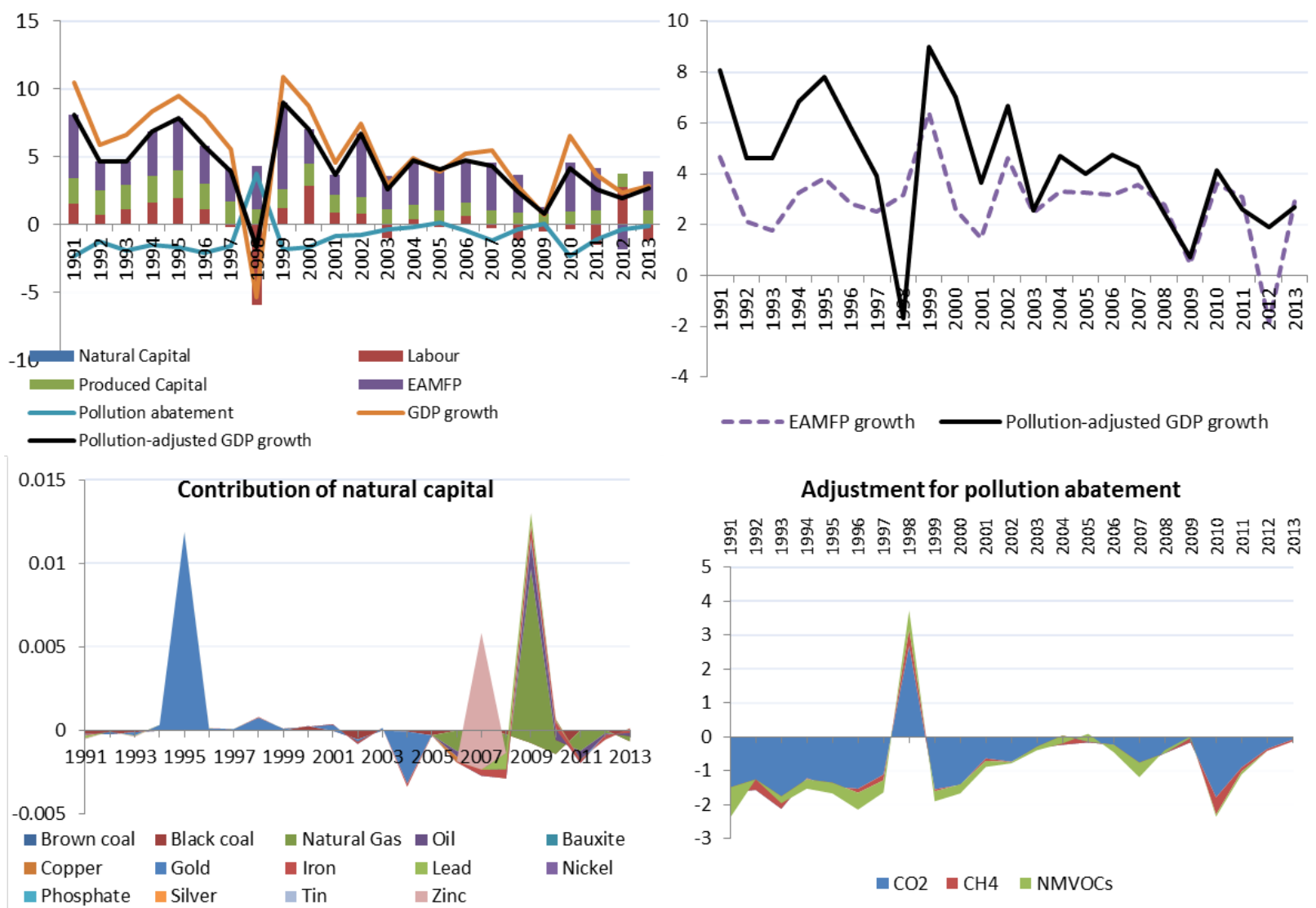

Adjustment for pollution abatement

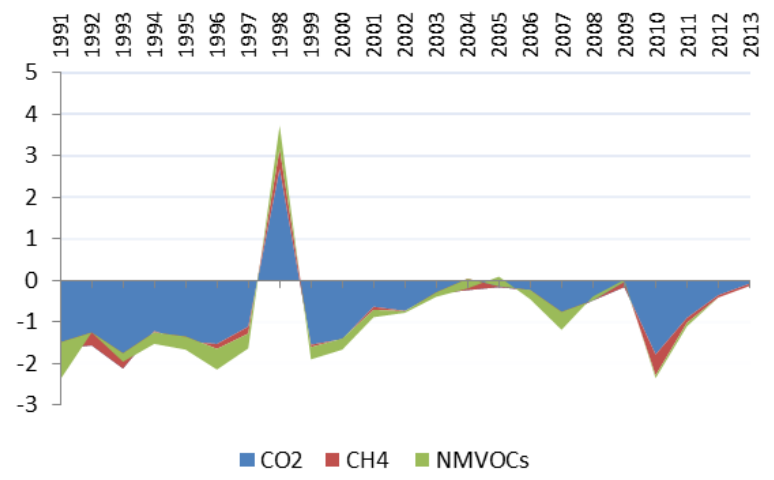




\subsubsection{India}

Despite fast productivity gains, India continued to rely on higher factor input use (mostly labour and produced capital) and pollution-intensive production to generate growth. The contribution of natural resources (subsoil assets) to output growth remains rather limited in India (esp. oil, iron and gas). India's growth has been fuelled by pollution-intensive (mainly $\mathrm{CO}_{2}$ ) production (note the high and negative adjustment for pollution abatement which accounted for almost 1 percentage point of India's GDP growth on average; lower-right panel on Figure 16).

\section{Figure 36. Detailed graphics for India}
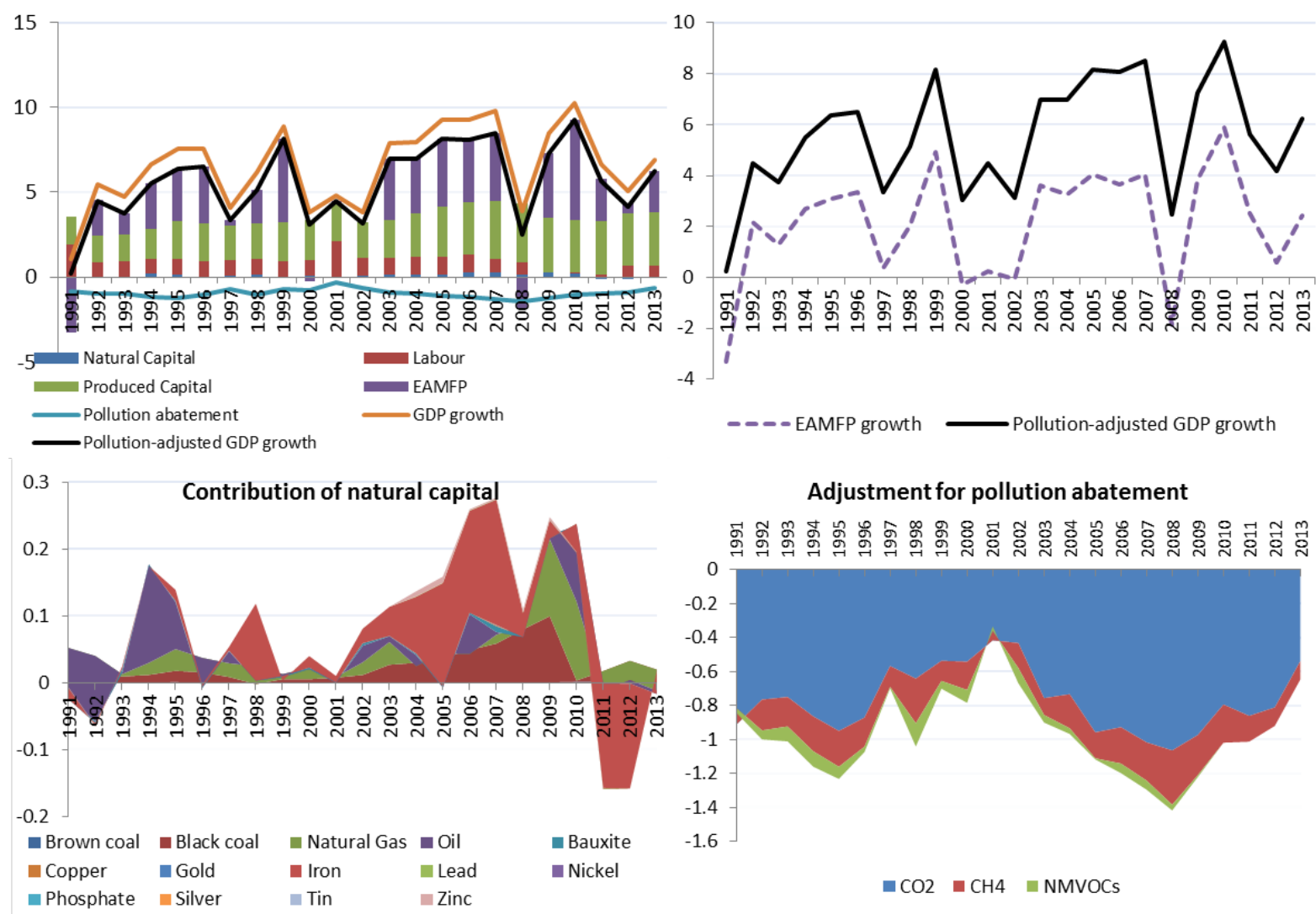

Adjustment for pollution abatement

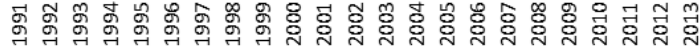

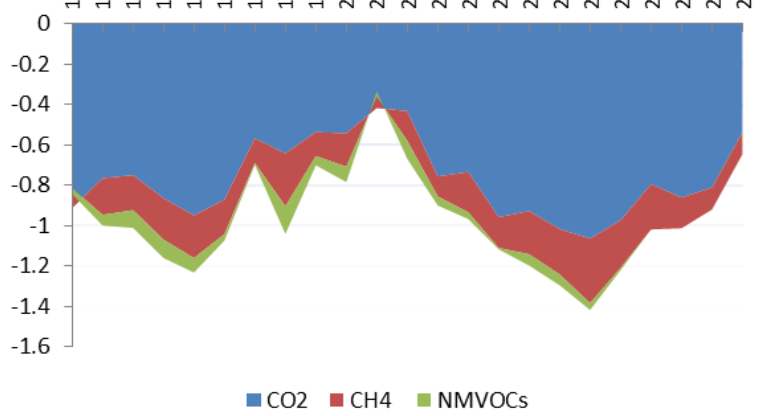




\subsubsection{Russia}

Russia has achieved important productivity gains in early 2000s as well as productivity losses in 1994 and 2009-10. Its growth has to a large extent relied on natural resource extraction as well as pollution-intensive production. Russia has the second highest extraction of domestic natural resources (subsoil assets) in absolute terms among the OECD and G20 countries, following China. Moreover, Russia also has the second highest percentage of natural resource rents on GDP. Not surprisingly, the contribution of subsoil assets to Russia's GDP growth is the highest among the OECD and G20 countries, in absolute terms as well as relative to other factor inputs (labour and produced capital). This contribution is mainly driven by oil, gas, and to a lesser extent black coal. Russia is the fourth highest emitter of $\mathrm{CO}_{2}$ in absolute terms and the emission-intensity of its production is the fifth highest. However, considerable pollution abatement has occurred in the 1990s, accompanying the economic downturn.

\section{Figure 37. Detailed graphics for Russia}
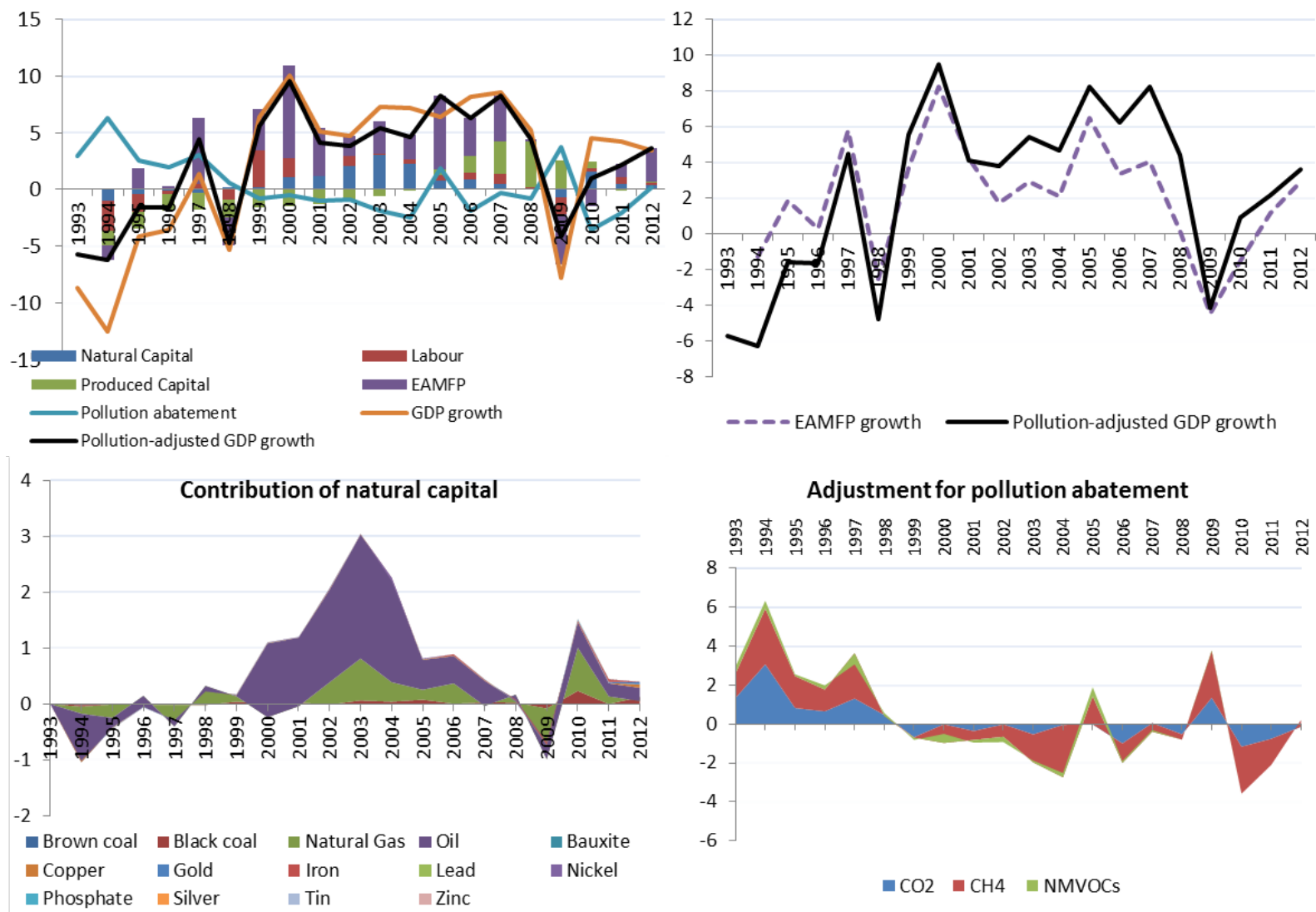

Adjustment for pollution abatement

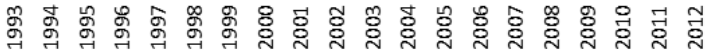

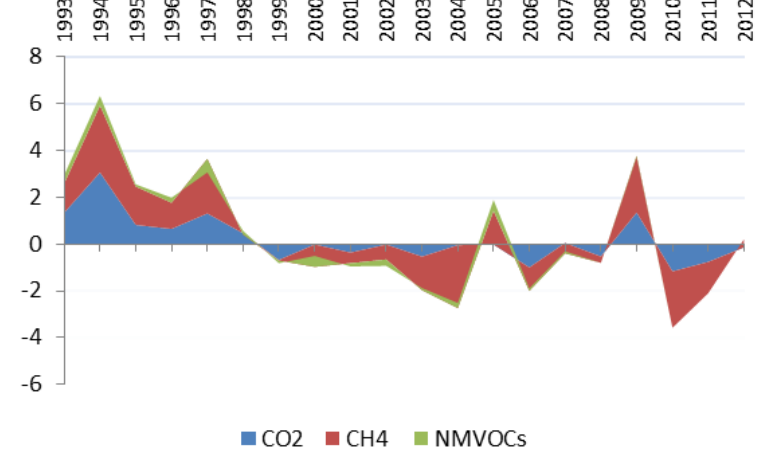




\subsubsection{Saudi Arabia}

In Saudi Arabia, an important share (75\%) of its growth has been due to productivity gains. Saudi Arabia has the highest natural capital rents per GDP, and, after Russia, it has the second highest contribution of natural capital (extraction of subsoil assets) to GDP growth. In recent years, natural resource contributions to output growth have accounted sometimes for more than the double of the contributions of labour and produced capital combined. The contribution of natural capital is mainly composed of oil extraction. Moreover, pollution emissions have been growing at an important rate, making Saudi Arabia rank fourth among countries where GDP growth depends most on increasing emissions. Saudi Arabia's emissions have been continuously increasing over the last 20 years.

Figure 38. Detailed graphics for Saudi Arabia
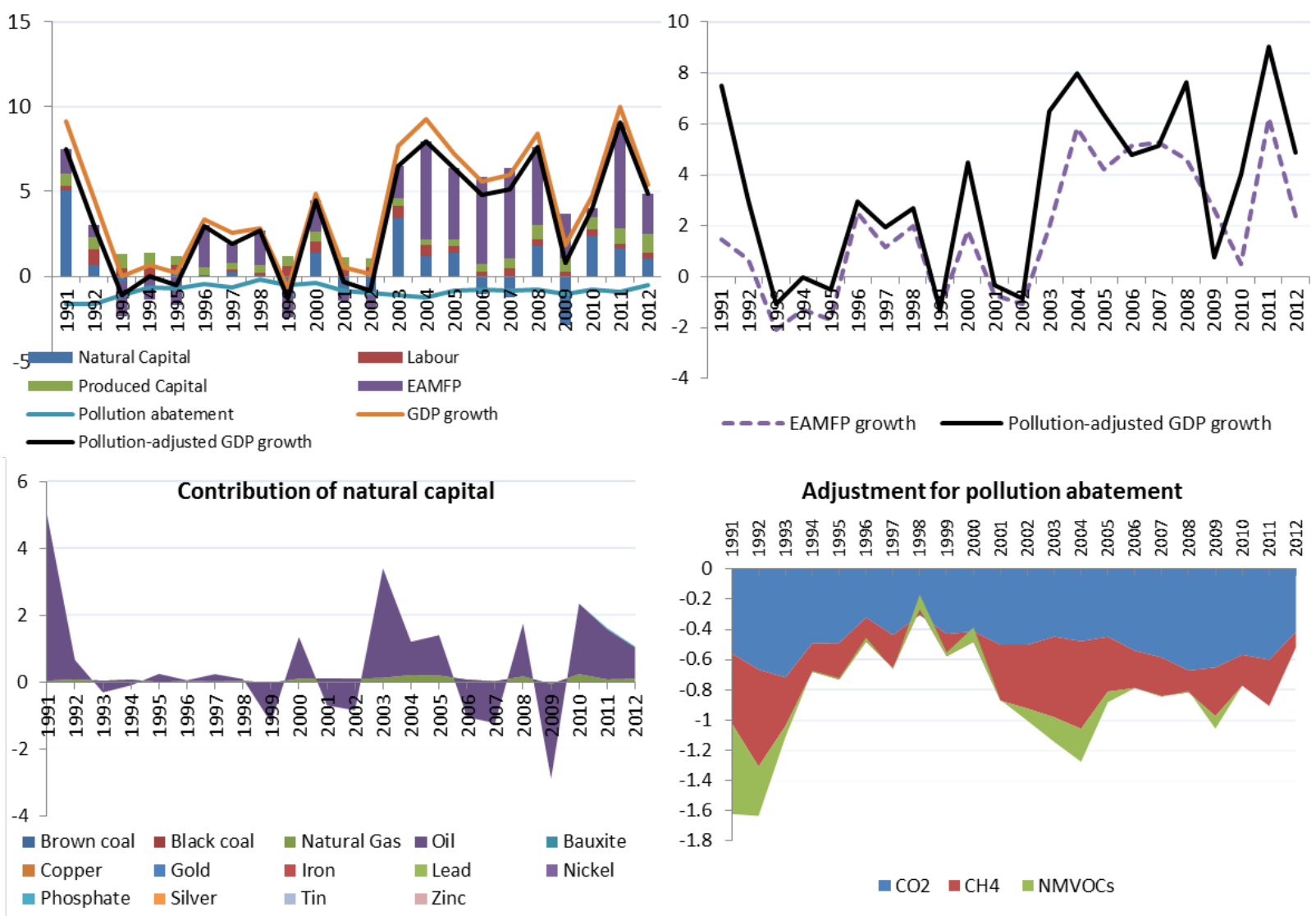

Adjustment for pollution abatement

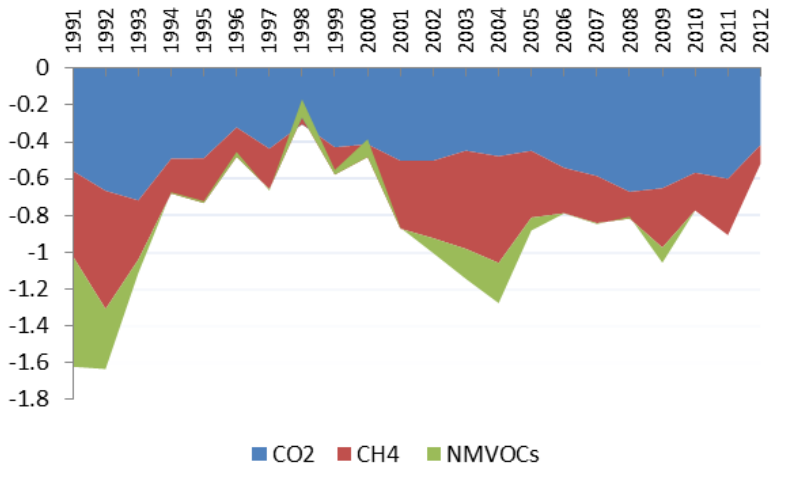




\subsubsection{United Kingdom}

United Kingdom has maintained a solid pace of productivity growth, allowing it to sustain economic growth in the face of decreasing extraction of natural capital (subsoil assets) and pollution abatement efforts. The declining natural capital contribution has been due to lower of oil and natural gas extraction (although gas extraction recovered somewhat after 2000). The UK has also undertaken pollution abatement efforts, achieving significant reduction of $\mathrm{CO}_{2}$ and methane emissions (that yield a positive adjustment of its GDP growth).

\section{Figure 39. Detailed graphics for the United Kingdom}
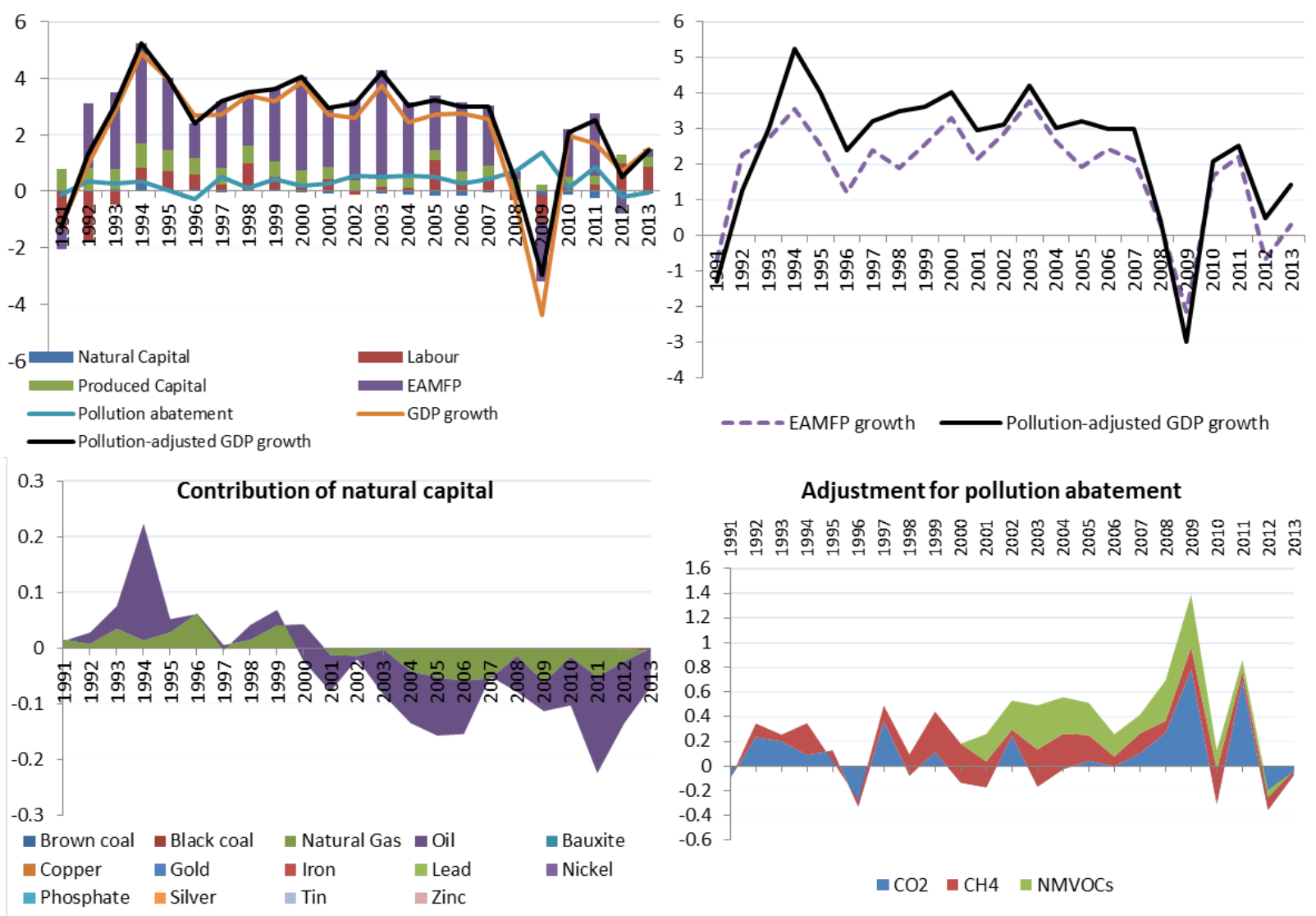

Adjustment for pollution abatement

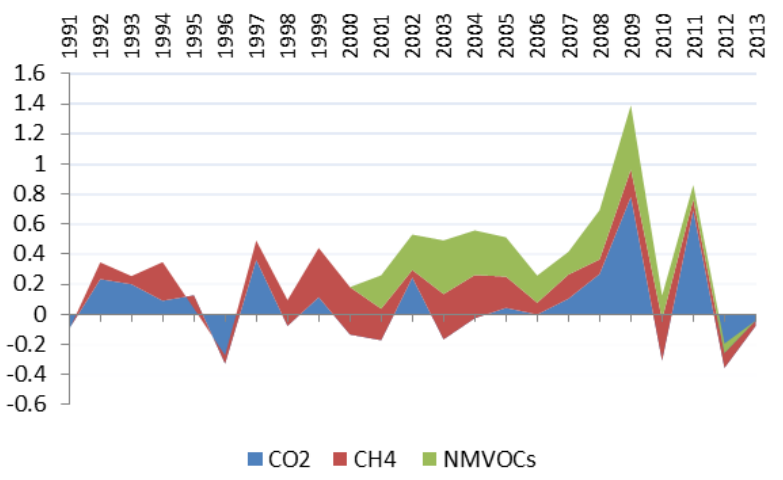




\subsubsection{United States}

EAMFP gains explain an important part of United States' growth. However, while in the 1990s it was growing at about $2 \%$ annually, recently this has been only about $1 \%$. In the USA, the contribution of domestic natural resources (extraction of subsoil assets) to output growth has been marginal, although increasing rapidly in recent years. This is despite the high volume of resource extraction in the US, ranking fourth in absolute terms. The mix of resource extraction was first dominated by natural gas, increasingly replaced by oil since 2009 (recall that the figures shown here represent only the direct contribution to growth, while there might be indirect growth effect through capital and labour demand). The US is the second highest emitter of pollution in absolute terms, increasing its emissions rapidly in recent years with the exception of a contraction in 2009.

Figure 40. Detailed graphics for the United States
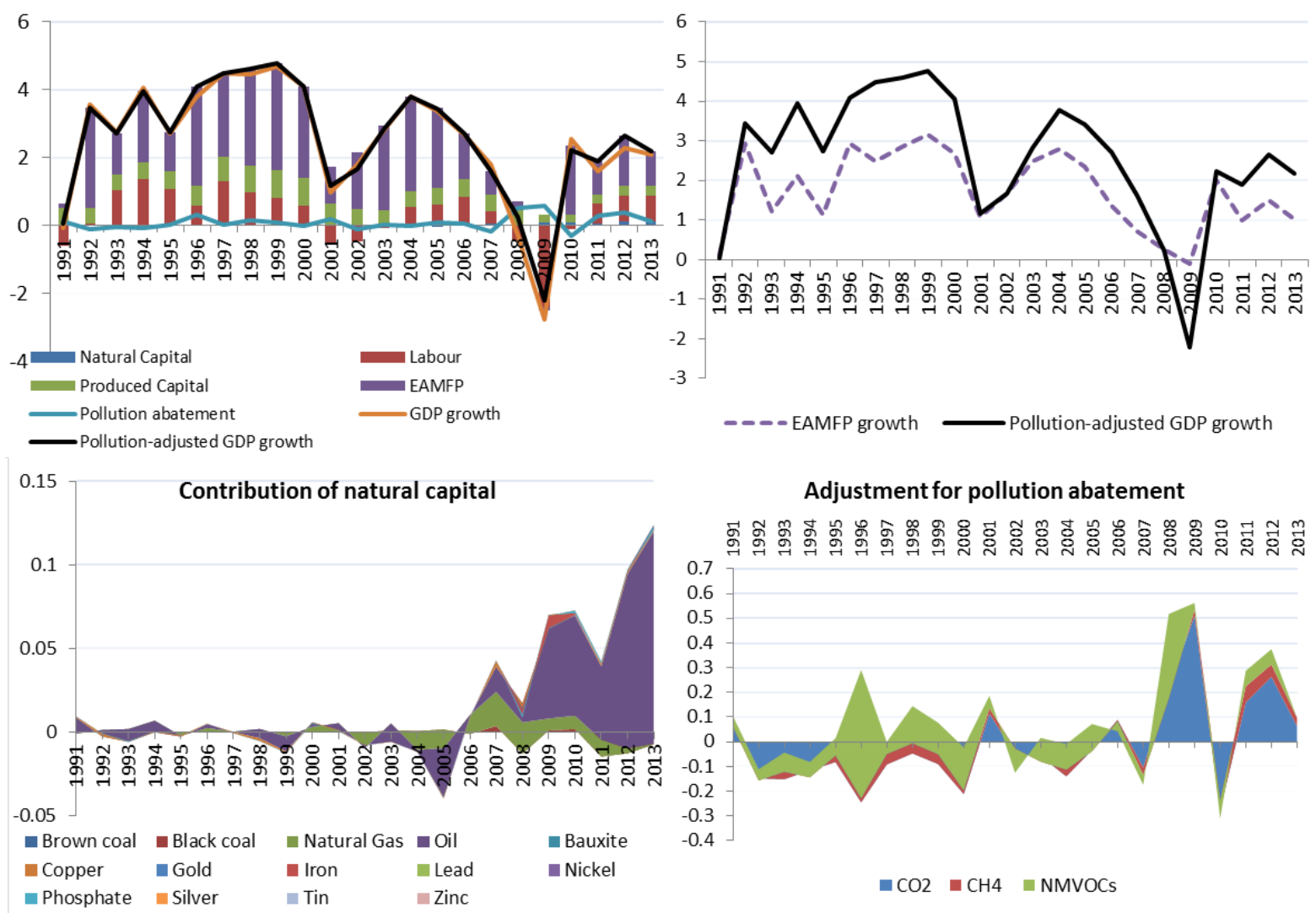

Adjustment for pollution abatement

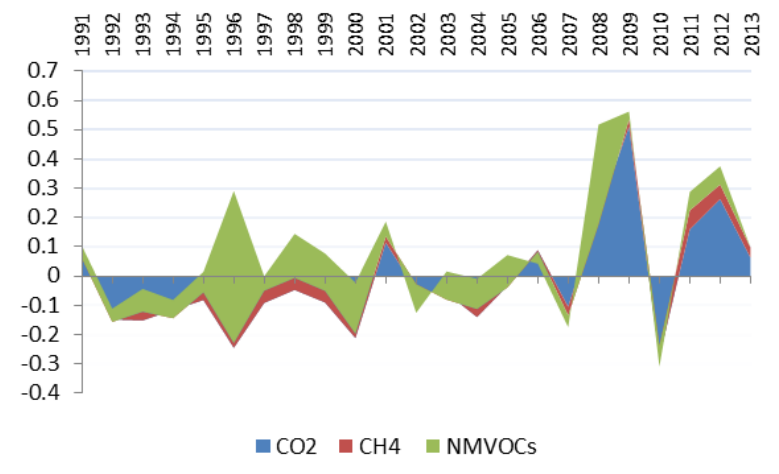




\section{INTERPRETATION AND LIMITATIONS}

This paper puts forward the importance of extending traditional multifactor productivity measures to account also for environmental services, and presents the initial results. However, the growth accounting framework developed here, and multifactor productivity measures more generally, are not without caveats, and therefore interpretation of the results must be done with care. Some of the most important limitations are outlined below.

\section{General remarks on economy-wide indicators of multifactor productivity (MFP) growth}

MFP indicators provide an aggregated picture of the economy. Recall that any macro-economic measure is, by definition, an aggregate. Country-level MFP is no exception and overall productivity growth aggregates across potentially important differences at the sectorial or micro-economic levels.

MFP indicators are retrospective. Moreover, the growth accounting approach measures the past performance of economies based on historic data. Any inference about future growth prospects should therefore be made keeping in mind that the economic context of countries may change in the future. For example, a new set of cleaner production technologies can make output growth less dependent on pollution emissions.

MFP indicators are sensitive to the business cycle. MFP growth can plunge disproportionately in times of economic recession. ${ }^{38}$ For example, during the Great Recession (2007-2009) productivity dropped significantly as a result of a drop in aggregate production but not necessarily due to a slowdown in innovation. Analysing the trend of MFP growth over longer time periods or expressing the MFP as a share of GDP helps to mitigate such effects. Nevertheless, a decrease in economic activity leads firms to underuse production factors, such as labour or capital, and makes them appear less productive. More generally, MFP indicators are most useful for analyses of long-term trends in productivity growth; year-to-year changes in MFP might be less informative for this purpose. ${ }^{39}$

MFP indicators measure growth, not the level, of productivity. Growth accounting allows measuring only changes in productivity over time ("growth") and it does not allow measuring productivity in levels. Consequently, when interpreting these indicators they should not be confused with the contribution to the level of GDP. That is, a zero contribution of an input does not mean that a country did not use the input in a given year; rather, it means that its economy has continued to rely on this input in the same way as during the previous year. For example, in the case of the EAMFP, a zero contribution of natural capital (Section 5.3) means that the country extracted domestic resources at the same rate as the previous year. Similarly, a zero adjustment for pollution abatement (Section 5.4) means that a country generated the same quantity of emissions as the previous year; in such cases the pollution-adjusted economic growth would be equal to GDP growth.

The MFP is a comprehensive indicator, yet it remains a measure of productivity and does not measure social welfare. As any other production-side indicator (such as the GDP), both MFP and EAMFP measurement frameworks are based on the producer's perspective. Changes in the utilisation of inputs (including natural capital) and changes in the production of outputs (including negative by-products such as emissions) are derived using market prices or using the private opportunity costs based on such prices. The MFP is therefore not a measure of social welfare (which would require non-market valuation of both inputs and outputs).

\footnotetext{
${ }^{38}$ Partly due to a measurement error (e.g., assumption on capital scrapping rate).

${ }^{39}$ See OECD (2001) for more details.
} 


\section{Specific remarks on adjusting the MFP growth for environmental services}

The EAMFP does not measure environmental quality. Positive EAMFP growth means that an economy performs better in utilising inputs to produce goods or to abate pollution; it does not necessarily mean that environmental quality improved. For example, production of goods per unit of total inputs may increase faster than per unit of pollution (the case of relative decoupling), yet the total amount of pollution might still grow.

The measured contribution of natural capital to output growth provides only a lower bound on the actual contribution of the resource extraction industry to the economy. Growth accounting measures decompose output growth into the direct contributions of individual inputs (from an accounting perspective), and thus it is likely a low estimate of the actual role of natural resources in the economy. For example, in the case of the oil industry, this measure takes into account only the contribution of the extracted oil itself, without the indirect contribution of the associated labour and capital investment, nor any spillover effects on other industries. The actual contribution of the oil industry to output growth is therefore greater because it also includes investment in produced capital and labour force.

The "environmental adjustment" of MFP remains partial. The coverage of environmental services in the EAMFP measurement framework is currently limited to 8 types of air emissions (greenhouse gases and air pollutants) and 14 types of subsoil assets (fossil fuels and minerals). Better data availability permitting, future work could improve upon the indicators presented here and expand the coverage to other, equally important, environmental pressures (e.g. effluents to water bodies) and natural capital (e.g. land, soils, freshwater, native forests or wild fisheries). In the meantime, the EAMFP remains a work-in-progress that provides partial - nonetheless important - information on the relationship between the composition of growth and its claims on environmental assets. 


\section{CONCLUDING REMARKS AND NEXT STEPS}

This paper refines the OECD productivity measurement framework and expands the measurement of the EAMFP and the related indicators to all OECD and G20 countries for the 1990-2013 period. Currently, the framework allows accounting for the extraction of subsoil natural assets (fossil fuels and minerals) and air emissions (greenhouse gases and air pollutants).

The main findings indicate that in some countries, such as the Russia, Saudi Arabia, Chile and the China, reliance on the extraction of subsoil assets has contributed to a significant share of income growth, supporting concerns about their ability to sustain past growth rates in the long run. This is all the more important in countries where productivity growth has been slow or has even decreased. In other countries, including the United Kingdom, declining extraction of subsoil assets has been compensated through greater reliance on other inputs to maintain output growth, or through productivity improvements. In countries such as Finland, Japan or Germany the bulk of income growth has been generated essentially via productivity gains.

Interestingly, long-run EAMFP growth rates have been rather similar between the OECD and BRIICS countries. The key factor that explains their different overall growth performance is the extent to which they rely on factor inputs: BRIICS countries have drawn to a much greater extent on increased utilisation of inputs (including labour, produced capital and natural capital) to generate additional growth, while in OECD countries growth has been generated almost exclusively through productivity gains.

The results also point to a shift towards cleaner production processes in many countries. In fact, most OECD countries have decreased their emissions over the last two decades, and their GDP growth rates would need to be adjusted upwards to correctly assess their growth performance. Such adjustment sheds light on the 'green' growth performance of countries, including those where significant pollution abatement efforts might otherwise lead us to undervalue their economic growth.

Looking forward, efforts to further refine this work should focus on covering a broader range of natural assets (including land and renewable resources) and pollution (such as discharges to water bodies and soils). While these extensions are currently constrained by a lack of data, further progress by countries, supported by the OECD Taskforce on the Implementation of the SEEA, will help generate such data in the future.

Improvements could also be envisaged regarding the valuation of natural capital use and pollution. On-going efforts by the above-mentioned OECD Taskforce and the World Bank to refine the estimates of the user cost of natural capital could potentially improve the findings.

Gaining experience from use of the indicator(s) will be essential, including:

- Drawing on feedback from applying the indicators in country studies, such as the OECD Environmental Performance Reviews, Economic Surveys, Going for Growth publications, and individual country experiences from developing their own Green Growth indicator sets.

- Promoting the use of these indicators in policy studies: accounting does not explain the underlying determinants of growth, and production of indicators could therefore be usefully complemented by applied policy analyses to help explain and facilitate the interpretation of the observed trends over time and differences across countries. Building on Albrizio et al. (2014), on-going work seeks to extend the analysis to drivers of the environmentally adjusted productivity growth. 


\section{REFERENCES}

Arlinghaus, J. (2015), "Impacts of Carbon Prices on Indicators of Competitiveness: A Review of Empirical Findings”, OECD Environment Working Papers, No. 87, OECD Publishing, Paris. http://dx.doi.org/10.1787/5js37p21grzq-en

Australian Productivity Commission (APC) (2011), Carbon Emission Policies in Key Economies, Productivity Commission Research Report, Canberra.

Beffy P.O., P. Ollivaud, P. Richardson and F. Sédillot (2006), "New OECD Methods for Supply-Side and Medium-Term Assessments: A Capital Services Approach", OECD Economics Department Working Papers, 482.

Brandt N., P. Schreyer and V. Zipperer (2014), "Productivity Measurement with Natural Capital and Bad Outputs”, OECD Economics Department Working Papers, No. 1154, OECD Publishing. http://dx.doi.org/10.1787/5jz0wh5t0ztd-en

Brandt, N., P. Schreyer and V. Zipperer (2013), "Productivity measurement with natural capital”, OECD Economics Department Working Papers, No. 1092, OECD Publishing. http://dx.doi.org/10.1787/5k3xnhsz0vtg-en

Coelli, T., Gautier, A., Perelman, S. and R. Saplacan (2013), "Estimating the Cost of Improving Quality in Electricity Distribution: A Parametric Distance Function Approach”, Energy Policy, 62, February, pp. 287-297.

Conference Board (2014), “The Conference Board - Total Economy Database,” extracted in September 2014. http://www.conference-board.org/data/economydatabase/

Cuesta, R., C.A. Knox Lovell and J. Zofio (2009), "Environmental efficiency measurement with translog distance functions: A parametric approach”, Ecological Economics, Vol. 68, pp. 2232-2242.

Dachraoui, K. and T.M. Harchaoui (2004), "Water Use, Shadow Prices and the Canadian Business Sector Productivity Performance”, Economic Analysis Research Paper Series 11F0027MIE, No. 26.

Dang, T. and A. Mourougane (2014a), "Adjusting Productivity for Pollution in Selected Asian Economies”, OECD Green Growth Papers, No. 2014/01, OECD Publishing.

Dang, T. and A. Mourougane (2014b), "Estimating Shadow Prices of Pollution in Selected OECD Countries”, OECD Green Growth Papers, No. 2014/02, OECD Publishing.

EC-JRC/PBL (2015). Emission Database for Global Atmospheric Research (EDGAR), release version 4.2. European Commission, Joint Research Centre (JRC)/Netherlands Environmental Assessment Agency (PBL), extracted in April 2015. http://edgar.jrc.ec.europa.eu

Färe, R., S. Grosskopf, D.-W. Noh and W. Weber (2005), “Characteristics of a polluting technology: theory and practice”, Journal of Econometrics, Vol. 126, pp. 469-492.

Färe, R., S. Grosskopf, F. Hernandez-Sancho (2004), "Environmental performance: an index number approach”, Resource and Energy Economics 26: 343-352.

Färe, R., S. Grosskopf, C. A. Knox Lovell and S. Yaisawarng (1993), "Derivation of Shadow Prices for Undesirable Outputs: A Distance Function Approach”, The Review of Economics and Statistics, Vol. 75(2), pp. 374-380. 
Färe, R., S. Grosskopf, C. A. K. Lovell and C. Pasurka (1989), "Multilateral Productivity Comparisons When Some Outputs are Undesirable: A Nonparametric Approach", Review of Economicsand Statistics 71, 90-98.

Fujii, H., S. Kaneko and S. Managi (2010), Changes in environmentally sensitive productivity and technological modernization in China's iron and steel industry in the 1990s. Environment and Development Economics 15(4) 485-504.

Gollop, F., and G.P. Swinand (2001), "Total Resource Productivity. Accounting for Changing Environment Quality”, in C. R. Hulten, E. R. Dean and M. J. Harper, New Developments in Productivity Analysis (pp. 587-608). University of Chicago Press.

Greene, W. H. (2008), Econometric analysis. Pearson.

Harrison, K. (2013), “The Political Economy of British Columbia's Carbon Tax”, OECD Environment Working Papers, No. 63, OECD Publishing, Paris.

Hoang, V-N. (2014), "Traditional and Environmental Agricultural Total Factor Productivity in OECD Countries - work in progress,” Report prepared for the OECD Secretariat, Trade and Agriculture Directorate.

Interagency Working Group on Social Cos of Carbon (2013), Technical Update of the Social Cost of Carbon for Regulatory Impact Analysis Under Executive Order 12866. United Sates Government, Washington D.C.

Jaraité, J. and C. Di Maria (2012), "Efficiency, productivity and environmental policy: A case study of power generation in the EU,” Energy Economics 34: 1557-1568.

Johnstone, N., S. Managi, M. Cárdenas Rodríguez, I. Haščič, H. Fujii and M. Souchier (2016), "Environmental Policy Design, Innovation and Efficiency Gains in Electricity Generation”, OECD Environment Working Papers, No. 104, OECD Publishing, Paris. http://dx.doi.org/10.1787/5jm0t716kwmw-en

Keilbach, M. (1995), "Estimation of the Value of the Marginal Product of Emissions in a Country where Emissions Output is Regulated - An Empirical Study”, Environmental and Resource Economics, Vol. 5, pp. 305-319.

Koundouri, P., Babalos, V., Stithou, M. and I. Anastasiou (2012), "A Micro-Econometric Approach to Deriving Use and Non-Use Values of in-situ Groundwater: The Vosvozis Case Study, Greece”, MPRA Paper No. 38266.

Kumar, S. and S. Managi (2010), "Environment and Productivities in Developed and Developing Countries: The Case of Carbon Dioxide and Sulfur Dioxide”, Journal of Environmental Management, 91, 1580-1592.

Kuosmanen, T. (2013), “Green productivity in agriculture: A critical synthesis”, Report prepared for the OECD Secretariat, Trade and Agriculture Directorate.

Maradan, D. and A. Vassiliev (2005), "Marginal Costs of Carbon Dioxide Abatement: Empirical Evidence from Cross-Country Analysis", Schweizerische Zeitschrift für Volkswirtschaft und Statistik, Vol. 141, pp. 377-410.

Nicoletti, G. and S. Scarpetta (2003), "Regulation, Productivity, and Growth: OECD Evidence”, Policy Research Working Paper, No. 2944.

OECD (2015a), “GDP per capita and productivity growth”, OECD Productivity Statistics (database). http://dx.doi.org/10.1787/data-00685-en (Accessed on February 2015).

OECD (2015b), “Aggregate National Accounts, SNA 2008: Gross domestic product”, OECD National Accounts Statistics (database). http://dx.doi.org/10.1787/data-00001-en (Accessed on February 2015). 
OECD (2015c), “PPPs and exchange rates”, OECD National Accounts Statistics (database). http://dx.doi.org/10.1787/data-00004-en (Accessed on February 2015).

OECD (2015d), Natural Resource Accounts database, forthcoming.

OECD (2015e), “Air and greenhouse gas emissions by industry”, OECD Environment Statistics (database). http://dx.doi.org/10.1787/data-00735-en (Accessed on February 2015).

OECD (2015f), “Air emissions by source”, OECD Environment Statistics (database). http://dx.doi.org/10.1787/data-00598-en (Accessed in February 2015).

OECD (2015g), “Greenhouse gas emissions by source”, OECD Environment Statistics (database). http://dx.doi.org/10.1787/data-00594-en (Accessed in February 2015).

OECD (2014a), Green Growth Indicators 2014, OECD Green Growth Studies, OECD Publishing. http://dx.doi.org/10.1787/9789264202030-en

OECD (2014b), “Agricultural Total Factor Productivity and the Environment - Review of Methodological Approaches: Work in Progress”, COM/TAD/CA/ENV/EPOC(2014)41, prepared for the OECD Joint Working Party on Agriculture and the Environment.

OECD (2014c), OECD Environmental Performance Reviews: Sweden 2014, OECD Publishing. http://dx.doi.org/10.1787/9789264213715-en

OECD (2014d), Greening Household Behaviour: Overview from the 2011 Survey - Revised edition, OECD Studies on Environmental Policy and Household Behaviour, OECD Publishing, Paris. http://dx.doi.org/10.1787/9789264214651-en

OECD (2011), Invention and Transfer of Environmental Technologies, OECD Studies on Environmental Innovation, OECD Publishing, Paris. http://dx.doi.org/10.1787/9789264115620-en

OECD (2009), Manual on Capital Stock Measurement, OECD Publishing, Paris.

OECD (2001), Measuring Productivity - OECD Manual: Measurement of Aggregate and Industry-level Productivity Growth, OECD Publishing, Paris. http://dx.doi.org/10.1787/9789264194519-en

Pearce, D.W. (2006), “The political economy of an energy tax: The United Kingdom's Climate Change Levy”, Energy Economics 28 (2008) 149 - 158.

Pearce, D., G. Atkinson and S. Mourato (2006), Cost-Benefit Analysis and the Environment: Recent Developments, OECD Publishing. http://dx.doi.org/10.1787/9789264010055-en

Qi S., L. Xu and J. Coggins (2004), “Deriving Shadow Prices of Environmental Externalities”, University of Minnesota.

Rabe-Hesketh, S. and A. Skrondal (2005), Multilevel and Longitudinal Modeling using Stata. Stata Press.

Rezek, J. P. and R. C. Campbell (2007), “Cost Estimates for Multiple Pollutants: A Maximum Entropy Approach”, Energy Economics, Vol. 29, pp. 503-519.

Richmond, A., R.K. Kaufmann and R.B. Myneni (2007), Valuing ecosystem services: A shadow price for net primary production. Ecological Economics, 454-462.

Salnykov M. and V. Zelenyuk (2005), "Estimation of Environmental Efficiencies of Economies and Shadow Prices of Pollutants in Countries in Transition”, EERC Working Paper Series 05-06e, EERC Research Network, Russia and CIS.

Schreyer P. (2010), “Measuring Multifactor Productivity when Rates of Return Are Exogenous”, Chapter 2, pp. 13-40 in W.E. Diewert, B.M. Balk, D. Fixler, K.J. Fox and A.O. Nakamura (2010), Price and Productivity Measurement, Vol. 6, Trafford Press. 
Shephard, R.W. (1970), “Theory of Cost and Production Functions", Princeton University Press, Princeton.

Smith, S. and N.A. Braathen (2015), "Monetary Carbon Values in Policy Appraisal: An Overview of Current Practice and Key Issues”, OECD Environment Working Papers, No. 92, OECD Publishing, Paris. http://dx.doi.org/10.1787/5jrs8st3nguh-en

Swinton, J.R. (2002), "The potential for cost savings in the sulfur dioxide allowance market: empirical evidence from Florida”, Land Econ, 78:390-404.

Van Soest, D. P., J.A. List and T. Jeppesen (2005), "Shadow prices, environmental stringency, and international competitiveness”, European Economic Review, 50(5), 1151-1167.

Wei, C., A. Löschel and B. Liu (2013), "An empirical analysis of the CO2 shadow price in Chinese thermal power enterprises”, Energy Economics 40:22-31.

Wooldridge, J. M. (2010), Econometric Analysis of Cross Section and Panel Data. The MIT Press.

World Bank (2015), World Development Indicators (WDI). Data retrieved March 2015.

World Bank (2014), Wealth Accounting and the Valuation of Ecosystem Services (WAVES) database, the World Bank. 


\section{ANNEX 1. REVIEW OF METHODOLOGIES FOR PRODUCTIVITY ANALYSIS}

Various methodologies can be used to estimate productivity growth. One way to categorise the methods is based on whether they account for possible measurement error or random 'noise' in the relationship between inputs and outputs. Methods that postulate a certain deterministic relationship (i.e. assume no measurement errors or noise) between inputs and output are referred to as non-parametric methods (e.g. growth accounting, data envelopment analysis (DEA)). On the other hand, parametric methods (e.g. regression analysis used in econometrics, stochastic frontier analysis (SFA)) allow for a stochastic term in the relationship to account for any measurement errors or random noise. A third group of methods, referred to as semi-parametric methods (e.g. stochastic semi-nonparametric envelopment of data (StoNED)) can combine elements of both parametric and non-parametric methods.

Similarly, this categorisation arises with the way the production process of the economy is described (i.e. specific properties of the transformation, production or distance functions). In the case of non-parametric approaches such relationships do not necessarily have an explicit functional specification. In contrast, parametric and semi-parametric methods assume some a priori knowledge of the production function expressed by a specific functional form (e.g. Cobb-Douglas, translog, etc.) and thus impose assumptions on the relationships among inputs and output (e.g. input substitution).

A complementary distinction is whether the method allows an assessment of efficiency. Methods that allow a production possibilities frontier to be estimated by comparing the performance of all countries in the sample (e.g. DEA and SFA) can identify those that lie on the frontier (the best performers, efficient ones) and those that lie below such frontier and hence perform inefficiently. On the other hand, some methods assume that all countries in the sample are fully efficient (e.g. growth accounting). This implies that any change in inputs or outputs leading to productivity change must be interpreted as a shift of the production frontier (e.g. due to technical change or organisational change). This is different from the frontier methods that allow such outcomes to be attributed also to changes in technical efficiency (i.e. moves away/towards the frontier from one year to another), allocative efficiency (i.e. composition of inputs) and scale efficiency (i.e. change in the scale of production).

Generally speaking, the more structure we impose on the empirical implementation upfront (e.g. in the form of approximations of empirical relationships and assumptions about error distribution), the more we constrain the space in which results can 'vary'. While this will lead to an apparently more coherent series across countries and over time, the risk is that such assumptions may not always be a correct representation of reality. Conversely, methods that provide more degrees of freedom for the data to 'speak for themselves' allow these relationships to be identified empirically (and hence are potentially closer to the 'true' relationship), but they also tend to require more data and run the risk that such empirical relationships will be different when the estimation sample changes, possibly raising questions of coherence over time.

While all these approaches - growth accounting, econometrics, DEA and SFA - seek to calculate a given index number, they necessarily arrive at somewhat different results due to different simplifying assumptions. In addition, the conceptual and methodological differences imply differences in interpretation of these results. Most importantly, while under growth accounting a country's (multifactor) productivity is a function of only its own inputs and outputs, under the other approaches reviewed here (econometric and frontier techniques) the result depends also on the performance of other countries in the sample, notably (i) the best performers (those that lie on the frontier) in the case of DEA and SFA, and (ii) all countries (not only best performers) in the case of econometric analysis. Therefore, efficiency scores might be 
overestimated if the most efficient countries worldwide are not included in the sample at hand (and hence the inefficient countries form the frontier). With the exception of growth accounting, all other methods are potentially sensitive to sampling variation because interpretation of results is always relative to countries in the data sample. Next, we discuss in more detail the methods mentioned in this section and provide an indication of how these methods have been applied in the literature.

Growth accounting is a traditional approach used to calculate index numbers. It does not impose a functional form on the relationship between inputs and outputs (i.e. the transformation function). Under this approach, any change in production that is not explained by changes in input use is interpreted as a change in productivity. A key feature is that weights have to be used to compare changes in pollution emissions to changes in inputs or outputs. One approach is to use the social cost of pollution so that changes in productivity reflect changes in social welfare. As such, this approach requires reliable estimates of the social cost of pollution and natural resource use which are currently not easily available. Plus, this approach requires weighting GDP such that it represents a measure of welfare, which is not the case with the production framework.

An alternative approach is to adopt the producer viewpoint and to weight pollution emissions using the private marginal abatement costs so that changes in emissions are expressed in unit of equivalent output growth. This is the approach adopted in this paper (for a comparison of the production- and the welfare-based paradigms, see Gollop and Swinand, 2001).

Deriving monetary values of both outputs and inputs is the major challenge of the growth accounting approach because prices of natural resources and environmental services are typically not observable. In Brandt et al. (2013) unit rent data were used to value natural capital inputs. However, inclusion of 'nonmarket' types of natural capital or valuation of undesirable outputs requires elasticities to be estimated econometrically, which is dependent on the availability of additional data and assumptions underlying the selected estimation method (see e.g. Brandt et al., 2014; Dang and Mourougane, 2014a,b).

This approach has been adopted by the OECD to develop a calculation method to account for, initially, natural resource inputs (Brandt et al., 2013) and later extended to account also for undesirable outputs (Brandt et al., 2014). This approach is consistent with the methodology used to construct the OECD Productivity Database that includes measures of traditional MFP (for more details, see OECD, 2001). While Brandt et al. (2013; 2014) applied this methodology on a sample of OECD countries; the same methodology has been applied also on a sample of selected Asian countries in a follow-up work by Dang and Mourougane (2014a). The present paper builds on this literature and further refines the application of the growth accounting approach to productivity measurement.

The econometric approach (regression analysis) requires assumptions about the form of the aggregate production function to estimate production elasticities (e.g. Cobb-Douglas, translog, etc.). However, the econometric approach benefits from the inclusion of random errors, and as such accounts for possible random shocks in inputs or outputs or data measurement issues. This approach has been used by Brandt et al. $(2013$; 2014) to impute observations for some of the countries with missing data; Dang and Mourougane (2014a) used this approach for robustness checks. More generally, this approach has been used in the work of the OECD Economics Department (e.g., Economic Outlooks).

Data envelopment analysis (DEA), or more broadly non-parametric frontier analysis, is a technique $^{40}$ that relies on the estimation of a production possibilities frontier and the concept of distance functions. Under this approach a country's performance (productive efficiency) is assessed relative to the best-performing countries in the sample (i.e. those on the frontier), and productivity improvements are

\footnotetext{
${ }^{40}$ See Färe et al. (1989, 1993, 2004).
} 
measured in terms of efficiency gains over time. This method does not require elasticities to be estimated in exchange for a set of deterministic assumptions (e.g. that data does not suffer from measurement errors).

A downside of DEA is that it requires an assumption of a common production frontier across countries. Any deviation from the frontier is interpreted as lower efficiency, suggesting that there is sometimes large scope for improving efficiency. In reality, deviations from the efficient frontier may be reflective of other variables that are not controlled for in the analysis.

A key advantage of this approach is that it does not require price data of any kind. This is particularly useful in the environmental domain, as evidenced by a large body of academic literature using this approach (e.g. Fujii et al., 2010; Jaraité and Di Maria, 2012; Kumar and Managi, 2010). In the OECD, relevant work has been undertaken to measure environmentally-adjusted MFP in the agricultural sector (Kuosmanen, 2013; Hoang, 2014) and the energy sector (Johnstone et al., 2016).

Stochastic frontier analysis (SFA) combines some of the assumptions and properties from econometric techniques and DEA. SFA requires assumptions about the functional form of aggregate production and is able to account for data measurement errors; yet, similarly to DEA, SFA does not rely on the assumption of technical efficiency of countries (i.e. is able to assess inefficiency). A clear advantage of SFA over DEA methods is the possibility to test conventional hypotheses on key parameters (e.g. input elasticities). On the other hand, the choice of the functional form for the production function and for the inefficiency term has strong implications in terms of underlying assumptions and might affect estimations.

In OECD's work, the SFA approach has been applied to estimate productivity of the agricultural sector in OECD countries (Kuosmanen, 2013). ${ }^{41}$ The need to make choices (about functional forms, error distributions, and estimation methods) is often seen as a disadvantage of this method and parametric approaches more generally (SFA, econometrics). Decisions have to be made on a case by case basis and, whenever possible, explore alternative models and estimation methods and assess adequacy of the results obtained.

Table A1.1 situates OECD's statistical and analytical work in the broader context of the most common methodological approaches to MFP calculation and provides an overview of the major advantages and limitations.

${ }^{41}$ OECD (2014b) summarises the recent results and the alternative methods used. 
Table A1.1. Alternative methodological approaches to MFP calculation used in OECD work

\begin{tabular}{|c|c|c|c|}
\hline \multirow{2}{*}{ Method } & \multirow[t]{2}{*}{ Traditional MFP } & \multicolumn{2}{|c|}{ Environmentally adjusted MFP } \\
\hline & & Applications & Pros and cons \\
\hline $\begin{array}{l}\text { Growth } \\
\text { accounting }\end{array}$ & $\begin{array}{l}\text { OECD Productivity Database } \\
\text { (OECD 2001; Schreyer 2010) }\end{array}$ & $\begin{array}{l}\text { OECD Green Growth Database } \\
\text { (present paper; Brandt et al. 2013, } \\
\text { 2014; Dang and Mourougane } \\
\text { 2014a, 2014b) }\end{array}$ & $\begin{array}{l}\text { (+) Consistent with traditional MFP calculation } \\
(+) \text { Coherent over time } \\
(+) \text { No need to specify the form of the production } \\
\text { function } \\
(-) \text { High data requirements (monetary values of all } \\
\text { outputs and inputs) } \\
(-) \text { Does not account for noise in data }\end{array}$ \\
\hline $\begin{array}{l}\text { Econometric } \\
\text { analysis }\end{array}$ & $\begin{array}{l}\text { OECD Economic Outlook and } \\
\text { policy studies } \\
\text { (e.g. Beffy et al. 2006; Nicoletti } \\
\text { and Scarpetta 2003) }\end{array}$ & $\begin{array}{l}\text { OECD Green Growth Database - } \\
\text { for imputation of missing data } \\
\text { (Brandt et al. 2013,2014; Dang } \\
\text { Mourougane 2014a) }\end{array}$ & $\begin{array}{l}\text { (+) Allows hypothesis testing } \\
(+) \text { Accounts for measurement error } \\
(-) \text { Results might be sensitive to estimator used and } \\
\text { data sample } \\
(-) \text { Assumes efficiency }\end{array}$ \\
\hline $\begin{array}{l}\text { Data } \\
\text { envelopment } \\
\text { analysis }\end{array}$ & & $\begin{array}{l}\text { OECD sectoral analysis } \\
\text { (Kuosmanen 2013; Hoang 2014; } \\
\text { Johnstone et al. 2016) }\end{array}$ & $\begin{array}{l}\text { (+) Does not assume efficiency } \\
(+) \text { Flexible with respect to data requirements (can } \\
\text { use both monetary values or physical quantities for } \\
\text { inputs and outputs) } \\
(+) \text { No need to specify the form of the production } \\
\text { function } \\
(-) \text { Results might change if analysis extended to } \\
\text { other countries }{ }^{42}\end{array}$ \\
\hline $\begin{array}{l}\text { Stochastic } \\
\text { frontier analysis }\end{array}$ & & $\begin{array}{l}\text { OECD sectoral analysis } \\
\text { (Kuosmanen 2013) }\end{array}$ & $\begin{array}{l}\text { (+) Does not assume efficiency } \\
(+) \text { Flexible with respect to data requirements } \\
(+) \text { Allows hypothesis testing } \\
(+) \text { Accounts for measurement error } \\
(-) \text { Need to specify the form of the production } \\
\text { function. } \\
(-) \text { Need to specify the form of the inefficiency term. }\end{array}$ \\
\hline
\end{tabular}

\section{Methodological choices for the OECD series of EAMFP indicators}

In practice, the growth accounting approach is a tool used primarily by national statistical offices and other regular indicator producers; within the OECD it has been used by the Statistics Directorate to produce the OECD Productivity database. In contrast, econometric approaches are more frequently used in the context of individual studies for policy analysis purposes; within the OECD such methods have been used, among others, by the Economics Department to produce the Economic Outlooks database.

For reasons of consistency with the existing approaches to traditional OECD productivity measures, the use of the growth accounting approach has been identified as the preferred choice for calculating a suite of EAMFP statistics that will be periodically produced for the OECD Green Growth indicator series.

The alternative methods constitute a potentially valuable complement to the growth accounting approach. Looking forward, the set of EAMFP indicators could be usefully complemented with productivity statistics based on alternative methodological approaches, for several reasons:

i) Ability to conduct robustness checks;

ii) Applications of econometric and frontier methods do not require inputs to be valued in monetary units which might be difficult to estimate for some countries, natural resources and pollutants; yet data on physical quantities might be available. An alternative productivity measurement tool would thus allow indicators to be derived with extended coverage of countries, resources and pollutants;

\footnotetext{
${ }^{42}$ Only if the most efficient countries worldwide are not included in the sample.
} 
iii) Applications of frontier methods would allow benchmarking countries' performance by identifying efficiency gaps (technical and allocative efficiency) which is not possible using the growth accounting approach. Information on efficiency gaps is useful to identify potential for productivity improvements. 


\section{ANNEX 2. RETURNS TO SCALE PROPERTIES}

The transformation function used in this paper is homogeneous of degree 1 in inputs and $\theta$ in good and undesirable outputs such that $H(\lambda . Y, \lambda . R, L, K, S, t)=\lambda^{\theta} \cdot H(Y, R, L, K, S, t)$. In this paper, no assumption is made on $\theta$ and therefore on the returns to scale properties of the function. This parameter is country-specific i.e. each country has its own returns to scale properties. Three cases can be distinguished:

- If $\theta=-1$ then production exhibits constant returns to scale (CRS): Increasing inputs by a factor $\lambda$, increases $\lambda$ times output and pollution.

- If $\theta>-1$ then production exhibits decreasing returns to scale (DRS): Increasing inputs by a factor $\lambda$, increases less than $\lambda$ times output and pollution.

- If $\theta<-1$ then production exhibits increasing returns to scale (IRS): Increasing inputs by a factor $\lambda$, increases more than $\lambda$ times output and pollution.

This parameter can be inferred from our estimation results. As $\mathrm{H}$ is homogeneous of degree $\theta$ in good and undesirable outputs, it can be derived that: $\theta_{i}=\sum \varepsilon_{H R j i}+\varepsilon_{H Y i}=\frac{\sum \beta_{j i}-1}{\gamma_{i}}$. In order to test this equation and obtain the average returns to scale property of the countries in our dataset ${ }^{43}$, we conduct a Wald test on the average coefficients of our preferred random coefficient model. The null hypothesis of the equality $\theta=-1$ is not rejected at the 0.05 significance level, suggesting that, on average, OECD and G20 countries exhibit constant returns to scale in environmentally adjusted output.

Note that returns-to-scale properties are in terms of both good and undesirable outputs. This is different from the returns-to-scale properties expressed in terms of good output only. As mentioned in Section 2, the transformation function is increasing in pollution and decreasing in output, this means that a drop of pollution triggers a drop of production. For example, if inputs are increased by a factor $\lambda$ and pollution is required to remain constant, output may still increase but less than the unconstrained pollution scenario. As a result, one could expect countries exhibiting constant returns to scale in both good output and pollution, but constant or decreasing returns to scale in good output only. Since an average country in our sample exhibits constant returns to scale, such results are consistent with other research finding constant or decreasing returns to scale in good output only.

\footnotetext{
${ }^{43}$ It is not possible to obtain the standard errors of country-specific coefficients with a random coefficient models estimated with the maximum likelihood approach. Thus, we cannot run a similar test for each country. However, the parameter $\theta_{i}$ remains country-specific, meaning that each country exhibits specific returnsto-scale properties.
} 


\section{ANNEX 3. ADDITIONAL REGRESSION RESULTS}

\section{Econometric estimation method}

Random coefficient models can be estimated in two alternative ways that are described as the first and second generations of random coefficient models by Greene (2008, p.223). The first generation uses a generalized least squares (GLS) estimator relying on the estimation of country-specific OLS regression for each country. This first-generation approach is not feasible in our case given the relatively short panel and the large number of regressors in the estimation equation (e.g. year dummies). The second generation of random coefficient models does not face the same shortcomings. It is based on a simulated maximum likelihood estimator and requires the intercept and the coefficients to follow a multivariate normal distribution ${ }^{44}$. In this paper, the latter approach is used to estimate the elasticities of pollution ${ }^{45}$.

Concerning the results shown in Table 2 (see Section 4), the likelihood ratio tests suggest that heterogeneity in the intercept is not rejected at the $1 \%$ level, i.e. the fixed effect and random effect specifications are preferred to the OLS. Moreover, the Hausman test shows support for the random effect specification against the fixed effect specification. Due to the large number of random coefficients in specification (4), we are not able to run a test comparing it with specification (3). Instead, we conduct a likelihood ratio test comparing specification (5) with the equivalent random-effects specification including only $\mathrm{CO}_{2}, \mathrm{CH}_{4}$ and NMVOC as pollutants. The test suggests that the random coefficient model of specification (5) is strongly favoured (at the $1 \%$ significance level) to the random effects model. This test confirms our preference for the RCM estimation method. Finally, specification (4) is preferred to specification (5) for two reasons: first, by including all pollutants in the estimation the coefficients take into account the effects of non-significant pollutants on GDP growth; second, the Bayesian Information Criterion (BIC) indicates that, even with additional regressors, specification (4) is preferred to specification (5). Additionally, we test for the stationarity of output growth and the covariates. The null hypothesis of all panels containing a unit root is strongly rejected for all variables using the augmented Dickey-Fuller test.

\section{Results for separate regression equations on the full sample}

Under this approach, each pollutant's elasticity is estimated separately. This allows investigating the correlation between pollutants, and the effect of each pollutant on GDP growth. As shown in Table A3.1, all pollutants have a positive and strongly significant coefficient. Compared with the pooled estimation (Table 2, Section 4), the coefficients of $\mathrm{CO}_{2}, \mathrm{CH}_{4}$ and NMVOC are on average $30 \%$ higher when estimated separately. This suggests that the correlation between pollutants might cause an omitted variable bias in the separate equations, artificially inflating the coefficient.

\footnotetext{
${ }^{44}$ For more details see Greene (2008, p. 222-225) and Wooldridge (2010, p. 377-381). For an introduction to Stata functions related to RCM, see Rabe-Hesketh and Skrondal (2005). Finally, for an application of RCM to estimate pollution shadow prices, see Richmond et al. (2007).

${ }^{45}$ Note that the intercept in the regression gives an estimate of EAMFP growth for each country, each year. This estimate of EAMFP growth appears to be very similar on average to the one obtained in Section 5. The only difference between the two comes from the fact that the intercept in the regression does not allow EAMFP to change differently over time for different countries.
} 
Table A3.1. RCM regression results with pollutants included separately (full sample)

\begin{tabular}{|c|c|c|c|c|c|c|c|c|}
\hline $\begin{array}{l}\text { Dependent variable: } \\
\text { GDP growth }\end{array}$ & $\mathrm{CO} 2$ & $\mathrm{CH} 4$ & $\mathrm{~N} 2 \mathrm{O}$ & NOX & SOX & $\mathrm{CO}$ & NMVOC & PM10 \\
\hline Total factor inputs growth & 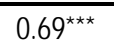 & $0.77^{\star \star \star}$ & $0.76^{\star \star \star}$ & $0.76^{\star \star \star}$ & $0.78^{\star \star \star}$ & $0.79 * \star \star$ & $0.78^{\star \star *}$ & $0.81^{\star \star *}$ \\
\hline CO2 growth & $0.16^{\star \star \star}$ & & & & & & & \\
\hline $\mathrm{CH} 4$ growth & & $0.13^{\star *}$ & & & & & & \\
\hline N2O growth & & & $0.06^{\star *}$ & & & & & \\
\hline NOX growth & & & & $0.07^{\star * \star}$ & & & & \\
\hline soX growth & & & & & $0.03^{\star \star \star}$ & & & \\
\hline CO growth & & & & & & $0.04^{\star *}$ & & \\
\hline NMVOC growth & & & & & & & $0.12^{\star \star *}$ & \\
\hline PM10 growth & & & & & & & & $0.05^{\star \star \star}$ \\
\hline $\mathrm{BIC}$ & 5289.09 & 5356.06 & 5372.61 & 5013.24 & 4949.62 & 4357.87 & 4317.22 & 4375.68 \\
\hline $\mathrm{N}$ & 1127 & 1127 & 1127 & 1050 & 1030 & 894 & 893 & 907 \\
\hline Year dummies & Yes & Yes & Yes & Yes & Yes & Yes & Yes & Yes \\
\hline
\end{tabular}

\section{Results for the restricted samples}

As explained above (Section 3), whenever possible, data on labour and produced capital are taken from the OECD Productivity database which currently covers 20 OECD countries ${ }^{46}$ for 1990-2013; for these countries the user cost of capital is calculated exogenously (hereafter, referred to as the PRODB panel). For the remaining countries, data on labour and produced capital are taken from the Total Economy Database, including 31 countries $^{47}$ for $1990-2013$, and the user cost of capital is calculated endogenously (hereafter, referred to as the TED panel). As a robustness exercise, the econometric analysis is conducted separately for the two sub-samples.

\section{The OECD Productivity Database subsample}

Similarly to the results using the full sample, in the PRODB panel GDP growth and input growth are positive on average (Table A3.2). However, for these countries emissions of $\mathrm{CO}_{2}$ and all other pollutants have been decreasing on average. The correlations between pollutants (not reported) are similar to those in the full sample.

46 Australia, Austria, Belgium, Canada, Denmark, Finland, France, Germany, Ireland, Italy, Japan, Korea, Netherlands, New Zealand, Portugal, Spain, Sweden, Switzerland, United Kingdom and United States.

47 Argentina, Brazil, Bulgaria, Chile, People’s Republic of China, Colombia, Costa Rica, Croatia, Cyprus, Czech Republic, Estonia, Greece, Hungary, Iceland, India, Indonesia, Israel, Latvia, Lithuania, Luxembourg, Malta, Mexico, Norway, Poland, Romania, Russian Federation, Saudi Arabia, Slovak Republic, Slovenia, South Africa, Turkey. 
Table A3.2. Summary statistics for the PRODB panel (20 countries)

\begin{tabular}{|c|c|c|c|c|c|c|}
\hline Variable & & Mean & Std. Dev. & Min & Max & Observations \\
\hline \multirow[t]{3}{*}{ GDP growth } & overall & 1.90 & 2.39 & -8.27 & 8.70 & $N=298$ \\
\hline & between & & 1.08 & 0.16 & 4.73 & $\mathrm{n}=$ \\
\hline & within & & 2.17 & -7.90 & 5.87 & $T=14.9$ \\
\hline Total factor inputs & overall & 1.18 & 1.57 & -5.77 & 5.76 & $N=298$ \\
\hline \multirow[t]{2}{*}{ growth } & between & & 0.59 & 0.32 & 2.46 & $n=$ \\
\hline & within & & 1.45 & -6.15 & 5.52 & $T=14.9$ \\
\hline \multirow[t]{3}{*}{$\mathrm{CO}_{2}$ growth } & overall & -0.02 & 4.62 & -17.45 & 20.18 & $N=298$ \\
\hline & between & & 1.39 & -2.21 & 3.61 & $n=20$ \\
\hline & within & & 4.43 & -17.21 & 20.43 & $T=14.9$ \\
\hline \multirow[t]{3}{*}{$\mathrm{CH}_{4}$ growth } & overall & -1.05 & 2.03 & -6.45 & 5.10 & $N=298$ \\
\hline & between & & 1.30 & -3.65 & 1.08 & $n=20$ \\
\hline & within & & 1.57 & -5.85 & 3.83 & $T=14.9$ \\
\hline \multirow[t]{3}{*}{$\mathrm{N}_{2} \mathrm{O}$ growth } & overall & -1.21 & 5.17 & -39.76 & 16.98 & $N=298$ \\
\hline & between & & 1.45 & -4.92 & 1.42 & $\mathrm{n}=$ \\
\hline & within & & 4.96 & -40.08 & 16.66 & $T=14.9$ \\
\hline \multirow[t]{3}{*}{ NOx growth } & overall & -2.20 & 4.18 & -20.32 & 11.54 & $N=298$ \\
\hline & between & & 1.93 & -4.48 & 2.36 & $n=$ \\
\hline & within & & 3.72 & -18.19 & 12.05 & $T=14.9$ \\
\hline \multirow[t]{3}{*}{ SOx growth } & overall & -5.08 & 8.67 & -30.76 & 24.15 & $N=$ \\
\hline & between & & 4.19 & -13.01 & 1.56 & $n=$ \\
\hline & within & & 7.73 & -26.87 & 25.44 & $T=14.9$ \\
\hline \multirow[t]{3}{*}{ CO growth } & overall & -3.54 & 4.30 & -19.59 & 16.98 & $N=298$ \\
\hline & between & & 2.05 & -8.27 & 0.83 & $n=$ \\
\hline & within & & 3.83 & -20.33 & 16.23 & $T=14.9$ \\
\hline \multirow[t]{3}{*}{ NMVOC growth } & overall & -2.50 & 3.68 & -18.81 & 12.35 & 298 \\
\hline & between & & 2.06 & -5.66 & 2.42 & $\mathrm{n}=$ \\
\hline & within & & 3.07 & -19.51 & 13.31 & $T=14.9$ \\
\hline \multirow[t]{3}{*}{$\mathrm{PM}_{10}$ growth } & overall & -1.46 & 7.22 & -59.00 & 51.01 & $N=298$ \\
\hline & between & & 2.64 & -5.44 & 7.16 & $\mathrm{n}=$ \\
\hline & within & & 6.75 & -55.02 & 42.40 & $T=14.9$ \\
\hline
\end{tabular}

While in the full sample all pollutants have a strongly significant coefficient, now only a few pollutants remain significant (Table A3.3). Interestingly, NMVOC does not have a significant impact on GDP growth in this setup. These results are a likely consequence of the small sample size, as it is now less than a half of the full sample. 
Table A3.3. Regression results with pollutants included separately (PRODB panel, 20 countries)

\begin{tabular}{|c|c|c|c|c|c|c|c|c|}
\hline $\begin{array}{l}\text { Dependent } \\
\text { variable: GDP } \\
\text { growth }\end{array}$ & $\mathrm{CO} 2$ & $\mathrm{CH} 4$ & $\mathrm{~N} 2 \mathrm{O}$ & NOX & sox & $\mathrm{CO}$ & NMVOC & PM10 \\
\hline $\begin{array}{l}\text { Total factor } \\
\text { inputs growth }\end{array}$ & $0.81^{* \star *}$ & $0.85^{\star * *}$ & $0.85^{* * *}$ & $0.87^{* * *}$ & $0.85^{* * *}$ & $0.90^{* * *}$ & $0.88^{* * *}$ & $0.88^{* * *}$ \\
\hline CO2 growth & $0.04^{*}$ & & & & & & & \\
\hline $\mathrm{CH} 4$ growth & & $0.06^{\star *}$ & & & & & & \\
\hline N2O growth & & & $0.00 E+00$ & & & & & \\
\hline NOX growth & & & & 0.02 & & & & \\
\hline sox growth & & & & & $0.02^{\star \star *}$ & & & \\
\hline CO growth & & & & & & 0.01 & & \\
\hline NMVOC growth & & & & & & & 0.04 & \\
\hline PM10 growth & & & & & & & & $0.02^{*}$ \\
\hline$B I C$ & 1571.75 & 1588.32 & 1591.41 & 1543.02 & 1522.5 & 1185.88 & 1165.36 & 1210.15 \\
\hline$N$ & 464 & 464 & 464 & 455 & 450 & 358 & 355 & 366 \\
\hline Year dummies & Yes & Yes & Yes & Yes & Yes & Yes & Yes & Yes \\
\hline
\end{tabular}

In the estimation of all pollutants simultaneously, only $\mathrm{CH}_{4}$ and $\mathrm{SO}_{\mathrm{X}}$ are significant in some specifications (Table A3.4). Again, these results should be taken carefully, given the small sample size.

Table A3.4. Pooled estimation results (PRODB panel, 20 countries)

\begin{tabular}{|c|c|c|c|c|c|}
\hline Dependent variable: & (1) & (2) & (3) & (4) & (5) \\
\hline GDP growth & OLS & $F E$ & $R E$ & $R C M$ & $R C M$ \\
\hline Total factor inputs growth & $0.88^{* * *}$ & $0.84^{* * *}$ & $0.84^{* * *}$ & $0.90^{* * *}$ & $0.87^{* * *}$ \\
\hline CO2 growth & 0.02 & -0.02 & -0.02 & -0.02 & 0.02 \\
\hline $\mathrm{CH} 4$ growth & 0.04 & $0.07^{*}$ & $0.06^{*}$ & $0.07^{* *}$ & $0.06^{*}$ \\
\hline N2O growth & $\begin{array}{c}1.10 E- \\
02\end{array}$ & $-2.00 E-03$ & $5.30 E-04$ & $1.10 E-03$ & \\
\hline NOX growth & -0.02 & $1.00 E-02$ & $0.00 E+00$ & 0.01 & \\
\hline soX growth & 0.01 & $0.02^{*}$ & $0.02^{*}$ & $0.02^{* *}$ & \\
\hline CO growth & -0.01 & 0.01 & $2.50 E-03$ & $9.80 E-05$ & \\
\hline NMVOC growth & 0.06 & 0.01 & 0.02 & 0.01 & 0.03 \\
\hline PM10 growth & 0.01 & $-2.60 E-04$ & $2.10 E-03$ & 0.01 & \\
\hline$B I C$ & 1003.25 & 888.85 & 1037.08 & 921.33 & 1157.2 \\
\hline$N$ & 298 & 298 & 298 & 298 & 355 \\
\hline Year dummies & Yes & Yes & Yes & Yes & Yes \\
\hline
\end{tabular}

\section{The Total Economy Database subsample}

As expected, the average output growth rate is higher in the TED panel than in the PRODB panel (3.84 compared to 1.90) because the former sub-sample includes also many emerging and (former) transition economies that have experienced important growth rates over the last 20 years (e.g. BRIICS countries). Moreover, some pollutants have been increasing over time for TED countries, including $\mathrm{CO}_{2}$, $\mathrm{CH}_{4}$ and $\mathrm{NO}_{\mathrm{X}}$. This difference in trends partly explains why MFP has often been overvalued in the TED panel and often undervalued in the PRODB panel (Table A3.5). 
Table A3.5. Summary statistics for the TED sub-sample (31 countries)

\begin{tabular}{|c|c|c|c|c|c|c|}
\hline Variable & & Mean & Std. Dev. & Min & Max & Observations \\
\hline \multirow[t]{3}{*}{ GDP growth } & overall & 3.84 & 4.38 & -14.81 & 21.83 & $N=489$ \\
\hline & between & & 1.80 & 1.15 & 10.48 & $n=31$ \\
\hline & within & & 3.98 & -15.66 & 20.31 & $T=15.7742$ \\
\hline \multirow[t]{3}{*}{ Total factor inputs growth } & overall & 2.87 & 2.76 & -11.50 & 11.60 & $N=489$ \\
\hline & between & & 1.52 & -1.07 & 5.79 & $n=$ \\
\hline & within & & 2.29 & -10.42 & 11.79 & $T=15.7742$ \\
\hline \multirow[t]{3}{*}{ CO2 growth } & overall & 1.60 & 4.95 & -19.54 & 19.13 & $N=489$ \\
\hline & between & & 2.60 & -3.60 & 6.54 & $n=$ \\
\hline & within & & 4.25 & -17.03 & 20.57 & $T=15.7742$ \\
\hline \multirow[t]{3}{*}{ CH4 growth } & overall & 0.40 & 2.82 & -10.04 & 14.66 & $N=$ \\
\hline & between & & 1.57 & -2.65 & 3.52 & $n=$ \\
\hline & within & & 2.32 & -8.53 & 15.07 & $T=15.7742$ \\
\hline \multirow[t]{3}{*}{ N2O growth } & overall & -0.26 & 4.77 & -35.17 & 19.82 & $N=489$ \\
\hline & between & & 1.73 & -4.31 & 2.63 & $n=31$ \\
\hline & within & & 4.45 & -36.10 & 21.96 & $T=15.7742$ \\
\hline \multirow[t]{3}{*}{ NOX growth } & overall & 0.46 & 5.39 & -25.26 & 20.20 & $N=489$ \\
\hline & between & & 2.31 & -4.95 & 4.65 & $n=31$ \\
\hline & within & & 4.91 & -22.93 & 19.58 & $T=15.7742$ \\
\hline \multirow[t]{3}{*}{ SOX growth } & overall & -1.84 & 8.69 & -36.68 & 27.04 & $N=489$ \\
\hline & between & & 4.38 & -11.75 & 4.40 & $n=$ \\
\hline & within & & 7.62 & -30.87 & 29.76 & $T=15.7742$ \\
\hline \multirow[t]{3}{*}{ CO growth } & overall & -1.98 & 7.32 & -33.79 & 24.63 & $N=489$ \\
\hline & between & & 2.78 & -9.50 & 4.63 & $n=31$ \\
\hline & within & & 6.76 & -27.06 & 25.61 & $T=15.7742$ \\
\hline \multirow[t]{3}{*}{ NMVOC growth } & overall & -0.77 & 4.99 & -18.48 & 17.45 & $N=489$ \\
\hline & between & & 2.30 & -7.98 & 2.73 & $n=$ \\
\hline & within & & 4.50 & -16.61 & 16.04 & $T=15.7742$ \\
\hline \multirow[t]{3}{*}{ PM10 growth } & overall & -1.06 & 12.64 & -69.25 & 108.95 & $N=489$ \\
\hline & between & & 3.01 & -11.06 & 2.76 & $n=$ \\
\hline & within & & 12.29 & -68.67 & 107.87 & $T=15.7742$ \\
\hline
\end{tabular}

Interestingly, in the TED panel all pollutants have significant coefficients (Table A3.6) while in the PRODB panel only a few are significant. This suggests that output growth in emerging and transition economies (the TED panel) is more dependent on emitting activities than in advanced economies (the PRODB panel). Finally, note that the coefficients are close to those obtained in Table 2 for the whole sample. 
Table A3.6. Regression results with pollutants included separately (TED panel, 31 countries)

\begin{tabular}{|c|c|c|c|c|c|c|c|c|}
\hline \multicolumn{9}{|l|}{ Dependent variable: } \\
\hline GDP growth & $\mathrm{CO} 2$ & $\mathrm{CH} 4$ & $\mathrm{~N} 2 \mathrm{O}$ & NOX & sox & $\mathrm{CO}$ & NMVOC & PM10 \\
\hline Total factor inputs growth & $0.62^{\star \star \star}$ & $0.70^{\star \star \star}$ & $0.69^{\star \star \star}$ & $0.68^{* \star *}$ & $0.71^{* * *}$ & $0.74^{* * *}$ & $0.73^{\star \star *}$ & $0.74^{\star \star *}$ \\
\hline CO2 growth & $0.21^{* \star *}$ & & & & & & & \\
\hline $\mathrm{CH} 4$ growth & & $0.16^{* *}$ & & & & & & \\
\hline N2O growth & & & $0.09^{* *}$ & & & & & \\
\hline NOX growth & & & & $0.08^{* *}$ & & & & \\
\hline soX growth & & & & & $0.04^{* *}$ & & & \\
\hline CO growth & & & & & & $0.05^{\star *}$ & & \\
\hline NMVOC growth & & & & & & & $0.15^{\star * \star}$ & \\
\hline PM10 growth & & & & & & & & $0.04^{* *}$ \\
\hline$B I C$ & 3431.57 & 3472.26 & 3479.86 & 3158.9 & 3101.38 & 2885.98 & 2874.85 & 2884.42 \\
\hline$N$ & 663 & 663 & 663 & 595 & 580 & 536 & 538 & 541 \\
\hline Year dummies & Yes & Yes & Yes & Yes & Yes & Yes & Yes & Yes \\
\hline
\end{tabular}

Based on results shown in Table A3.7, $\mathrm{CO}_{2}$ and NMVOCs are significant in our preferred RCM specification (column 4), $\mathrm{CH}_{4}$ does not have a significant effect in this sub-sample probably due to a sample size issue. The high significance of the coefficient of $\mathrm{CO}_{2}$ reinforces the predominant role of these emissions for output growth.

Table A3.7. Pooled estimation results (TED panel, 31 countries)

\begin{tabular}{|c|c|c|c|c|c|}
\hline Dependent variable: & (1) & (2) & (3) & (4) & (5) \\
\hline GDP growth & OLS & $F E$ & $R E$ & $R C M$ & $R C M$ \\
\hline Total factor inputs growth & $0.61^{* * *}$ & $0.62^{* * *}$ & $0.62^{* * *}$ & $0.59^{* * *}$ & $0.62^{* * *}$ \\
\hline CO2 growth & $0.24^{* \star *}$ & $0.26^{\star \star \star}$ & $0.25^{\star \star *}$ & $0.16^{* * *}$ & $0.15^{* * *}$ \\
\hline $\mathrm{CH} 4$ growth & 0.08 & 0.14 & $0.11^{*}$ & 0.1 & 0.11 \\
\hline N2O growth & 0.05 & 0.04 & 0.04 & 2.00E-04 & \\
\hline NOX growth & -0.07 & -0.07 & $-0.07^{* *}$ & 0.01 & \\
\hline sox growth & -0.02 & -0.02 & -0.02 & -0.01 & \\
\hline CO growth & -0.02 & -0.03 & -0.02 & -0.01 & \\
\hline NMVOC growth & $0.09^{* *}$ & 0.07 & $0.08^{* *}$ & $0.05^{*}$ & $0.07^{* *}$ \\
\hline PM10 growth & $1.60 E-03$ & $3.10 E-03$ & $2.40 E-03$ & $4.50 E-03$ & \\
\hline$B I C$ & 2634.51 & 2547.46 & 2629.78 & 2573.87 & 2842 \\
\hline$N$ & 489 & 489 & 489 & 489 & 538 \\
\hline Year dummies & Yes & Yes & Yes & Yes & Yes \\
\hline
\end{tabular}




\section{ANNEX 4. POLLUTION ABATEMENT COSTS}

The elasticities of output with respect to pollution estimated based on the economy's performance during the past 20 years (Section 4) serve as a proxy for the implicit cost of pollution abatement. As such, they can provide information on the implicit cost of future emission reduction targets and help assess the effectiveness of environmental policies in internalising externalities. The abatement costs of pollution are given by the elasticities of GDP with respect to different pollutants $\left(\varepsilon_{Y R}\right)$. They should be understood as the percentage change in output growth that has historically (in the last 20 years) followed by marginal changes in pollution growth.

As highlighted in Section 4, marginal abatement costs (i.e. elasticities) differ across countries. This heterogeneity implies that it has been more costly to reduce emissions in some countries than in others. To illustrate this point, we estimate the impact of one additional percent decrease of $\mathrm{CO}_{2}$ emissions on countries' annual GDP growth in the last 20 years (Figure A4.1). This impact is directly given by equation [6] when all other variables - labour, produced capital, natural capital as well as productivity growth - are held constant:

$$
\frac{\partial \ln Y}{\partial t}=\varepsilon_{Y R} \frac{\partial \ln R}{\partial t}
$$

Figure A4.1. Annual cost of abating $\mathrm{CO}_{2}$ emissions by $1 \%$ per year

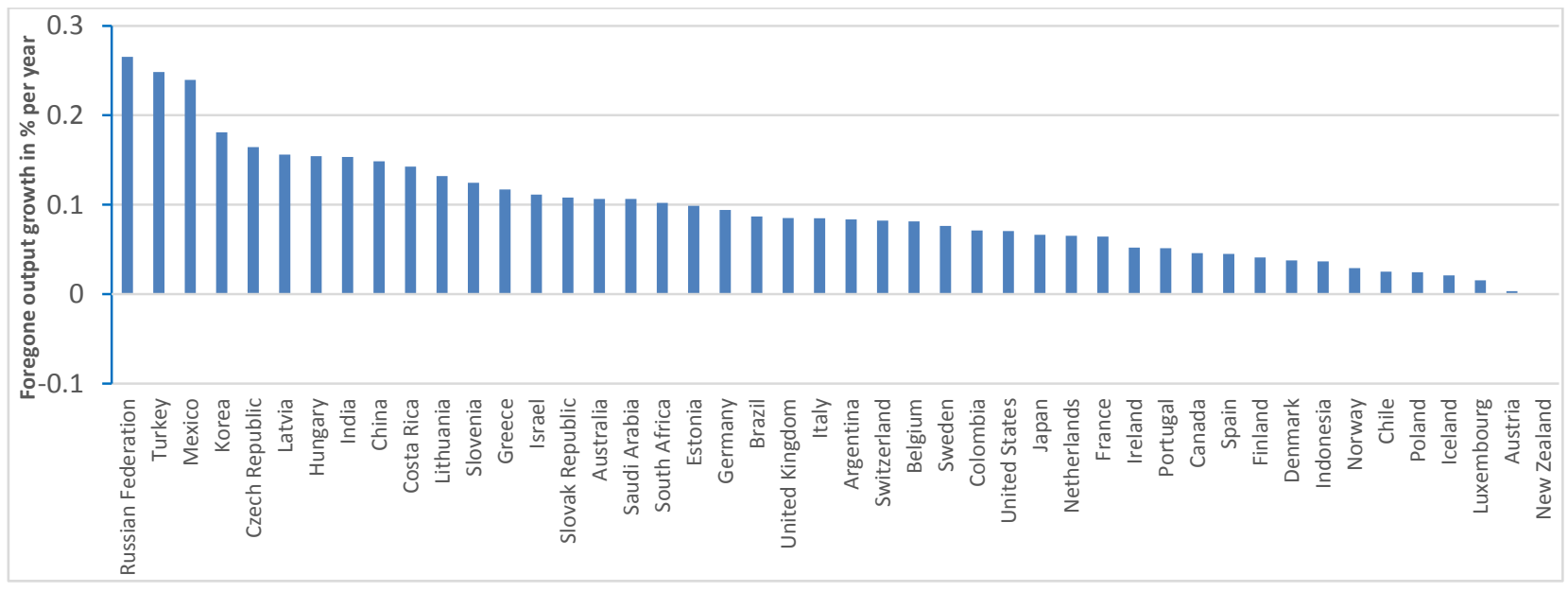

The cost of $\mathrm{CO}_{2}$ abatement is highest in countries where output growth has been most dependent on increasing pollution emissions, such as Russia, Turkey and Mexico (0.25 percentage points of output growth per year). By contrast, countries like Luxembourg, Iceland or Poland have had a much lower cost of reducing $\mathrm{CO}_{2}$ emissions ( 0.009 points of output growth per year) because, over time, they have achieved a lower dependency on dirty technologies to generate income. The cost of abatement can even be negative when countries succeed to reduce $\mathrm{CO}_{2}$ emissions while generating more output at the same time, such as in New Zealand. ${ }^{48}$ Looking forward, it is reasonable to believe that even for these countries additional $\mathrm{CO}_{2}$ abatement (on top of what they achieved in the past 20 years) will be more costly, at least beyond a certain level of abatement.

\footnotetext{
${ }^{48}$ See Section 4 for more explanation of this negative relationship between pollution and output.
} 
Next, to put these numbers in perspective and to account for the size of the economies, we express these percentages of growth in US dollars. That is, multiplying equation [15] by the value of GDP for a given year yields the cost (in USD) of abating one additional percentage point of $\mathrm{CO}_{2}$ emissions (Table A4.1). This gives a more concrete idea of the magnitude of the cost and could allow an assessment of cost effectiveness of environmental policies. Pollution abatement costs depend on countries' elasticities of output with respect to pollution and GDP, thus, for two countries with the same ambition of environmental regulations and the same level of technology (i.e. same elasticities) but with different sizes, the larger one will face a higher abatement cost.

Table A4.1. Cost of abating an additional percentage of CO2 in 2012 (million USD 2005 using PPP)

\begin{tabular}{rr|rr|rr}
\hline Country & Cost & Country & Cost & Country & Cost \\
\hline China & 19607 & Romania & 603 & Ireland & 93 \\
United States & 9933 & Canada & 591 & Costa Rica & 80 \\
India & 8383 & Spain & 561 & Lithuania & 75 \\
Russia & 5784 & Czech Republic & 425 & Finland & 72 \\
Mexico & 3785 & Netherlands & 423 & Norway & 70 \\
Germany & 2757 & Colombia & 352 & Denmark & 70 \\
Korea & 2732 & Belgium & 308 & Chile & 69 \\
Japan & 2643 & Switzerland & 275 & Slovenia & 63 \\
Turkey & 2532 & Greece & 270 & Latvia & 53 \\
Brazil & 2337 & Hungary & 267 & Estonia & 25 \\
United Kingdom & 1863 & Sweden & 262 & Cyprus & 19 \\
Italy & 1416 & Israel & 256 & Austria & 10 \\
Saudi Arabia & 1361 & Poland & 173 & Luxembourg & 5 \\
France & 1311 & Bulgaria & 155 & Iceland & 2 \\
Australia & 926 & Croatia & 150 & New Zealand & -1 \\
Indonesia & 748 & Slovak Republic & 126 & Malta & -4 \\
Argentina & 650 & Portugal & 113 & & \\
\hline
\end{tabular}

When interpreting these abatement costs, one should keep in mind that: the cost estimates are valid only for marginal changes in pollution abatement because the underlying elasticities will likely change as more stringent policies are put in place: (i) low-cost opportunities for additional emissions reductions become scarcer and (ii) new abatement technologies might be deployed that were not economical in the past (see discussion in Section 4 and Annex 5). Second, the historic abatement costs should be used carefully to make forecasts; performance in the past 20 years might not accurately reflect future costs as new technologies, or other conditions, might lower the cost of reducing pollution in the future. Third, these are the costs that producers face when abating emissions, which are likely different from the cost that pollution represents for society. 


\section{ANNEX 5. SHADOW PRICES OF POLLUTION}

\section{Review of methodologies to estimate shadow prices of pollution}

The academic literature on shadow prices largely developed with the application of non-market valuation methods to study real estate markets (e.g. estimate the values of proximity to businesses, commerce or cultural amenities that are implicit in land prices). Later, this approach was applied to study also negative environmental externalities and to derive the implicit value of pollution. To date, most papers focus only on a limited number of pollutants; some study only $\mathrm{CO}_{2}$ emissions (e.g., Wei et al., 2013; APC, 2011) or only $\mathrm{SO}_{\mathrm{x}}$ emissions (e.g., Swinton, 2002; Färe et al., 2005). The countries studied include, predominantly the US and a limited sample of other countries (mostly OECD), frequently involving industry-level analyses in a single country; only a few studies covered a larger sample of countries (to our knowledge, the largest sample was covered by Salnykov and Zelenyuk 2005 who included 96 countries).

The shadow prices of pollution are derived from the observed behaviour of firms (production of output and use of inputs) given the constraints they face (output and input prices). Most papers build on functions describing the production process, such as distance functions (e.g. Färe et al., 1993, among many others), cost functions (e.g. Van Soest et al., 2005), or transformation functions (e.g., Brandt et al., 2014), and rely on a profit-maximisation problem to derive pollution shadow prices. Shadow prices are therefore estimated from a producer's perspective: they only give an indication of the implied cost that firms face when they emit less one extra unit of pollution. The families of functions used to derive shadow prices are similar to those related to efficiency and productivity measurement. They can be classified into two groups: those based on output distance functions, and those that rely on parametric functions.

Output distance functions are the most widely used type of distance functions used in shadow price estimations. A large majority of papers build on the work of Färe et al. (1993) who introduced pollution in the multi-output distance function framework developed by Shepard $(1970)^{49}$. They give a value of the maximal and proportional expansion of the output vector, given an input vector. In OECD work, Dang and Mourougane (2014), among others, followed this approach. Other forms of distance functions have also been used in the literature, such as input distance functions that compute the maximal and proportional contraction of the input vector given an output vector. (e.g. Coelli et al., 2013; Koundouri et al., 2012), or directional output distance functions that allow for a simultaneous expansion of good outputs and decrease of bad outputs (e.g. Färe et al., 2005). The homogeneity properties of different distance functions are described in e.g. Cuesta et al. (2009).

The second group of papers use more traditional functions such as cost functions, production functions or transformation functions. For example, cost functions and cost-minimisation assumptions have often been used to derive shadow prices (e.g., Dachraoui and Harchaui, 2004; Van Soest et al., 2005). Other papers consider an explicit production function (e.g. a Cobb-Douglas) and use the fact that the marginal productivity of each factor should equal its price (e.g. Richmond et al., 2007). In the same vein, Brandt et al. (2014) used a transformation function and a profit-maximisation problem to derive a relationship between shadow prices and elasticities.

Finally, an alternative distinction can be made between papers that impose a certain functional form on the modelled relationship or not. For example, a translog parametric form is often imposed on output distance functions; in this case, stochastic frontier analysis (SFA) is then used to estimate shadow prices.

\footnotetext{
49 The growth accounting equation can also be computed using a multi-output distance function such as the one defined by Shepard (1970), making the growth accounting approach fully consistent with the literature on efficiency.
} 
When the function remains non-parametric under the distance function approach, data envelopment analysis (DEA) can be conducted. For the second group of functions, the distinction between parametric and non-parametric also holds. For example, while cost functions are sometimes approximated by a translog function (e.g., Dachraoui and Harchaoui, 2004), Brandt et al. (2014) kept a non-parametric transformation function.

\section{Calculation of implied shadow prices}

Using a methodology similar to that discussed in Section 2.2.3, pollutant shadow prices can be obtained from the estimated elasticities. The profit-maximisation problem of a firm can be written as follows:

$$
\begin{gathered}
\operatorname{Max} P_{Y} \cdot Y+\sum P_{R_{j}} \cdot R_{j}-w . L-u_{K} \cdot K-u_{S} . S \\
\text { s.t. } H\left(Y, \sum R_{j}, L, K, S, t\right) \geq k
\end{gathered}
$$

Solving for the first-order conditions with respect to good output and pollutants yields:

$$
\begin{gathered}
P_{Y}=-\lambda . H_{Y} ; P_{R_{j}}=-\lambda . H_{R_{j}} \quad \forall j \in[1 ; 8] \\
\text { together with } \lambda .\left(H\left(Y, \sum R_{j}, L, K, S, t\right)-k\right)=0 \quad \text { and } \lambda \geq 0
\end{gathered}
$$

Using the total value of outputs $\rho$ and applying the Euler theorem on a homogeneous function of degree $\theta$ in outputs, one can obtain:

$$
\rho=P_{Y} \cdot Y+\sum P_{R_{j}} \cdot R_{j}=-\lambda \cdot\left(H_{Y} \cdot Y+\sum H_{R_{j}} \cdot R_{j}\right)=-\lambda \cdot H \cdot \theta
$$

This gives:

$$
\begin{gathered}
\varepsilon_{H Y}=\frac{H_{Y} Y}{H}=-\frac{P_{Y} Y}{\lambda \cdot H}=\frac{\theta P_{Y} Y}{\rho} \\
\varepsilon_{H R_{j}}=\frac{H_{R_{j}} R_{j}}{H}=-\frac{P_{R_{j}} R_{j}}{\lambda . H}=\frac{\theta P_{R_{j}} R_{j}}{\rho} \quad \forall j \in[1 ; 8]
\end{gathered}
$$

Using $\varepsilon_{H Y}$ and rearranging the equation for $\varepsilon_{H R_{i}}$ yields:

$$
P_{R_{j}}=P_{Y} * \frac{Y}{R_{j}} * \frac{\varepsilon_{H R_{j}}}{\varepsilon_{H Y}} \quad \forall j \in[1 ; 8]
$$

The intuition behind the profit-maximisation problem above is the following: A positive elasticity of output with respect to emissions implies that firms can produce more only if they emit more pollution. There exists no such price of emissions for firms which would allow emissions to be unconstrained. And since the quantities of emissions produced by firms are constrained, there is a cost of emitting pollution. Therefore, the implied shadow prices computed above represent the costs in terms of the foregone income from polluting one extra unit. The prices are expected to be negative because they represent a cost to firms. As explained in Section 4, these private costs of pollution are a joint outcome of several factors, including environmental policies and available abatement technology. Thus, pollution shadow prices represent a firm's effective cost of emissions and can serve as a proxy for how internalized are pollution effects from the producer's perspective. 


\section{Empirical results}

The evolution of estimated shadow prices of $\mathrm{CO}_{2}$ in selected countries is displayed in Figure A5.1. It shows that in most countries pollution shadow prices have grown in magnitude over time (have become even more negative $)^{50}$, probably in response to the introduction of more ambitious environmental policies, and other factors. Saudi Arabia is a notable exception with shadow prices having actually diminished in magnitude (become less negative) and this could be the result many factors such as less stringent environmental regulation or structural changes (see Section 4).

Figure A5.1. Shadow price per tonne of $\mathrm{CO}_{2}$ (USD 2005 PPP)

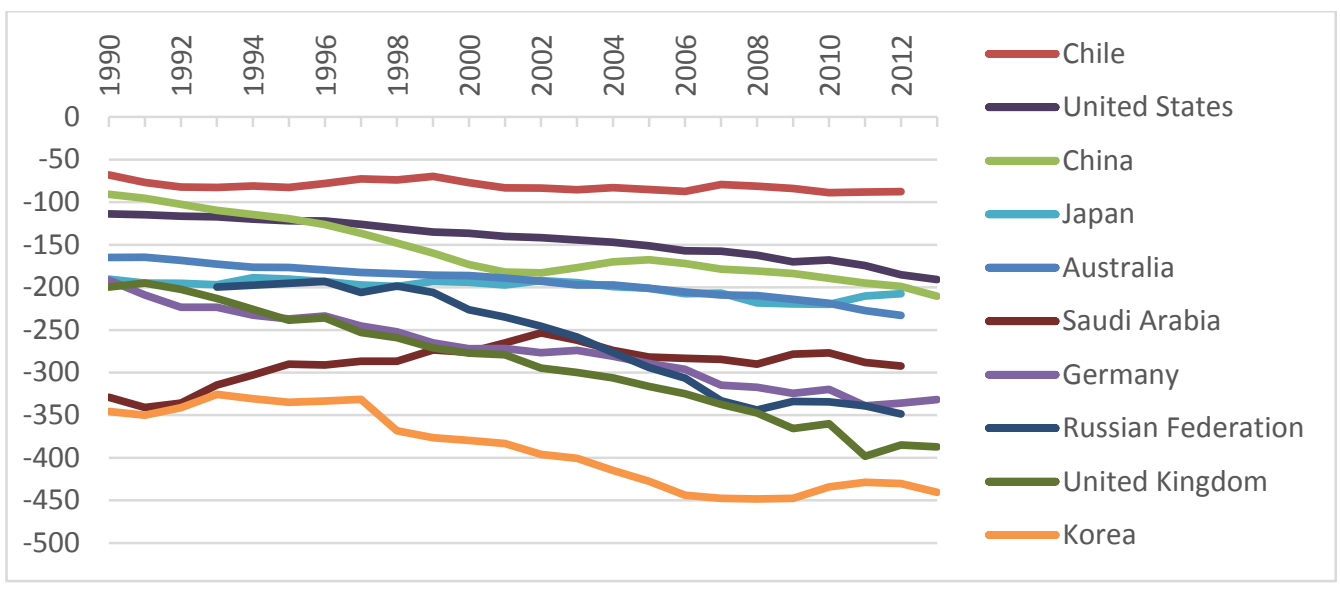

Figure A5.2 shows the average shadow prices for $\mathrm{CO}_{2}, \mathrm{CH}_{4}$, and NMVOC (in real terms, using constant USD) for all 51 countries, together with the range of estimated values within the 1991-2013 time period. The shadow prices of $\mathrm{CO}_{2}$ have been increasing over time (have become more negative) for most countries in our dataset. In absolute terms, average shadow prices per tonne of $\mathrm{CO}_{2}$ range between USD 221 in 1993 and USD 331 in 2012, with USD 1150 as the highest private cost attained in Costa Rica. In some cases the estimated prices have the opposite sign (New Zealand and Malta) ${ }^{51}$. However, in the vast majority of countries estimated shadow prices vary between USD 100 and USD 400, in absolute terms.

The shadow prices of $\mathrm{CH}_{4}$ and NMVOC have also been increasing (becoming more negative) over time in real terms. The heterogeneity of prices for $\mathrm{CH}_{4}$ and NMVOC is much larger than for $\mathrm{CO}_{2}$. For $\mathrm{CH}_{4}$, most countries have shadow prices between USD 100 and USD 5000 (in absolute terms) per tonne of $\mathrm{CO}_{2}$ equivalent (global warming potential).

NMVOC shadow prices are higher as in most countries they vary from USD 3000 to USD 100000 (in absolute terms) per tonne of NMVOC. All NMVOC prices have the expected sign because the elasticity of output with respect to this group of pollutants is positive, constant and homogeneous across countries (see Section 4). Interestingly, the magnitude of NMVOC prices is lowest in BRIICS countries while it is highest in many Western European countries.

\footnotetext{
${ }^{50}$ Note that shadow prices are negative since they represent the cost that producers face when abating pollution, thus, a more negative price implies higher costs.

${ }^{51}$ Shadow prices are positive when the elasticity of output with respect to pollution is negative (see Section 4 for a discussion).
} 
Figure A5.2. Estimated shadow prices of pollution (USD 2005 using PPP)
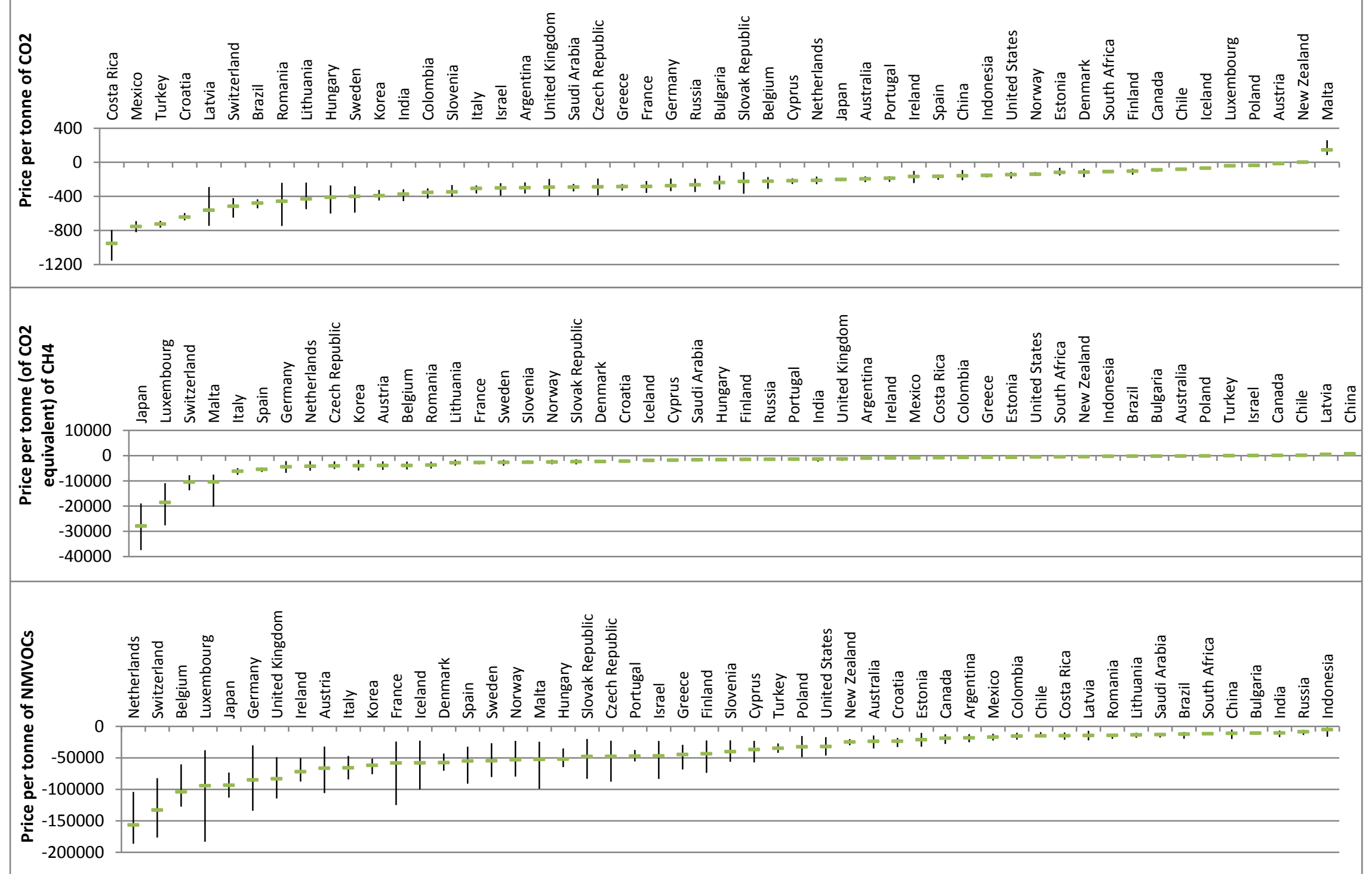


\section{Shadow price estimates in the literature}

Next, the shadow prices estimated in this paper are put in perspective and compared with three sets of figures: (i) producer shadow prices from previous research, (ii) actual marginal tax rates and (iii) estimates of the social cost of pollution. This short review is not intended to be exhaustive of the vast literature on shadow prices; besides, no comparable values were found for $\mathrm{CH}_{4}$ and NMVOC.

The $\mathrm{CO}_{2}$ shadow prices estimated in this paper are very close to those estimated by Brandt et al. (2014) and Dang and Mourougane (2014b). This is not surprising because the methodology and the data used are similar. Shadow prices close to USD 400 have also been found by Qi et al. (2004) using macro-level data on 44 countries over 1980-2000. ${ }^{52}$ Keilbach (1995) also found prices close to USD 400 for Western Germany between 1966 and 1990. Some studies found much lower $\mathrm{CO}_{2}$ shadow prices. For example, Resek and Campbell (2007) studied US electric power plants in 1998 and found a $\mathrm{CO}_{2}$ price of USD 22. Maradan and Vassiliev (2005) studied 76 countries in 1985 using a Kuznets curve approach and found that $\mathrm{CO}_{2}$ shadow prices were lower for developed countries (USD 2.1) than for emerging economies (USD 9.5).

Next, if shadow prices are a good proxy for environmental policy stringency then they can be compared to emission taxes or equilibrium prices in cap-and-trade systems. Concerning taxes on emissions, $\mathrm{CO}_{2}$ shadow prices appear to be above the actual tax rate in different countries. For example, in the UK the tax rate varied between USD 24 to 47 per tonne of $\mathrm{CO}_{2}$ between 2001 and 2004 (Pearce, 2006) while our estimates of $\mathrm{CO}_{2}$ shadow prices in the UK average USD 280 for the same period. This is not surprising because other policy instruments, in addition to carbon taxes, also determine the economy's shadow price. Similarly, British Columbia's tax on $\mathrm{CO}_{2}$ emissions was USD 25 in 2012 (Harrison, 2013) while the shadow price in Canada was USD 107 in the same year. Finally, the EU's Emissions Trading System (ETS) reached prices between USD 0 to 35 between 2006 and 2007 (Arlinghaus, 2015), which is below the estimated $\mathrm{CO}_{2}$ shadow prices for most European countries in those years.

Finally, shadow prices could be contrasted with estimates of the social cost of pollution to assess the extent to which externalities are being internalised. However, unlike shadow prices, social cost estimates cover both the private as well as the external cost of damages caused by an additional unit of pollution. Moreover, comparing shadow prices and social cost estimates is difficult because estimations of social costs depend on the choice of the discount factor, $\mathrm{CO}_{2}$ stock, and other parameters. For example, the social cost of one tonne of $\mathrm{CO}_{2}$ in the US in 2010 varies between USD 10 and 84 (Interagency Working Group on Social Cost of Carbon, 2013), which is below our estimates of USA's $\mathrm{CO}_{2}$ shadow prices equal to USD 185 in the same year (Smith and Braathen, 2015).

\section{Discussion}

While the structure of the economy and the availability of cleaner technologies determine a country's ability to reduce emissions (and hence the slope of the MAC curve - see Section 4), the level of emissions and their implicit price (where countries lie on the curve) are a function of regulatory stringency and its enforcement. Thus, differences in shadow prices of pollution can be interpreted as (i) differences in environmental policy ambition (e.g. power plant emission standards) and its enforcement, and (ii) differences in the producer's ability to reduce emissions (e.g. flat or steep portion of the marginal abatement cost curve, availability of cleaner production technologies).

\footnotetext{
${ }^{52}$ In this section, CO2 shadow prices, social costs and taxes taken from other papers are converted to 2005 USD using PPP when they are expressed in other currencies. For the Euro area, the German PPP value is used.
} 
Comparing shadow prices across countries is challenging due to the simultaneity of factors that influence them. For, example one could reasonably expect shadow prices to be higher when environmental regulation is more ambitious. However, this outcome also depends on the ability of countries to adjust production when facing such regulations. For example, firms in manufacturing industries with a low rate of capital turnover (thus a steep MAC curve) will have more difficulties to implement emissions reduction measures than firms in the services sector. Highly innovative firms might be able to more easily adapt to the changing regulation than technological laggards. Similarly, developing countries could be expected to have less stringent environmental regulation than some advanced economies and should therefore exhibit lower shadow prices. However, such countries might also have greater barriers to adoption of cleaner technologies (e.g. lower absorptive capacity), which makes it more difficult for them to cope with tighter regulations. In addition, pollution intensive industries often count for a greater share of the economy in developing countries than in advanced economies where the service sector is much more prominent. These last two characteristics could increase the economy-wide costs of pollution and reinforce the effect of environmental regulation on firms' costs.

Observing the evolution of shadow prices over time is nevertheless informative. For example, consider a scenario in which OECD countries implement on average tighter environmental regulations in the course of the last 20 years. At the same time, and partly because of this tighter regulation, firms develop and deploy less polluting technologies. Finally, the share of polluting industries in the economy goes down over time, at least in some countries. The first effect should trigger a rise in shadow prices while the second (innovation) and the third effects (structural changes) should push shadow prices down. The first effect will be reinforced if marginal abatement costs are increasing rapidly (i.e. the firm lies at the steep portion of the MAC curve). In such scenario an interpretation for the observed rise of shadow prices over the past 20 years (Figure A5.1) would then be that green technology development did not completely offset the effect of a tighter environmental regulation in OECD countries. 


\section{ANNEX 6. EAMFP VS. MFP}

The environmentally adjusted multifactor productivity (EAMFP) can be compared to the traditional measure of productivity (MFP) that does not take into account natural capital use as an input and pollution as an undesirable output. As such, the MFP can be seen as a special case of the EAMFP when pollution R and natural capital S are omitted.

Taking equation [5] and replacing elasticities as in Section 2.2 gives:

$$
\frac{d \ln E A M F P}{d t}=\frac{d \ln Y}{d t}+\frac{P_{R} R}{P_{Y} Y} \frac{d \ln R}{d t}-\frac{\rho P_{K} K}{\gamma P_{Y} Y} \frac{d \ln K}{d t}-\frac{\rho P_{L} L}{\gamma P_{Y} Y} \frac{d \ln L}{d t}-\frac{\rho P_{S} S}{\gamma P_{Y} Y} \frac{d \ln S}{d t}
$$

where $\gamma=\mathrm{P}_{\mathrm{K}} \mathrm{K}+\mathrm{P}_{\mathrm{L}} \mathrm{L}+\mathrm{P}_{\mathrm{S}} \mathrm{S}$ and $\rho=\mathrm{P}_{\mathrm{Y}} \mathrm{Y}+\mathrm{P}_{\mathrm{R}} \mathrm{R}$. When there is no pollution (R) and no natural capital $(\mathrm{S})$, MFP growth is equal to:

$$
\frac{d \ln M F P}{d t}=\frac{d \ln Y}{d t}-\frac{P_{K} K}{\gamma^{\prime}} \frac{d \ln K}{d t}-\frac{P_{L} L}{\gamma^{\prime}} \frac{d \ln L}{d t}
$$

where $\gamma^{\prime}=P_{K} K+P_{L} L$. Inserting equation [22] into equation [21] yields:

$$
\frac{d \ln E A M F P}{d t}=\frac{d \ln M F P}{d t}+\frac{P_{R} R}{P_{Y} Y} \frac{d \ln R}{d t}-\frac{\rho P_{S} S}{\gamma P_{Y} Y} \frac{d \ln S}{d t}+\left(\frac{P_{Y} Y}{\gamma^{\prime}}-\frac{\rho}{\gamma}\right) \cdot\left(\frac{P_{K} K}{P_{Y} Y} \frac{d \ln K}{d t}+\frac{P_{L} L}{P_{Y} Y} \frac{d \ln L}{d t}\right)
$$

Using the elasticities of output with respect to pollution and to natural capital, the adjustment of MFP growth can be written as: ${ }^{53}$

$$
\underbrace{\frac{d \ln E A M F P}{d t}}_{\text {EAMFP }}=\underbrace{\frac{d \ln M F P}{d t}}_{\text {MFP }}+\underbrace{\varepsilon_{Y R} \frac{d \ln R}{d t}}_{\begin{array}{c}
\text { Adjustment } \\
\text { for pollution }
\end{array}}-\underbrace{\varepsilon_{Y S} \frac{d \ln S}{d t}}_{\begin{array}{c}
\text { Adjustment for } \\
\text { natural capital }
\end{array}}+\underbrace{\left(\frac{P_{Y} Y}{\gamma^{\prime}}-\frac{\rho}{\gamma}\right) \cdot\left(\frac{P_{K} K}{P_{Y} Y} \frac{d \ln K}{d t}+\frac{P_{L} L}{P_{Y} Y} \frac{d \ln L}{d t}\right)}_{\begin{array}{c}
\text { Adjustment for changing contributions } \\
\text { of labour and capital }
\end{array}}
$$

Therefore, the adjustment of MFP for the inclusion of environmental services in the accounting framework relies on three terms:

- The adjustment for pollution emissions. MFP should be adjusted downward when pollution emissions increase as the elasticity of output w.r.t. pollution is negative.

- The adjustment for natural capital use. MFP should be adjusted downward when natural capital use increases as the elasticity of output w.r.t. natural capital is positive.

- The adjustment for changing contributions of labour and capital. The contributions of labour and capital are computed differently when pollution and natural capital are included (EAMFP) or not (MFP). In the EAMFP framework, two additional factors help explain output growth: pollution emissions and natural capital use. As a result, the contribution of traditional factors (labour and capital) will be lower in this framework than in the traditional one. This also means that the share of output growth that is not explained by labour and capital growth is higher, i.e. productivity growth should be adjusted upward. Intuitively, when pollution emissions and natural capital use are kept constant, EAMFP is greater than MFP because the contributions of capital and labour to output growth have been revised downwards.

To sum up, traditional MFP should be adjusted for changing pollution emissions, changing natural capital use, and also for the new values of labour and produced capital contributions.

\footnotetext{
${ }^{53}$ As a special case, if we assume zero profit and constant returns to scale, then $\gamma^{\prime}=P_{Y} Y$ and $\rho=\gamma$, which gives: $\frac{d \ln E A M F P}{d t}=\frac{d \ln M F P}{d t}+\varepsilon_{Y R} \frac{d \ln R}{d t}-\varepsilon_{Y S} \frac{d \ln S}{d t}$
} 
Figure A6.1. EAMFP and MFP by country
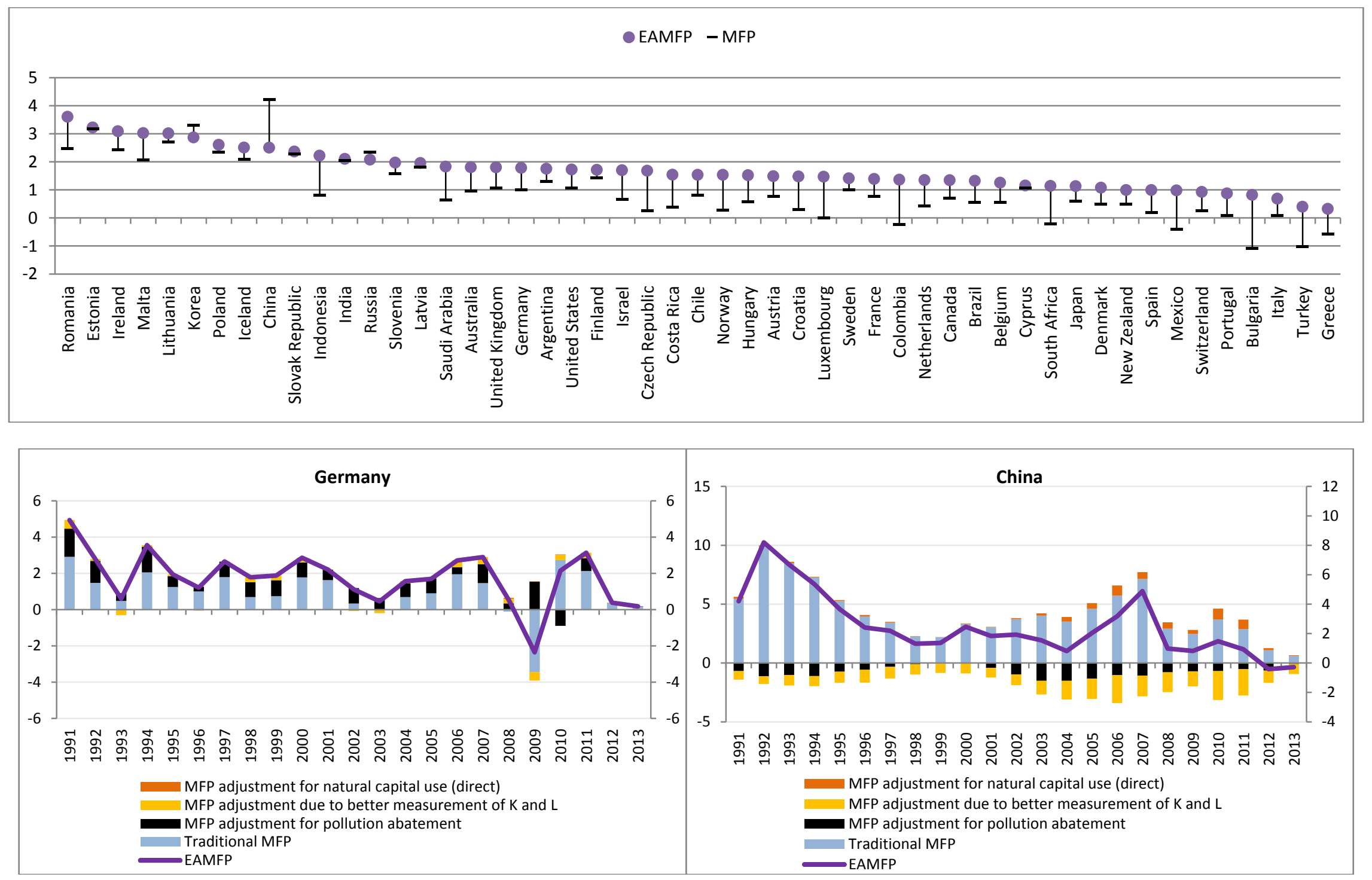
www.oecd.org/greengrowth 